University of Wisconsin Milwaukee UWM Digital Commons

Theses and Dissertations

December 2012

\title{
Wind Turbine Level Energy Storage for Low Voltage Ride Through (LVRT) Support
}

Ali Yousef

University of Wisconsin-Milwaukee

Follow this and additional works at: https://dc.uwm.edu/etd

Part of the Engineering Commons

\section{Recommended Citation}

Yousef, Ali, "Wind Turbine Level Energy Storage for Low Voltage Ride Through (LVRT) Support" (2012). Theses and Dissertations. 47.

https://dc.uwm.edu/etd/47

This Thesis is brought to you for free and open access by UWM Digital Commons. It has been accepted for inclusion in Theses and Dissertations by an authorized administrator of UWM Digital Commons. For more information, please contact open-access@uwm.edu. 


\title{
WIND TURBINE LEVEL ENERGY STORAGE FOR LOW VOLTAGE RIDE THROUGH (LVRT) SUPPORT
}

by

\author{
Ali Yousef \\ A Thesis Submitted in \\ Partial Fulfillment of the \\ Requirements for the Degree of \\ Master of Science \\ in Engineering
}

at

The University of Wisconsin-Milwaukee

December 2012 


\title{
ABSTRACT \\ WIND TURBINE ENERGY STORAGE LEVEL FOR \\ LOW VOLTAGE RIDE THROUGH (LVRT) SUPPORT.
}

by

\author{
Ali Yousef \\ The University of Wisconsin-Milwaukee, 2012 \\ Under the Supervision of Professor Dr.Adel Nasiri
}

Renewable energy is a green source of energy that is clean, available and sustainable. Wind energy generation has been experiencing the largest growth among renewable sources due to lower cost and advanced technologies. Wind energy power plants or farms need low maintenance and last for a long time. The increasing higher penetration of wind energy in the grid has transformed wind energy into major player in grid operation and economics. Wind energy systems now have to participate in grid support and provide ancillary services.

Variable wind speed leads to variable wind power generation, voltage fluctuations, and frequency deviations, which are the main problems related to wind energy integration into a grid. These problems become more evident in weak grids. In addition, wind farms have to take the grid problems into consideration and have to provide support during grid instability and transients.

In this thesis, a PMSG wind turbine full energy conversion system design and modeling have been performed using Matlab Simulink. The system is grid integrated and applies MPPT control to extract the maximum power from the wind and utilizes full conversion circuitry to interface the unregulated generator AC power to the grid. Modules of 
Lithium-Ion Capacitors (LIC) have been placed on the DC bus in order to support the grid with wind energy power smoothing and LVRT. LICs offer high power density and reasonable energy density. During grid faults, wind energy can be stored in the LICs and discharged into the grid as soon as the voltage is restored. This feature will support the grid to stabilize the voltage. Detailed modeling of the architecture and controls has been performed to verify the viability of the proposed system. 
CCopyright by Ali Yousef, 2012

All Rights Reserved 


\section{Dedicated to:}

My parents, Brothers and Sisters.

Dec/2012 


\section{TABLE OF CONTENTS}

\section{Introduction and Wind Energy Background.}

1.1 Wind power overview.

1.2 Wind power statistics in US.

1.3 Wind turbine types.

1.3.1 Horizontal axis wind turbine.

1.3.2 Vertical axis wind turbine.

1.4 Wind turbine components.

1.5 Wind power extraction principle.

1.6 Issues associated with wind power integration to power systems.

\section{Wind Energy Conversion System.}

2.1 Wind energy conversion system description.

2.2 Wind turbine generator types.

2.2.1 Fixed wind speed squirrel cage and wound rotor induction generators.

2.2.2 Variable speed permanent magnet synchronous generators.

2.2.3 Variable resistance wound rotor induction generators (limited wind speed).

2.2.4 Variable speed wound rotor synchronous generator.

2.2.5 Variable speed wind turbine with doubly fed induction generator.

2.3 Power electronics conversion system (back to back converter).

2.4 Wind energy storage.

2.4.1 Lead-Acid (LA) battery.

2.4.2 NickelCadmium(NiCd) battery.

2.4.3 Sodium Sulphur (NaS) battery. 
2.4.4 Vandium Redox (VR) flow battery.

2.4.5 Polysulphide Bromide (PSB) flow battery.

2.4.6 Zinc Bromine ( $\mathrm{ZnBr})$ flow battery or (ZBB).

2.4.7 Supercapacitor energy storage (SCES).

3 Grid Faults and Requirements.

3.1 Different types of faults.

3.2 Grid requirements.

3.2.1 Power control quality capability.

3.2.2 Frequency control capability.

3.2.3 Voltage and low voltage ride through capability.

3.2.4 Power plant modeling and verification.

3.3 Low voltage ride through (LVRT) different in grid codes.

4 Wind turbine system modeling and control.

4.1 Wind turbine modeling.

4.2 Generator modeling.

4.3 Back to back converter (AC/DC/AC) modeling and control.

4.3.1 Generator side converter (AC/DC) and MPPT control.

4.3.2 Grid side converter (DC/AC) control.

4.3.2.1 Normal operation in DC bus voltage control.

4.3.2.2 Normal operation adaptive filter control for power smoothing.

4.3.2.3 Grid side control for low voltage ride through support.

4.4 Ultracapacitor energy storage level for LVRT support. 
5 Simulation Results.

5.1 Normal operation with DC bus voltage control.

5.1.1 Fixed speed wind profile.

5.1.2 Variable wind speed profile.

5.2 Normal operation with Adaptive filter for power smoothing control.

5.3 LVRT operation.

5.3.1 LVRT reactive power support up to $2 \mathrm{pu}$.

5.3.2 LVRT 1 pu reactive power support.

6 Conclusion.

7 References. 


\section{LIST OF FIGURES}

Figure 1.1 Wind energy generation capacity for U.S. states at end of 2011.

Figure 1.2 The exponential increase rate of wind energy capacity for several years.

Figure 1.3 US Wind capacity installed in Megawatts since 2001.

Figure 1.4 Thousand of megawatt hours wind energy Generated in US since 1997.

Figure 1.5 Annual and cumulative wind installation by 2030 .

Figure 1.6 General wind turbine power systems.

Figure 1.7 Wind turbine components.

Figure 1.8 Pitch angle and air flow on the blade.

Figure 1.9 Tip speed ratio Vs power coefficient, $\theta$ in the plot is the pitch angle.

Figure 2.1 Wind power conversion system general components.

Figure 2.2 Different types of wind turbines generators.

Figure 2.3 Fixed speed squirrel cage induction generator conversion system.

Figure 2.4. Variable Speed Permanent Magnet Synchronous Generator.

Figure 2.5 Variable Resistance Wound Rotor Induction Generator.

Figure 2.6 Wound Rotor synchronous Generator.

Figure 2.7 Variable-Speed Wind Turbine with Double Fed Induction Generator.

Figure 2.8 Back to back converter.

Figure 2.9 Most common converters topologies. a) Diode and line-commutated converter.b) Diode and PWM VSI converter. C) Diode and DC/DC chopper and PWM VSI converter. d) Back-to-back PWM VSI converter. e) Matrix converter

Figure 2.10.Lead acid battery structure.

Figure 2.11 Sealed nickel cadmium battery structure. 
Figure 2.12 Sealed nickel cadmium battery structure.

Figure 2.13 Sodium Sulphur cell structure.

Figure 2.14 Vanadium Redox flow battery structure.

Figure 2.15 Polysulphide Bromide flow battery.

Figure 2.16 Zinc Bromine flow battery structure.

Figure 2.17 Supercapacitor energy storage device components.

Figure 3.1 Voltage divider model for balanced fault.

Figure 3.2 Typical transformer connections for wind turbine and the types of voltage sags for a fault on PCC.

Figure 3.3 E.ON (Germany) voltage code during faults.

Figure 3.4 Voltage support during the grid faults, E.ON code.

Figure 3.5 E.ON offshore requirement minimum useable P/Q-operating range of a generation unit, within a $+5 \%$ range around the nominal voltage

(at the generation unit).

Figure 3.6 Irish grid code frequency response curve.

Figure 3.7 Reactive output current during voltage sage according to the Spanish grid code.

Figure 3.8 United State FERC voltage code for grid fault.

Figure 3.9 Comparison of fault ride through for different codes.

Figure 4.1 Variable pitch angle wind turbine.

Figure $4.2 \mathrm{Cp}$ as a function of pitch angle and tip speed ratio.

Figure 4.3 Matlab Simulink model of the wind turbine. 
Figure 4.4 turbine output power as a function per unit turbine speed and wind speed when pitch angle is zero.

Figure 4.5 The electrical model of the generator related to q axis.

Figure 4.6 The electrical model of the generator related to d axis.

Figure 4.7 Synchronous generator used in Matlab Simulink.

Figure 4.8 Back to back converter characteristics.

Figure 4.9 Generator side converter simulations for MPPT control.

Figure 4.10 Grid side converter control under normal operation.

Figure 4.11 Adaptive filter and control for power smoothing.

Figure 4.12 Grid side converter control for LVRT.

Figure 4.13 Adaptive filter and control for power smoothing.

Figure 4.14 Grid side converter control for LVRT

Figure 5.1 Fixed wind speed.

Figure 5.2 Generator speed and generator reference speed for fixed wind speed.

Figure 5.3 DC bus voltage for fixed wind speed.

Figure 5.4 Generator voltage and current for fixed wind speed.

Figure 5.5 Generator voltage and current over a small enlarged

period fixed wind speed.

Figure 5.6 Grid voltage and current for fixed wind speed.

Figure 5.7 Grid voltage and current over a small enlarged period for

fixed wind speed.

Figure 5.8 Active power delivered to the Grid and wind generator active power for fixed wind speed. 
Figure 5.9 Reactive power delivered to grid and wind generator reactive power for fixed wind speed.

Figure 5.10 Variable wind speed profile.

Figure 5.11 Generator speed and generator reference speed for variable wind speed. (66)

Figure 5.12 DC bus voltage for variable wind speed.

Figure 5.13 Generator voltage and current for variable wind speed.

Figure 5.14 Generator voltage and current over a small enlarged period of time for variable wind speed.

Figure 5.15 Grid voltage and current for variable wind speed.

Figure 5.16 Grid voltage and current over a small enlarged period of time for variable wind speed.

Figure 5.17 Active power delivered to the grid and wind generator active power for variable wind speed.

Figure 5.18 Variable wind speed profile in power smoothing.

Figure 5.19 Generator speed and generator reference speed within power smoothing. (70)

Figure 5.20 DC bus voltage within power smoothing.

Figure 5.21 Generator voltage and current within power smoothing.

Figure 5.22 Generator voltage and current or a small enlarged period of time within power smoothing.

Figure 5.23 Grid voltage and current within power smoothing.

Figure 5.24 Grid voltage and current over a small enlarged period of time within power smoothing. 
Figure 5.25 Active power delivered to the grid and wind generator active power within power smoothing.

Figure 5.26 Reactive power delivered to grid and wind generator reactive power within power smoothing.

Figure 5.27 Grid voltage and current for (2) pu reactive power support.

Figure 5.28 Generator voltage and current for (2) pu reactive power support.

Figure 5.29 Generator voltage and current for (2) pu reactive power support over a small enlarged period of time.

Figure 5.30 Active power delivered to the grid and generator active power for (2) pu reactive power support.

Figure 5.31 Reactive power delivered to the grid and wing generator reactive power for (2) pu reactive power support.

Figure 5.32 DC bus voltage for (2) pu reactive power support.

Figure 5.33 Grid voltage and current for (1) pu reactive power support.

Figure 5.34 Reactive power delivered to the grid and wind generator reactive power for (2) pu reactive power support. 


\section{LIST OF TABLES}

Table 1.1. The top ten wind farms in US.

Table 2.1 Wind turbines generators advantages and disadvantages.

Table 3.1 fault types and percentage of happens.

Table 3.2 Faults types and the corresponding per unit phase voltages as a

function of per unit characteristic fault voltage, $h$.

Table 4.1 wind turbine characteristics.

Table 4.2 synchronous generator parameters. 


\section{LIST OF ABBREVIATIONS}

DOE: Department Of Energy

AWEA: American Wind Energy Association.

NREL: North American Renewable Energy Laboratory.

NERC: North America Electricity Reliability council.

DC: Direct Current.

AC: Alternative current

NSF: National Science Foundation.

HWAT: Horizontal axis wind turbine .

VAWT: Vertical axis wind turbine.

TSR: Tip speed ratio.

SCIG: Squirrel cage induction generator.

WRIG: Wound rotor induction generator.

DFIG: Doubly fed induction generator.

SG: Synchronous generator.

PMSG: Permanent magnet synchronous generator.

PWM: Pulse width modulator.

VSC: Voltage source converter.

VSI: Voltage source inverter

HVAT: High voltage ride through

LVRT: Low voltage ride through.

SCES: Supercapacitor energy storage.

DOC: Depth of charge. 
FLA: Flooded Lead Acid.

VRLA: Valve regulated Lead Acid.

MPPT: Maximum power point tracking

PLL: Phase locked loop. 


\section{ACKNOWLEDGMENTS}

I would like to highly acknowledge my adviser, Professor Adel Nasiri for his support, guidance, patience and great theoretical and practical experience that he delivers to his students.

In addition of my professor Adel Nasiri, I would like to highly thank my brother, Omar for his help and support during my education.

I would also like to acknowledge my friends and colleagues in the Power Electronics and Electric Motor Drives laboratory who have stood with me and shared some of their practical and theoretical knowledge and experience in addition of good memories. 


\section{Chapter 1: Introduction and Wind Energy Background}

\section{Introduction}

Wind energy is available and clean source of energy that has been used to generate electrical power. The focus on electrical power generated from wind energy has been noticeably increased due to the environmental problems that fossil fuels make. Global warming and green house emissions are the main harmful results of fossil fuel consumption. United States wind power has been quickly spread and wind generation installed capacity for 2012 is increasing. It has reached approximately $50(\mathrm{GW})$ of power according to the U.S Department of Energy (DOE) and the American Wind Energy Association (AWEA) and according to the report prepared by the U.S. Department of Energy with contributions from the National Renewable Energy Laboratory (NREL), the wind energy installed capacity by 2030 will be around $20 \%$ of the total capacity. Wind power integration to the grid has limitations and standards that have to be followed. Standards for wind integration to the grid are addressed in the Institute of Electrical and Electronics Engineers (IEEE), North American Electric Reliability Corporation (NERC) and by different utility companies. [1]

Wind power integration to the grid has different difficulties and problems due to the variation of the wind speed which results in fluctuation of the wind generated power that leads to fluctuations in voltage and frequency. Grid faults also one of the problems that wind turbine control should take into consideration. Wind turbines should be properly controlled to overcome the grid faults that lead to voltage and frequency drop. It has to have a fault right through capabilities or as it is called voltage ride trough to protect the turbine generator form accelerating and damaging mechanical part due to instability that 
increases vibration and stress on the mechanical parts like the speed conversion system ( gear box). Generator acceleration also leads to over current and overvoltage in the DC bus of the electrical conversion system that makes the mechanical system unstable and might damage the electrical converter. [2]

\subsection{Wind power overview.}

Wind power is the power coming from the conversion of wind energy into a usable type of energy which might be electrical or mechanical. In the antiquity, wind power was used to power boat and ships by using attached sails to capture the wind energy. It was used after as a wind driven wheel to drive a machine for example, and irrigation machines used by The Babylonian emperor Hammurabi and since the $4^{\text {th }}$ centaury a prayer machine used in Tibet and China .[3]

In the early middle ages, wind power started to be commonly used as windmills to grind grains like corn. People started using the horizontal windmills and then the vertical windmills by the 1180 s for flour grinding. After that, in the late middle ages, windmills were developed and used in different shapes and design and it continued to the $18^{\text {th }}$ and the $19^{\text {th }}$ century since the first windmills used for production of electricity. Windmills were built and used for electricity production for the first time in Scotland in 1887 by Prof James Blyth of Anderson's College, Glasgow (the precursor of Strathclyde University). The Blyth wind turbine was installed in the garden of his holiday cottage at Marykirk

in Kincardineshire and it was used to power the lighting in the cottage through out charging an accumulators developed by the Frenchman Camille Alphonse Faure. 
At the beginning of the $20^{\text {th }}$ century, wind power was used to generate electricity using individual wind generators. Denmark was the fastest country in developing wind turbines to generate electricity; it produced $5 \mathrm{kw}$ to $25 \mathrm{kw}$ wind turbines until a huge change took a place in 1978 by producing a multi-megawatt wind turbine that had the capability to deliver 2MW. Wind turbine manufacturing and developments are ongoing process different wind turbines were produced with different capacity and huge wind farms have been installed to support power utilities. [3]

\subsection{Wind power statistics in the US.}

Wind power has been used in the United States and increased in the past several years. The US government worked with the industrial companies from 1947 to the mid-1980s to allow big scale industrial wind turbines. NASA wind turbines were built and developed and funded by the National Science Foundation (NSF). DOE put 13 experimental wind turbines into operation and they were constructed and developed in four major designs. The above research and development program ledo many of the multi-megawatt turbine technologies in use nowadays. [4]

Wind power generation capacity in the United States has been increasing over the past years. The generation capacity in 2012 reached a 4728MW in the first three quarters and the total capacity reached 51630MW. The United State produced 133 terawatt-hours which is equivalent to $3.3 \%$ of the total generated electrical energy. This $3.3 \%$ amount of energy is enough to power over around 11 Million US households annually.

Wind farms produce low cost electricity for consumers. They can produce 5-8 cent per $\mathrm{kWh}$, which is a low and competitive price compared with the electricity generated by fossil fuel power plants. [4] 


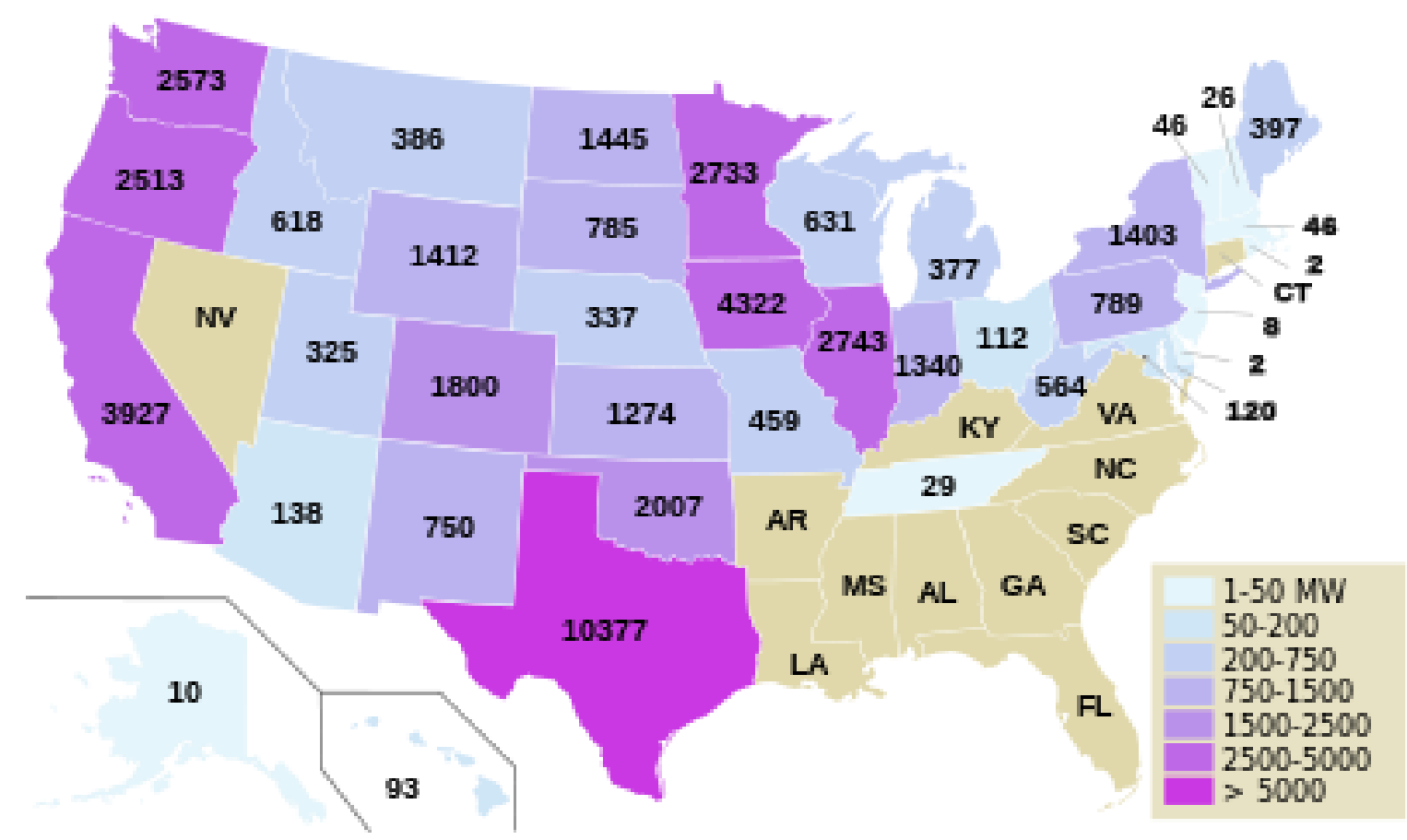

Figure 1.1.Wind energy generation capacity for U.S. states at end of 2011. [4]

As shown and illustrated in Figure 1 the five states that generate the most wind energy and has a large portion of the generation are Texas, California, Oregon, Washington, Iowa and Illinois. The top five states that generate more wind energy and have greater capacity installed are: [4]

- $\quad$ Texas $(10,929 \mathrm{MW})$

- $\quad$ California (4,570 MW)

- $\quad$ Iowa $(4,536 \mathrm{MW})$

- $\quad$ Oregon $(3,153 \mathrm{MW})$

- $\quad$ Illinois $(3,055 \mathrm{MW})$. 
And the top ten wind farms installed capacity in unites states is shown below in table 1 .

\begin{tabular}{|l|l|l|}
\hline Project & Capacity(MW) & State \\
\hline Alt wind Energy Center & 1020 & California \\
\hline Shepherd Flat Wind Farm & 845 & Oregon \\
\hline $\begin{array}{l}\text { Roscoe Wind Energy } \\
\text { Center }\end{array}$ & 781 & Texas \\
\hline $\begin{array}{l}\text { Horse Hollow Wind } \\
\text { Energy Center }\end{array}$ & 736 & Texas \\
\hline $\begin{array}{l}\text { Tehachapi Pass Wind } \\
\text { Farm }\end{array}$ & 705 & California \\
\hline $\begin{array}{l}\text { Capricorn Ridge Wind } \\
\text { Farm }\end{array}$ & 662 & Texas \\
\hline $\begin{array}{l}\text { San Gorgonio Pass Wind } \\
\text { Farm }\end{array}$ & 619 & California \\
\hline Fowler Ridge Wind Farm & 600 & Indiana \\
\hline Sweetwater Wind Farm & 585 & Texas \\
\hline $\begin{array}{l}\text { Tehachapi Pass Wind } \\
\text { Farm }\end{array}$ & 576 & California \\
\hline
\end{tabular}

Table 1.1. The top ten wind farms in US. [4]

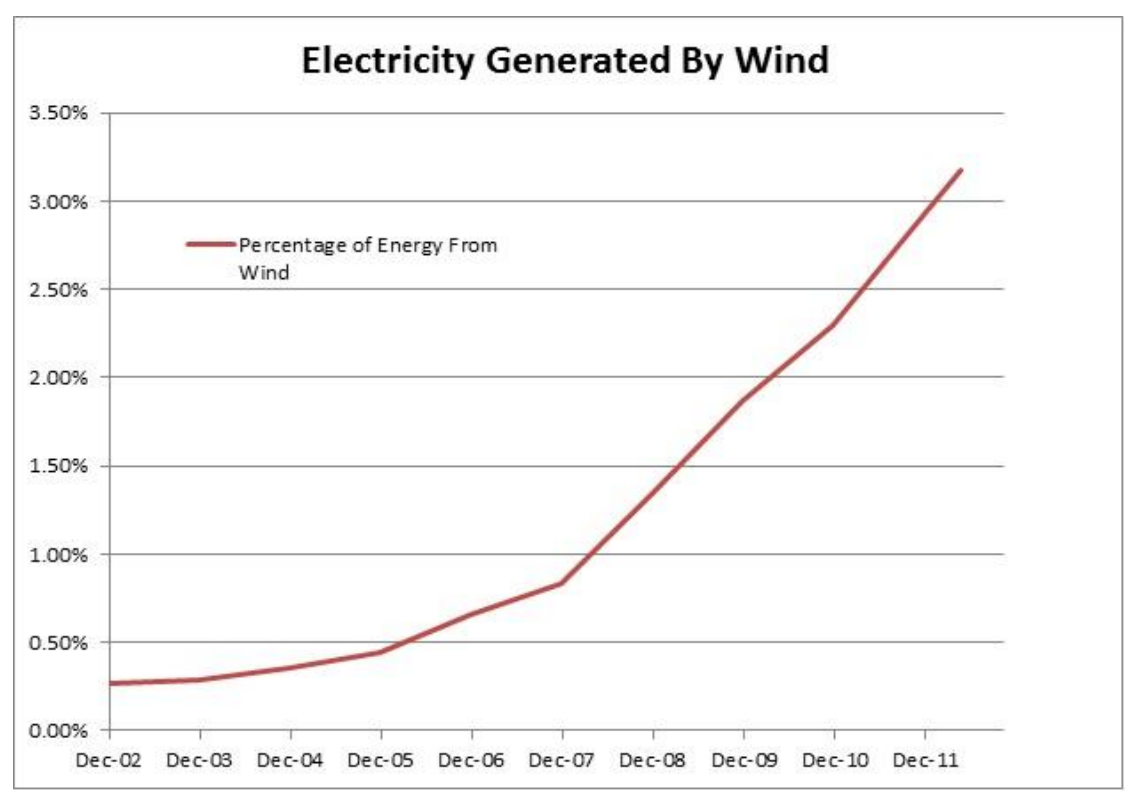

Figure 1.2.The exponential increase rate of wind energy capacity for several years. [4] 


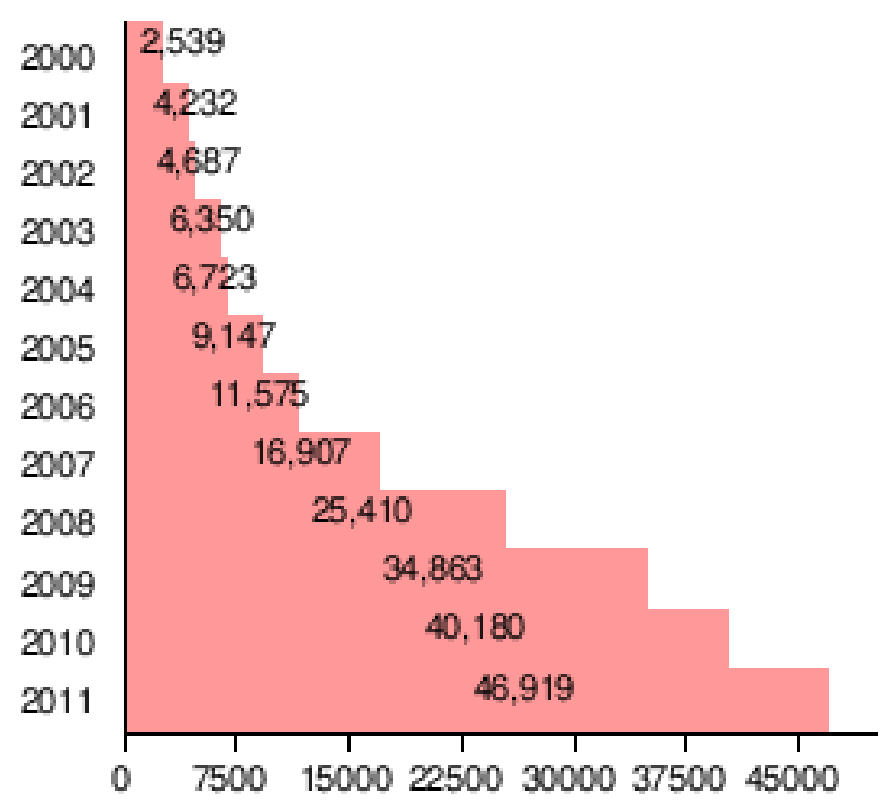

Figure 1.3. US Wind capacity installed in Megawatts since 2001. [4]

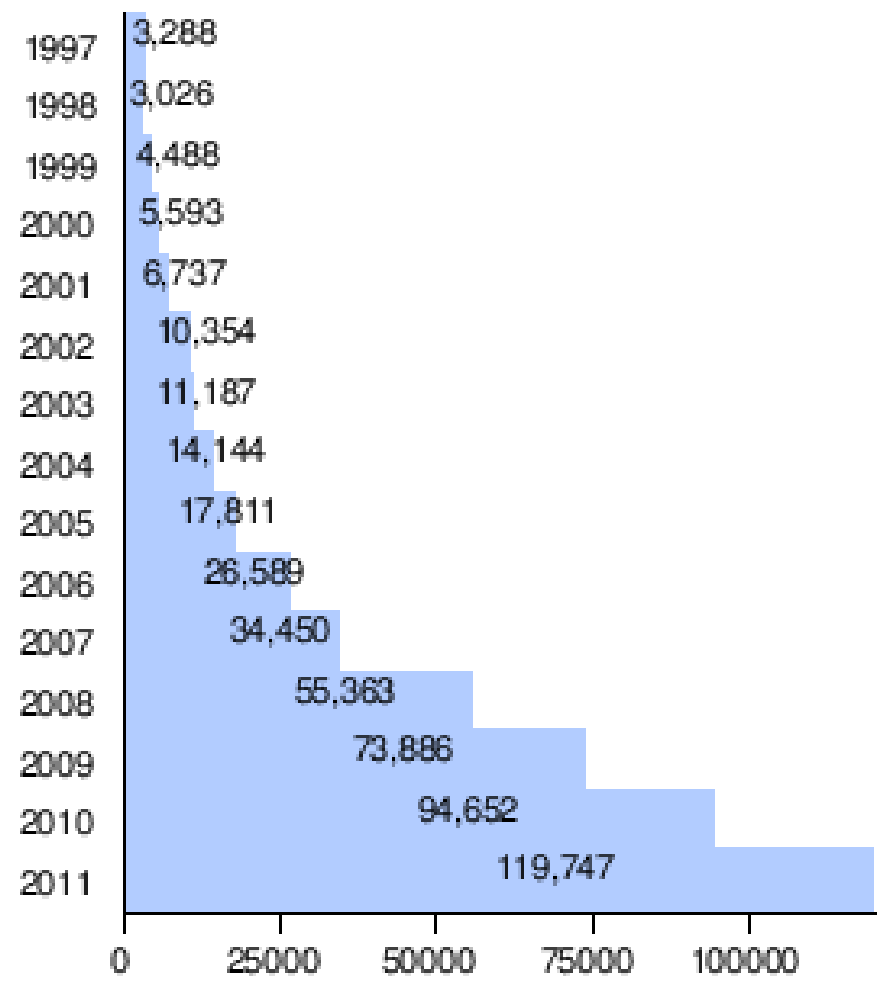

Figure 1.4. Thousand of megawatt hours wind energy Generated in US since 1997. [4] 
According to the American wind energy association (AWEA), wind power generation capacity will reach to $20 \%$ of the total US capacity, as illustrated in Figure 5 below and to reach that, wind power installation should increase by 16000 MW per year until 2018 and keep on that rate from 2018 to 2030. [5]

\section{Annual and cumulative wind installations by 2030}

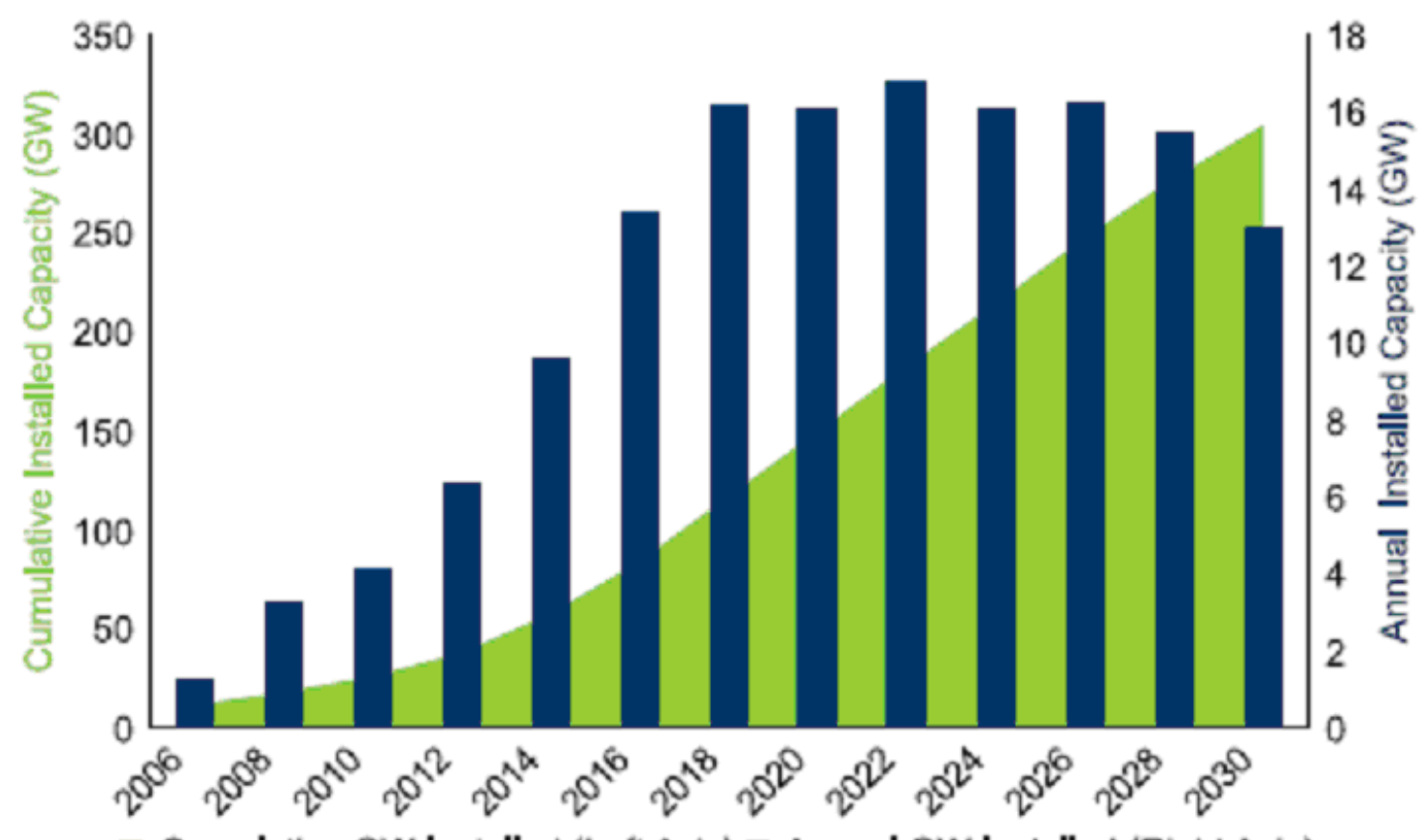

Cumulative GW Installed (Left Axis) a Annual GW Installed (Right Axis)

Figure 1.5.Annual and cumulative wind installation by 2030. [5]

\subsection{Wind turbine types.}

Wind turbine design is recognized as two main types, vertical axis wind turbines and horizontal axis wind turbines. The type of each turbine is referred to the rotation of the blades; the horizontal axis wind turbine has blades that rotate around a horizontal axis. However, the vertical wind turbine has blades that rotate around a vertical axis. Each wind turbine type has its own advantages and disadvantages. 


\subsubsection{Horizontal axis wind turbines.}

Horizontal axis wind turbines (HAWT) are most common type of wind turbines. Its design is taken from the design of windmills, which have blades that rotate and spin around a horizontal axis. The horizontal axis mainly is the rotor shaft that is considered the electrical generator shaft. The horizontal shaft is connected directly to the generator shaft when the wind turbine is small size and it's connected through a gear box when the wind turbine is large in size. The Gear box is located between the slow rotation speed and high rotation speed; it has the function of speed increase, stress reduction and vibration reduction. Horizontal wind turbines might be an upwind or down wind turbines. [6], [7]

Upwind turbines have blades mounted and pointed upwind since this will reduce the turbulence effect caused by the tower and this needs the wind turbine blades to be stiffly designed to prevent the bending by strong wind toward the tower. [6], [7]

Downwind turbines have the problem of turbulence that is caused by the tower, and blades can be designed with less stiffness because they have space to bend and it's not going to bend toward the tower. Turbulence causes fatigue failures stress on the blades, so that most of the wind turbines are upwind designed. [6], [7]

HAWT has plenty of advantages and disadvantages. The main advantages are as follows: [6], [7]

- Stable since blades rotate close to the center of gravity.

- High efficiency since blades rotation is normal to the wind speed which allow more angle of attach and thus more extracted power form the wind.

- Long towers allow high speed wind and then more generated power.

- Blades pitch angle can be controlled in storms to prevent failure. 
The main disadvantages are listed as follows: [6], [7]

- Huge tower construction to carry the blades, generator and the electrical component since the operation difficulty near ground.

- Difficulty parts transportation, insulation, and maintenance.

- Large and heavy components are carried lifted to the position.

- Their height makes them clearly visible which ruin the general scene.

- More than one control are needed to control the turbine such as yaw contol, pitch control and breaking system in case of high speed wind.

\subsubsection{Vertical axis wind turbines.}

Vertical axis wind turbines (VAWT), have a rotor shaft mounted vertically. The blades rotate around a vertical shaft and it doesn't have to be pointed into the wind. Vertical axis rotation shaft gives an advantage that the generator and the electrical components can be placed near the ground. VAWT has turbulence effect on the blades and it has a drag force as well. It's hard for the vertical blades to be mounted on a tall tower, so it has to be somehow near the ground which leads to a turbine affected by slow wind and more turbulence that leads to vibration and more maintenance. [6], [7]

Vertical axis wind turbines have the following advantages and disadvantages. [6], [7] Main advantages are as follows:

- Less control is needed such as you control.

- Easy transportation, installation and maintenance because it is closed to ground.

- It can be installed in places where height buildings are not allowed.

- It has a low speed startup capability.

Main disadvantages are as follows: 
- Blades cause a drag force.

- Less efficient.

- Operate in more wind turbulence.

- May require energy to start since the speed might be very slow and thus low torque.

\subsection{Wind turbine components.}

Wind turbines harness the power of the wind and use it to generate electricity. The energy in the wind rotates two or three blades around a rotor. The rotor is connected to the generator shaft, either through out a gear box or directly. The electrical generator shaft rotates and the generator generates electricity. The electrical power produced passes through a power conversion system then to the grid. [8]

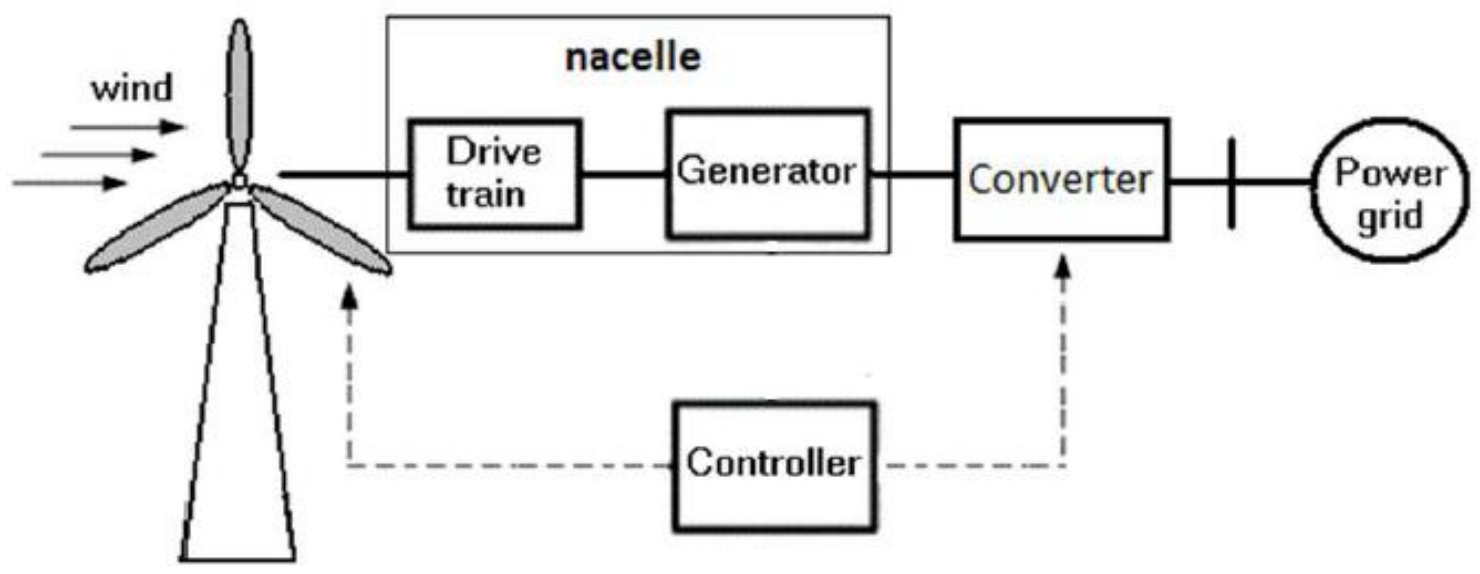

Figure 1.6. General wind turbine power system. [9] 


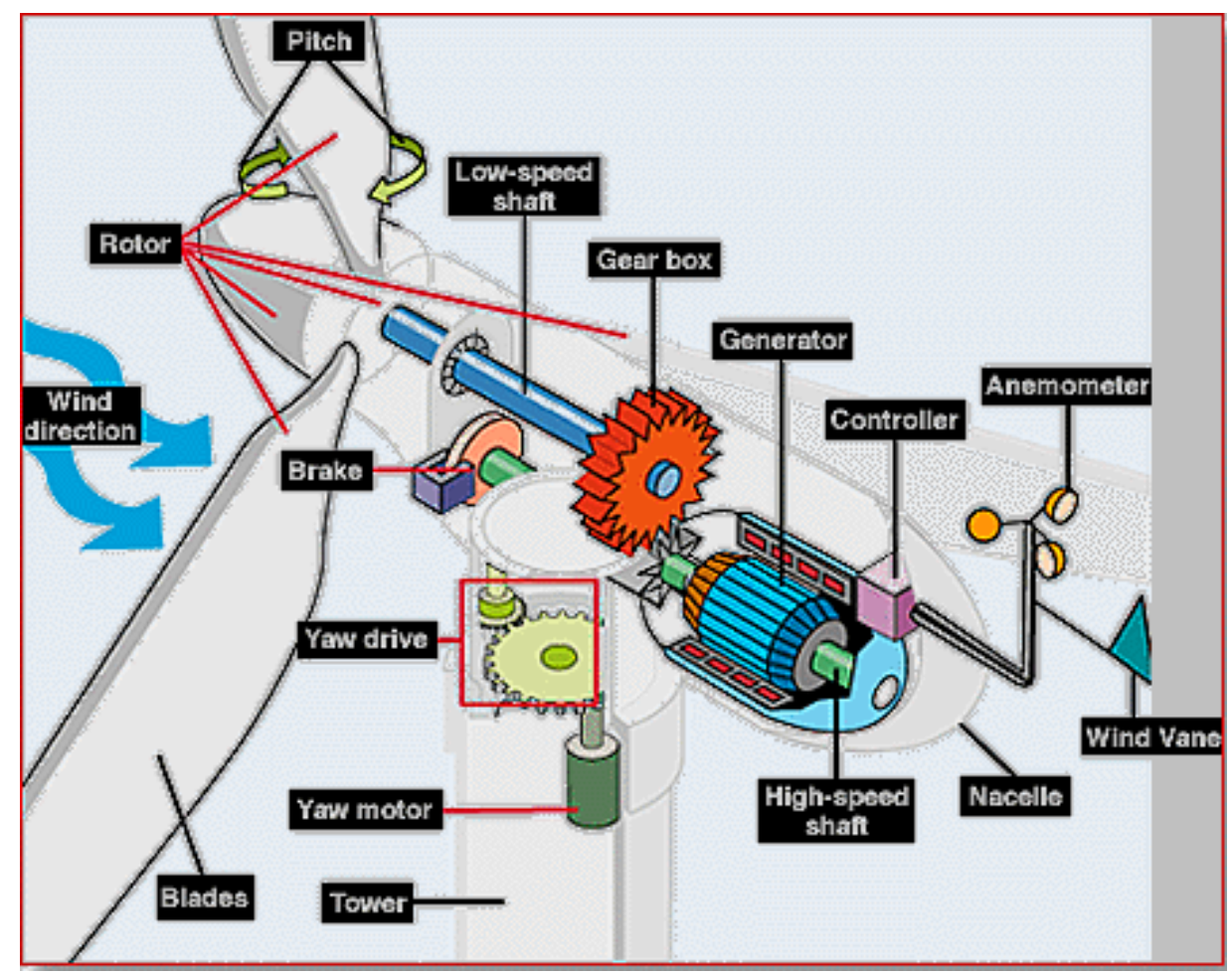

Figure 1.7. wind turbine components. [8]

The function of the Anemometer is to Measure the wind speed and so that a speed velocity is an output from this device and an input for the controller. The controller takes the wind speed as an input and starts the machine or stops it according the allowed speed range. It also controls different parts on the machine like the converter, yaw angle and pitch angle of the blades which is most likely three blades and these blades extract the power from the wind according to its design. Lift force will be acting on the blades due to the pressure difference on the top and bottom surfaces of the blade and the Lift forces on the blade make a rotation that rotates the generator shaft. The generator shaft can be stopped by the break which is a mechanism attached on the high speed shaft to stop it. This mechanism might be mechanical, hydraulic or electrical. Gears box connect the lowspeed shaft to the high-speed shaft to increase the rotational speed that required operating the generator and producing electricity. All the parts mentioned above are contained in 
the nacelle that is located in top of the tower which is made of tabulated material. However, the Pitch, the external part of the rotor (hub), tower, wind vane and yaw motor are located outside the nacelle. Blades are mounted and gathered to the rotor by the hub and controlled through out the pitch angle to increase or decrease the rotation speed to the desired speed which produces electricity. To produce more power, the blades should be facing the wind to extract more power and it is the functionality of the wind vane and the yaw drive since the wind vane measures the direction of the wind the yaw drives adjust the tower and the blades to be facing the wind. [8]

\subsection{Wind power extraction principle.}

Wind turbines use the blades to convert the kinetic energy into electrical energy. Wind turbine blades capture the wind and convert the energy in the wind into a rotational energy that rotates a generator shaft which is responsible for producing energy. The amount of power in the wind is a function of the wind density $\rho$, swept area of the blades ,$A_{b}$, the coefficient of performance,$C_{p}$, that has to be less than 0.59 which is Betz limit and proportional tp cube of wind speed, $v_{w}$,. Betz limit is the upper limit of power that we can extract from the wind. The wind power equations is: [10]

$$
P_{w}=\frac{1}{2} \cdot \rho \cdot A_{b} \cdot v_{w}^{3}
$$

The mechanical power, $P_{m}$, extracted from the wind can then be expressed as

$$
P_{m}=\frac{1}{2} \cdot \rho \cdot A_{b} \cdot v_{w}^{3} \cdot C_{p}(\lambda, \beta)
$$

And the tip speed ratio are:

$$
T S R=\frac{w r}{v_{w}}=\lambda
$$


The coefficient of performance, $C_{p}$, is a function of the tip speed ratio (TSR) of the turbine. This is the ratio of speed of the tip (wr) of the blade that equals the rotational speed ( $\mathrm{w}$ ) multiplied by the blade radius of rotation(r) to the speed of the wind. The pitch of the blade also plays an important rule governing the power extracted from the wind since changing the pitch angle increases and maximizes the energy captured and protects the wind turbine when the wind speed it over the desired limits. [10]
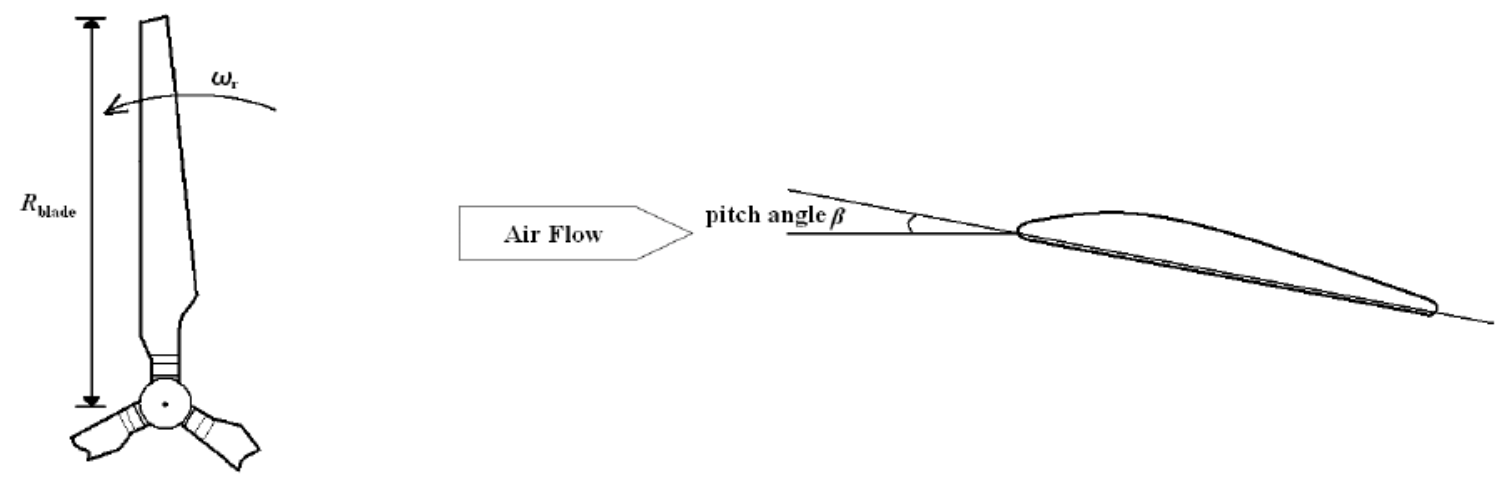

Figure 1.8. Pitch angle and air flow on the blade. [9]

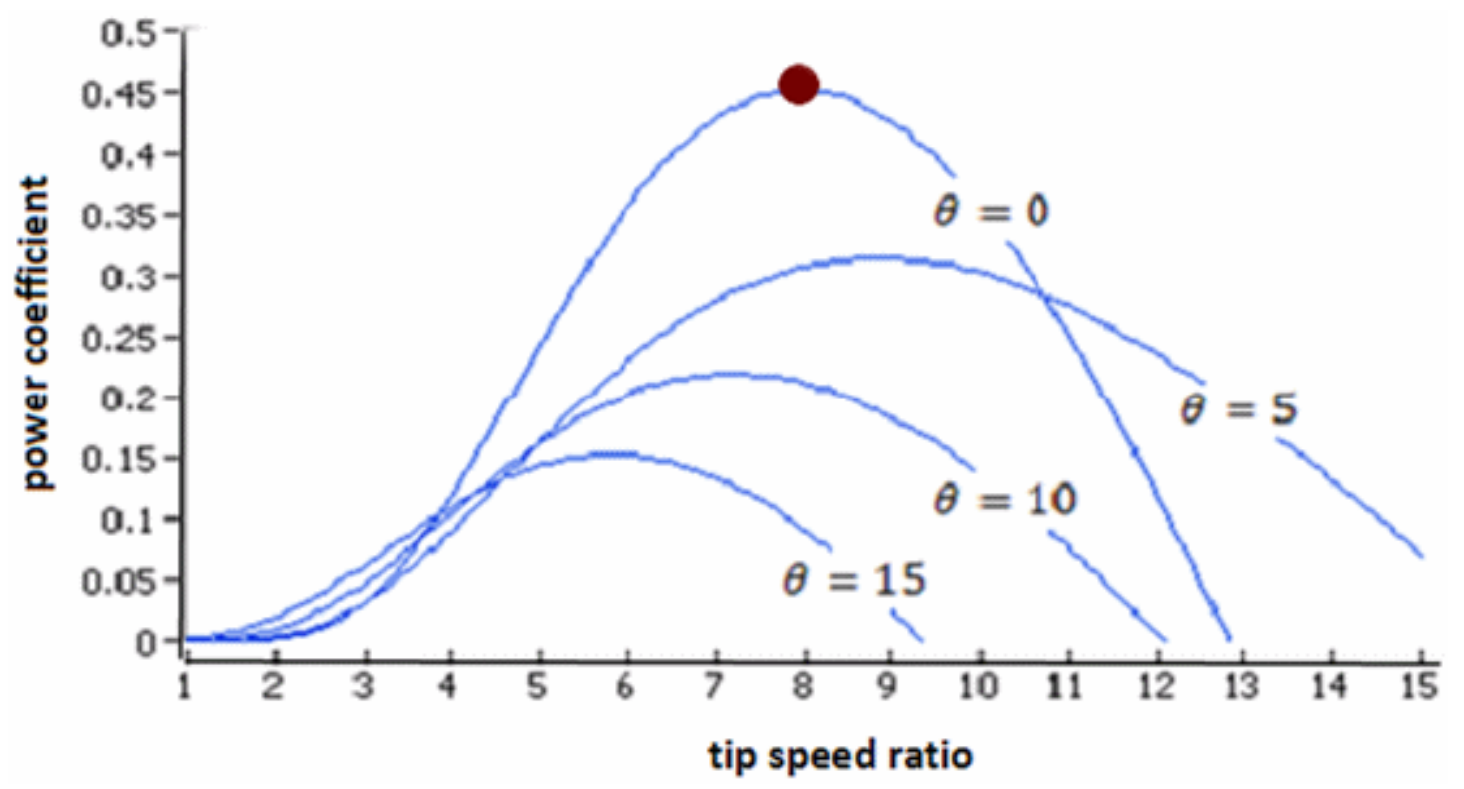

Figure 1.9. Tip speed ratio Vs power coefficient, $\theta$ in the plot is the pitch angle. [9] 


\subsection{Issues associated with wind power integration to power systems.}

Integration of large scale wind power to the power system has different effects on the system operation. As the wind power penetration into the power grid rapidly increases, more considerations and requirements are needed to maintain system reliability and stability. Different grid codes have been defined by different countries to limit the steady and the transient operation that wind turbines must meet in order to integrate to the grid. These requirements addressed under voltage and frequency control by active and reactive power support to the system. Different requirements and codes are imposed by different countries or different local utilities on how the active and reactive power support rate must be, how long the wind turbine must stay in that mode of operation and how the wind turbine must act when there is a fault in the grid. The active power support is regulation concerns the frequency and the reactive power regulated with voltage. Under grid faults, different voltage variations will happen and depending on that variation and the duration

of that variation, the wind turbine must stay connected or disconnect from the grid. [11], [12], [13] 


\section{Chapter 2: Wind Energy Conversion Systems.}

\subsection{Wind energy conversion system description.}

Wind energy conversion system mainly consist of different mechanical and electrical components which include a wind turbine, a generator, power conversion components, and controllers. The most common wind turbines are three blades turbines that rotate and transmit the rotation to an electrical generator through out a gear box velocity conversion system. Generators have different types such as synchronous generators, permanent magnet and induction generators. The power conversion components are responsible for conversion of the unregulated $\mathrm{AC}$ power coming from the turbine generator to DC power through out a energy storage system and then from Dc power to a regulated Ac source to meet the load current and voltage requirements.

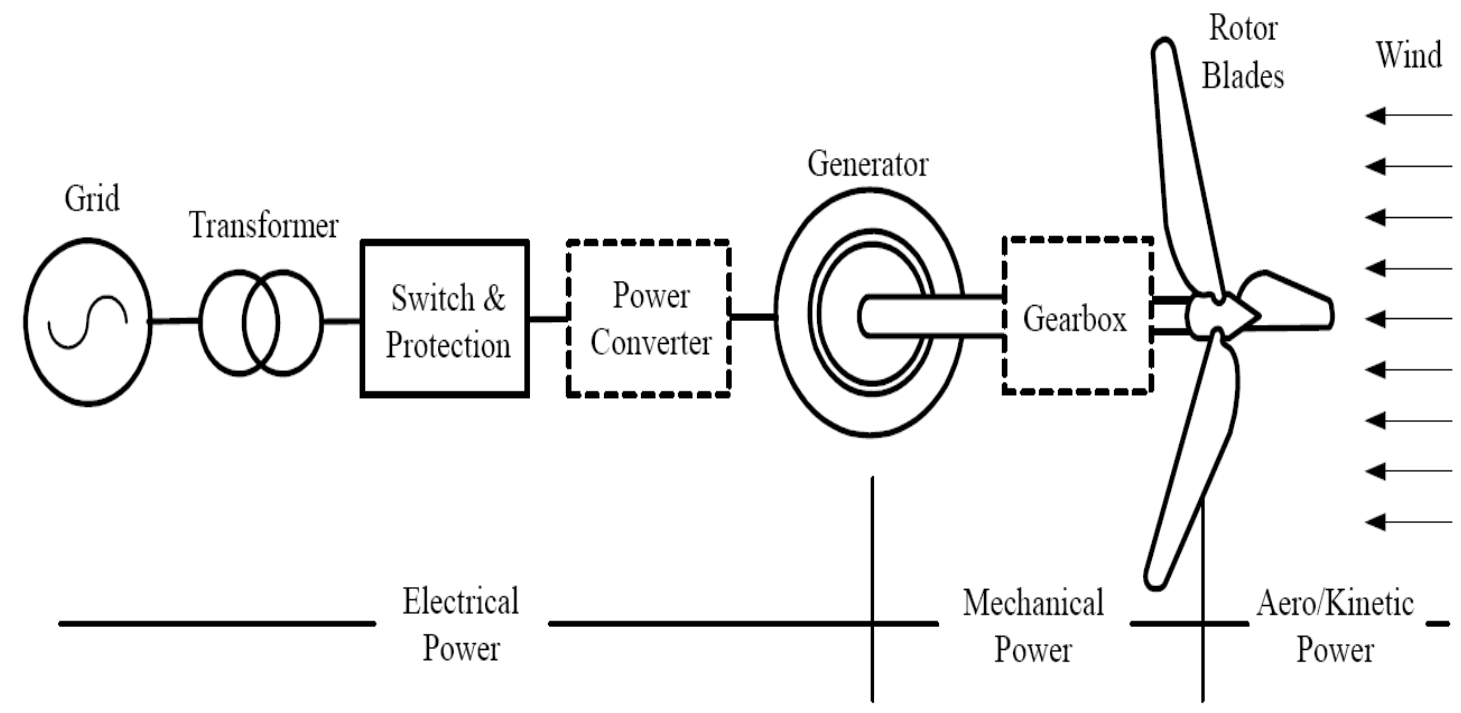

Figure 2.1 wind power conversion system general components. [10] 


\subsection{Wind turbine generator types.}

The electrical wind turbine generators are an interface connection between the mechanical part of the system and the electrical part. The main function of the electrical generator is to convert the mechanical energy coming from the wind turbine which act as a prim mover to electrical energy that is transferred to the electrical grid. Wind turbines are different types and generally categorized in two types according the wind speed, variable wind speed turbines and fixed wind speed turbines.

Wind turbines electrical generators commonly used are:

1- Squirrel-Cage rotor Induction Generator (SCIG).

2- Wound-Rotor Induction Generator (WRIG).

3- Doubly-Fed Induction Generator (DFIG).

4- Synchronous Generator (SG) with external field excitation.

5- Permanent Magnet Synchronous Generator (PMSG).

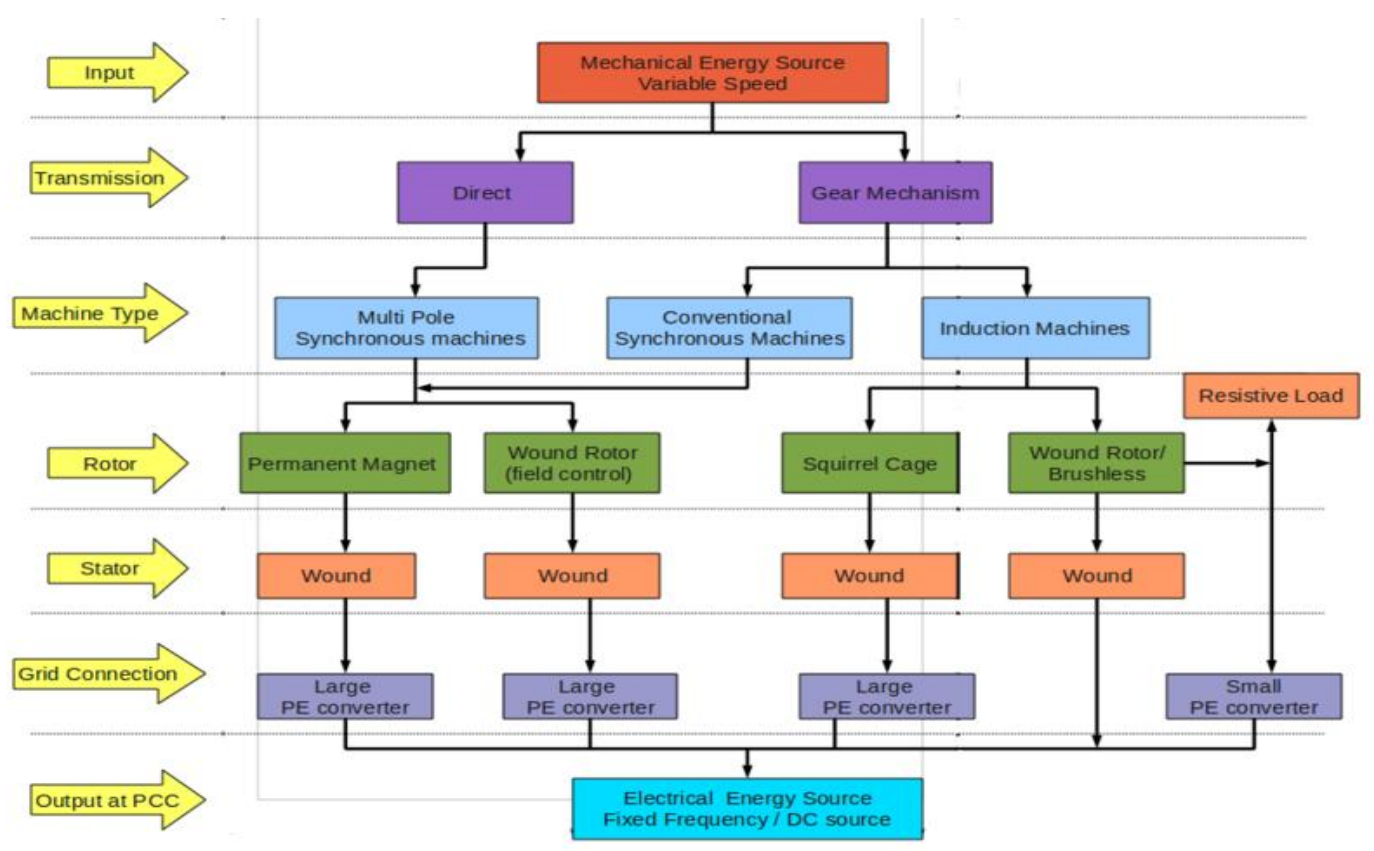

Figure 2.2 different types of wind turbines generators. [15] 


\begin{tabular}{|c|c|c|}
\hline & Advantages & Disadvantages \\
\hline $\begin{array}{l}\text { Fixed-speed System } \\
\text { SCIG, WRIG }\end{array}$ & $\begin{array}{l}\text { a. Simple construction and } \\
\text { robust; } \\
\text { b. Low cost and maintenance; } \\
\text { c. Easy control; }\end{array}$ & $\begin{array}{l}\text { a. Not optimal operation } \\
\text { thus low efficiency; } \\
\text { b. Easy power fluctuation } \\
\text { caused by wind speed } \\
\text { and tower pressure; } \\
\text { c. External reactive power } \\
\text { compensation is needed; } \\
\text { d. Weak capability of FRT; }\end{array}$ \\
\hline $\begin{array}{l}\text { Limited-speed } \\
\text { System } \\
\text { WRIG }\end{array}$ & $\begin{array}{l}\text { a. Limited speed variation is } \\
\text { implemented; } \\
\text { b. The slip ring may be replaced } \\
\text { by optical coupling; }\end{array}$ & $\begin{array}{l}\text { a. Speed variation range } \\
\text { depends on the size of } \\
\text { the variable rotor } \\
\text { resistance }(<10 \%) \text {; } \\
\text { b. The controlled rotor } \\
\text { power must be dissipated } \\
\text { by heat in the resistor; } \\
\text { c. Still need reactive power } \\
\text { compensation and cannot } \\
\text { support the grid alone; }\end{array}$ \\
\hline $\begin{array}{l}\text { Variable-speed } \\
\quad \text { System } \\
\text { PHSGDFIG } \\
\text { WRSG and WRIG } \\
\text { with variable } \\
\text { roter resister }\end{array}$ & $\begin{array}{l}\text { a. Large range of speed } \\
\text { variation; } \\
\text { b. Appropriate control enables } \\
\text { optimal operation for } \\
\text { maximum power extraction; } \\
\text { c. No external power } \\
\text { compensation is needed and is } \\
\text { able to support the grid; } \\
\text { d. High FRT capability; } \\
\text { e. Suitable and commonly used } \\
\text { for large scale wind farms; }\end{array}$ & $\begin{array}{l}\text { a. Relatively complicated } \\
\text { control system; } \\
\text { b. Higher converters and } \\
\text { control costs; } \\
\text { c. May need a multi-stage } \\
\text { gearbox and slip ring in } \\
\text { DFIG system; } \\
\text { d. May need expensive PM } \\
\text { material and large } \\
\text { diameter design in direct } \\
\text { drive; }\end{array}$ \\
\hline
\end{tabular}

Table 2.1 Wind turbines generators advantages and disadvantages. [9]

\subsubsection{Fixed wind speed squirrel cage and wound rotor induction generators.}

Fixed speed wind turbines are installed with squirrel cage induction generators or wound rotor induction generators and they are directly connected to the grid without a gear box. Squirrel cage induction generators are more commonly used because they are more reliable and inexpensive. The operational speed of the (SCIG) is a constant rotational speed of the rotor because it operates at a slip around 1\%, [13]. The induction 
machine requires reactive power to operate. It absorbs reactive power from the grid so it is very important that a shunt capacitor bank is installed at the wind turbine or farm terminals and this considered the to be one disadvantage in addition to the fact that speed variability imposes high stresses on the turbine structure of the IG and a soft starter is needed to prevent inrush current to the grid. The advantages of the Induction generator are, robust design, which requires little maintenance, can withstanding overloading and it has decent cost, [14]. The pitch angle of the squirrel cage induction generator is held constant for different wind speeds and the gear ratio of the gear box is constant do to the fixed speed of the generator that operates on small slip range; around 1\%. [10].

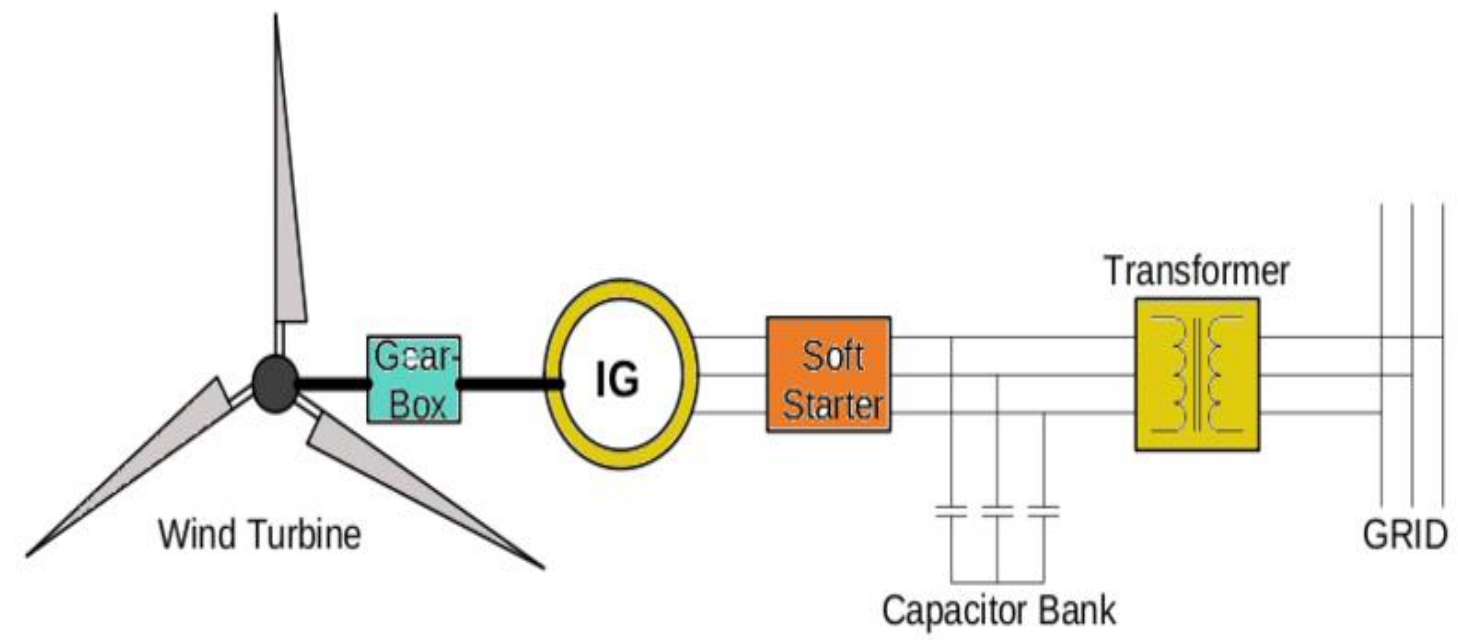

Figure 2.3 fixed speed squirrel cage induction generator conversion system. [15]

\subsubsection{Variable Speed Permanent Magnet Synchronous Generator}

Synchronous Generators (SG) are commonly used in direct drive wind turbines that operate without a gear box. The PMSG has its magnetization provided by a Permanent Magnet pole system that provides a self-excitation property. Self-excitation makes the generator operate at a high power factors and high efficiencies. 


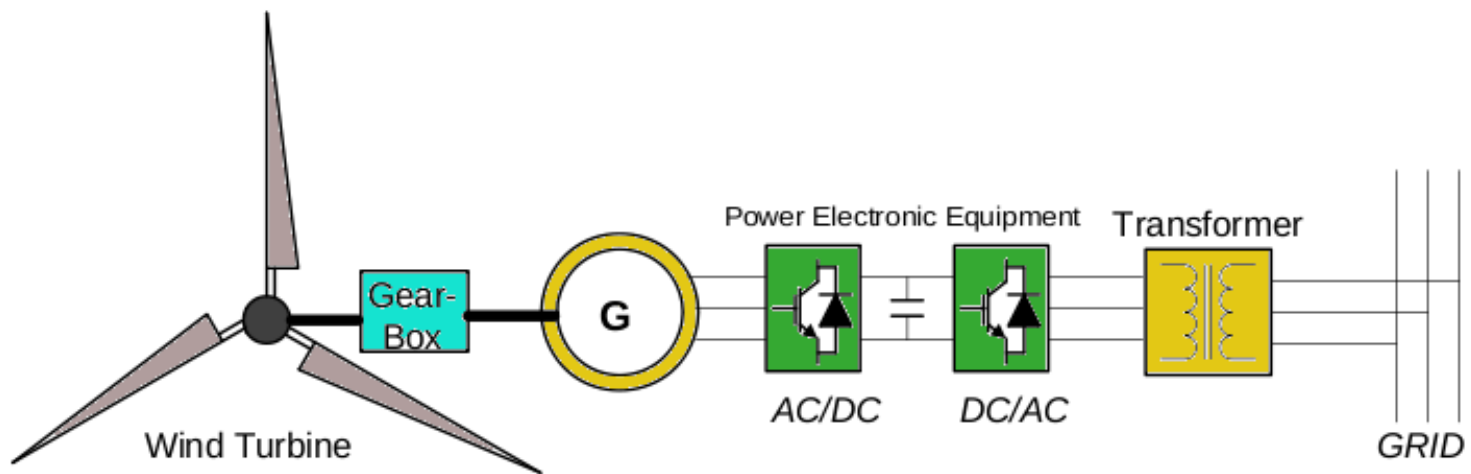

Figure 2.4 Variable Speed Permanent Magnet Synchronous Generator. [15]

\subsubsection{Variable Resistance Wound Rotor Induction Generator (limited variable speed).}

WRIG (wound rotor induction generators), works on the principle of a slip and is to be driven at synchronous speed. It is usually directly connected to the grid because of its constant speed. Capacitor banks are installed at the generator terminals to support reactive power. A starter is needed to prevent inrush current and ensure smoother grid connection. The power output is controlled through out the rotor resistor that can be changed by an optically controlled converter mounted on the shaft. The wound-rotor generator (WRG) is suitable for speed control. Wound rotor induction generator has the disadvantage of high price compared with squirrel cage induction generators. [16],[9],[13]

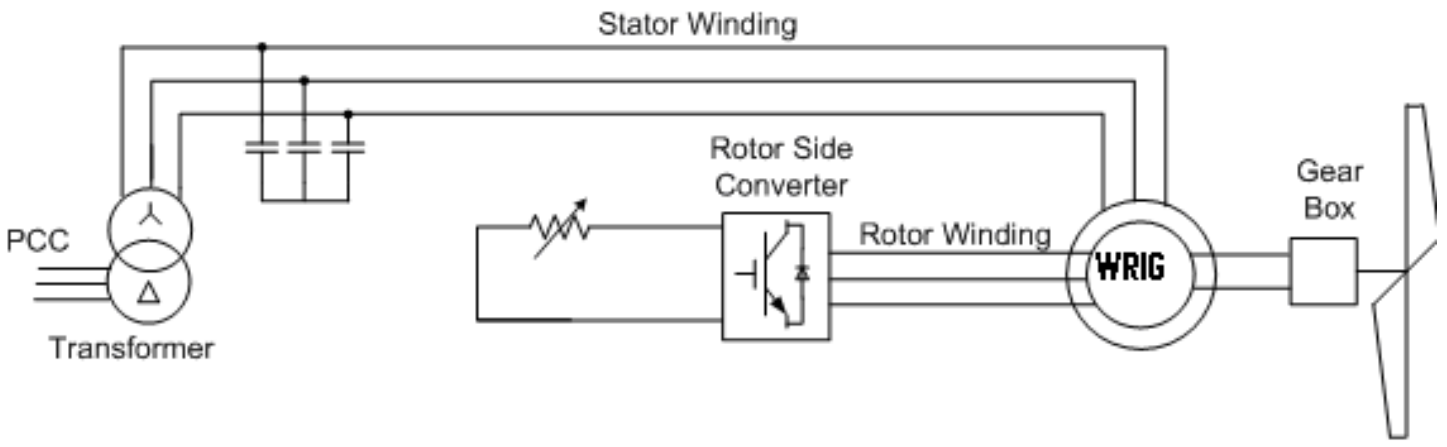

Figure 2.5 Variable Resistance Wound Rotor Induction Generator. [10]. 


\subsubsection{Variable Speed Wound Rotor synchronous Generator.}

Synchronous generators as mentioned above have the capability of direct connection to wind turbines with no gearbox. Wound Rotor synchronous Generators have an electrically excited rotor. Electrical excitation is provided by a DC supply on the rotor.

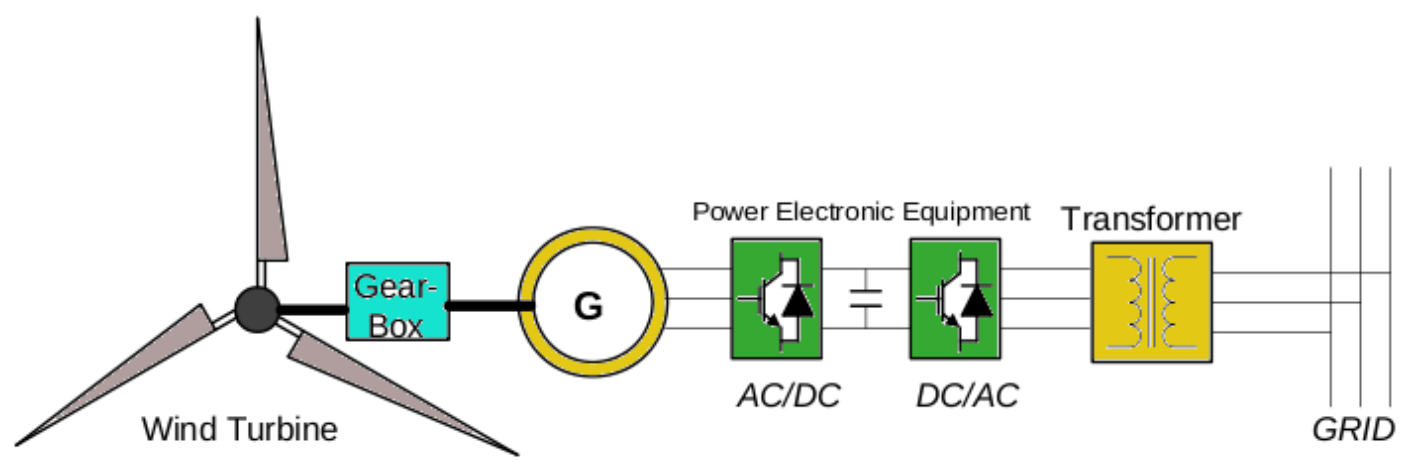

Figure 2.6 Wound Rotor synchronous Generator. [15]

\subsubsection{Variable-Speed Wind Turbine with Double Fed Induction Generator.}

The Doubly-Fed Induction Generator (DFIG) is an induction machine where the stator and the rotor windings are connected to the source. Rotor windings are connected to a power electronic converter. The advantage of connecting the converter is to perform the reactive power compensation and ensure a smooth connection to the grid and a variable speed operation is allowed with a smaller and cheaper converter. [16], [14]

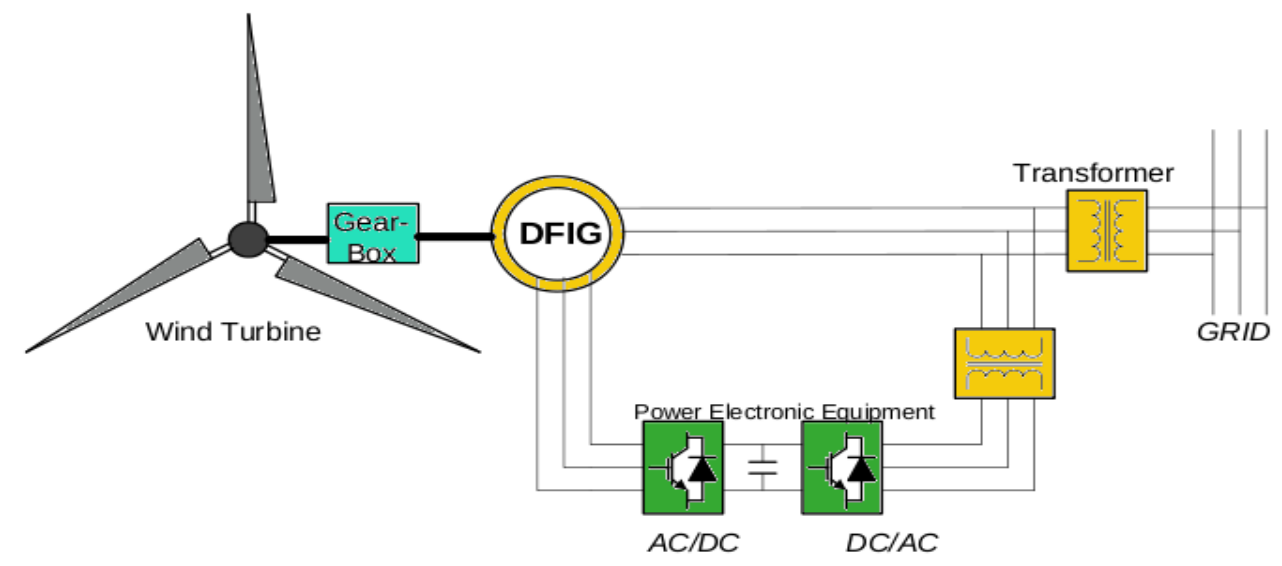

Figure 2.7 Variable-Speed Wind Turbine with Double Fed Induction Generator. [15] 


\subsection{Power electronics conversion system (back to back converter).}

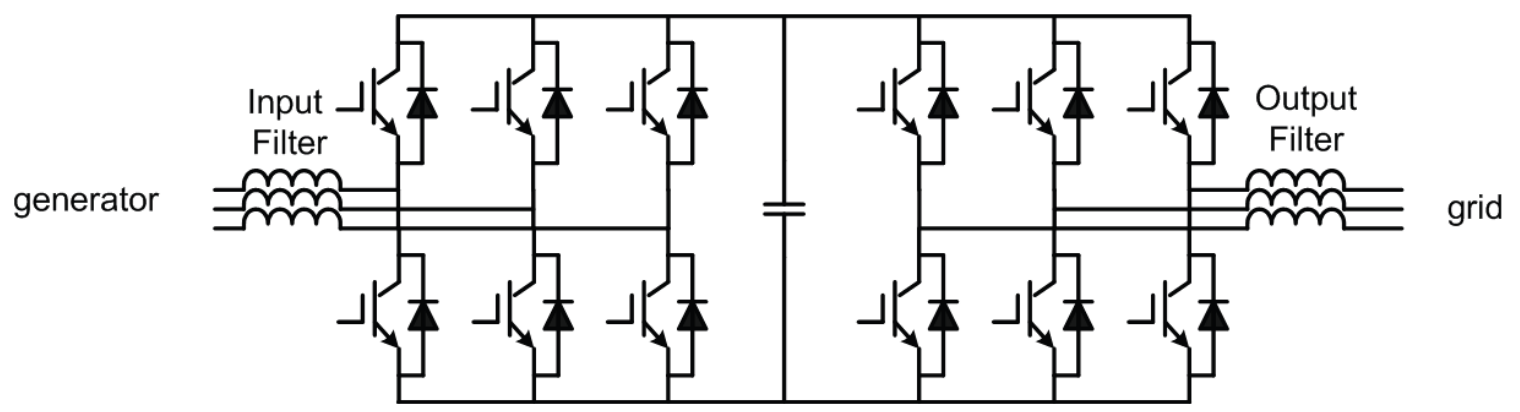

Figure 2.8 back to back converter. [17]

The back-to-back power converter is the interface connection between the wind turbine generator and the grid that control the magnitude of the voltage and the frequency according to the grid requirements. It consists of two conventional pulse width modulation (PWM)- voltage source controllers (VSCs) as shown in the figure above. Back to back is a rectifier that rectifies the unregulated $\mathrm{AC}$ voltage to $\mathrm{DC}$ voltage which is represented in an energy storage device, and an inverter that convert the DC voltage to regulated Ac voltage with fixed frequency. The power flow of the grid side converter is controlled in order to keep the DC-link voltage constant or within a desirable voltage limit according to the control scheme while the generator on the turbine side is controlled to meet specific speed references, torque references or power references and all that related to different control schemes for different purposes. The main function of the capacitor on the DC bus it to store energy and to act as a decoupling between the rectifier and the inverter so that each can be controlled separately and isolate the wind turbine systems from the grid witch give some protection. [9],[14], [17] 


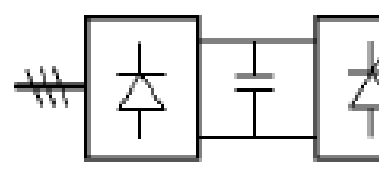

(a)

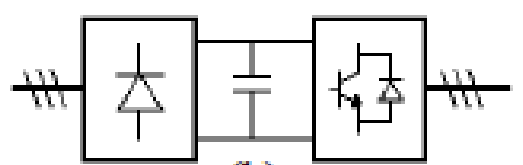

(b)

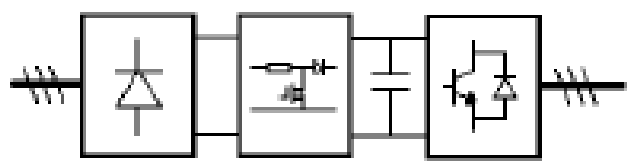

(c)

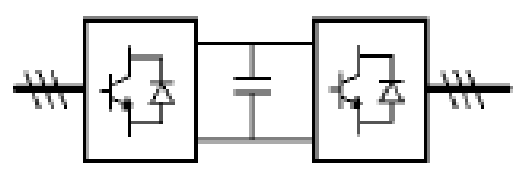

(d)

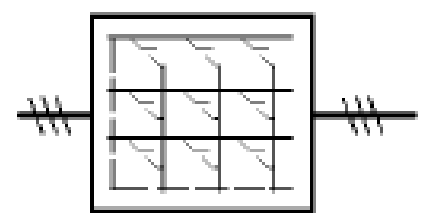

(e)

Figure 2.9 most common converters topologies. a) Diode and line-commutated converter.

b) Diode and PWM VSI converter.C) Diode and DC/DC chopper and PWM VSI converter. d) back-to-back PWM VSI converter. e) Matrix converter. [9]

\subsection{Wind power energy storage.}

Batteries are the most common conventional energy storage used for wind grid integration system. Batteries are used to store and support DC power unless if it is accompanied with an electrical converter to convert the DC power to AC power and vies versa. There are different types of batteries according to different application. Wind turbine grid integration application needs deep cycle, heavy duty batteries that designed for high reliability and long life so it can be fully charged and discharged. Battery developments are ongoing to develop a fast charging rate and lighter batteries.

There are three important types of batteries that have been developed and they operate as the conventional batteries but in large scale and they have a long life and low temperature performance and they are: 


\section{Lead-Acid (LA)}

2. Nickel-Cadmium (NiCd)

3. Sodium-Sulphur $(\mathrm{NaS})$

These types of batteries have two electrodes that are immersed in an electrolyte, to produce a current as a result of a chemical reaction.

There is another type of battery energy storage called flow batteries energy storage (FBES) that are electrochemical energy storage based. These types of batteries have a charge to discharge ratio, depth of charge (DOC) and memory effect terminologies and they are three primary types.

1. Vanadium - Redox (VR)

2. Polysulphide - Bromide (PSB)

3. Zinc - Bromine (ZnBr)

Another type of new technology batteries energy storage systems are called Supercapacitor batteries and will be lustrated in the upcoming sections

\subsubsection{Lead-Acid (LA) battery}

The lead acid battery are the most common energy storage that is used for wind energy storage systems because of it's low cost, fast response, low self discharge rate and lighter weight. Lead acid batteries can be used for different applications; they can be for long time or short time storage periods which are seconds to hours. Lead acid batteries are two types, one is flooded lead acid batteries (FLA) that has two lead plates electrodes immersed in a chemical mixture to produce current due to a chemical reaction and the other one is valve regulated lead acid batteries (VRLA) which have the same working principle of flow batteries but with regulated pressure valve. These type of batteries are most commonly used in wind and solar applications and they have higher initial cost and shorter lifetime, however they have are lighter in weigh, less volumes and lower cost of 
maintenance. Power and energy capacity depends on the battery size and the electrode plate's size and surface area. Increasing the surface are by increasing the electrodes plates and making it thinner will increase the power and energy but making the capacity stronger plates should be less and thicker. Lead acid batteries responds within milliseconds at full power and have a life of approximately 5 years which is 250 to 1000 charging and discharging cycles depends on the depth of charging and discharging. Lead acid batteries have a short life cycle and it needs to be replaced occasionally for compensation of short or long duration variability. [18], [19], [21].

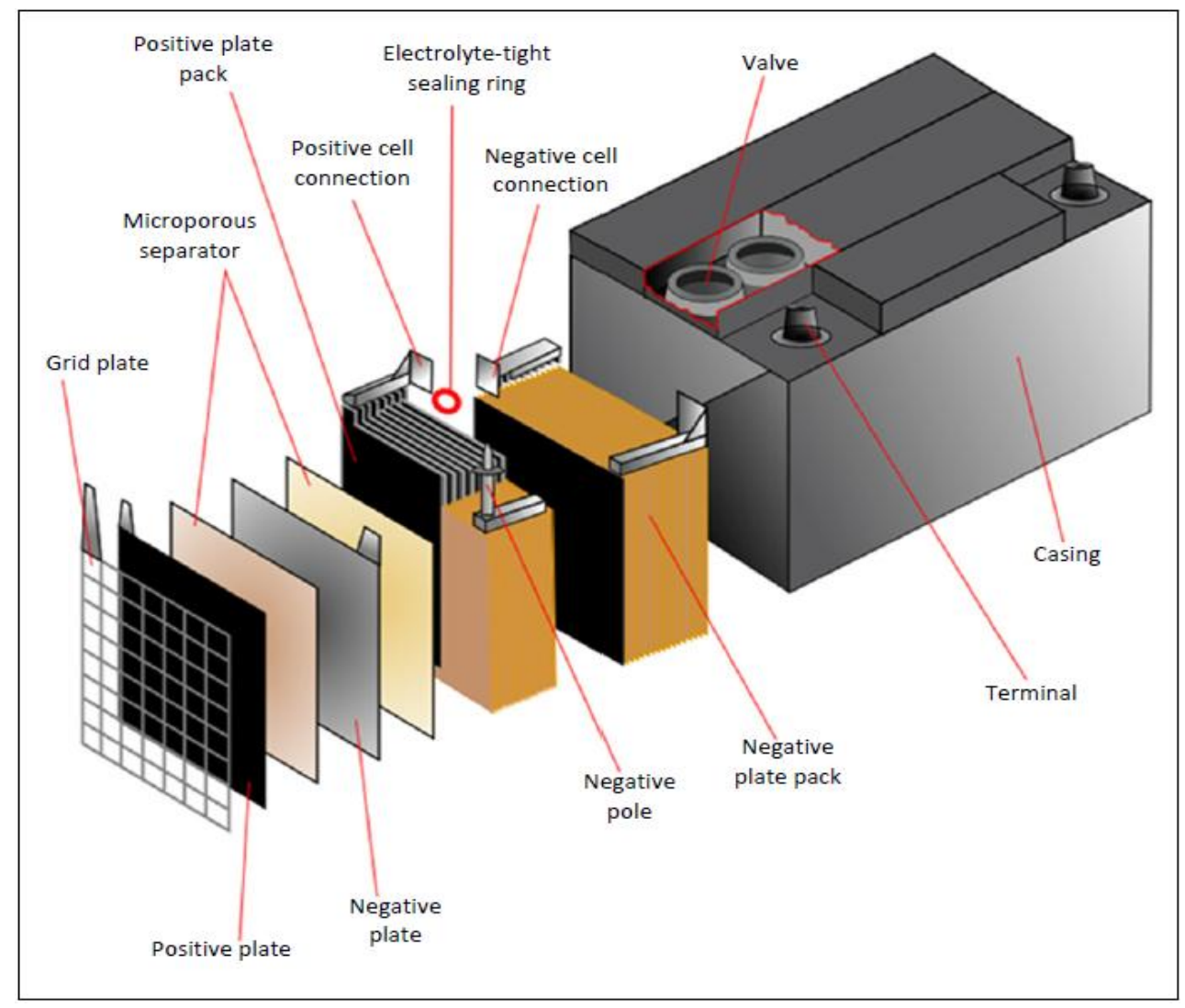

Figure 2.10.Lead acid battery structure. [18]. 


\subsubsection{Nickel-Cadmium (NiCd) battery}

A NiCd battery is made from a positive electrode with nickel oxyhydroxide and a negative electrode of metallic cadmium which are separated by a nylon divider. The electrolyte liquid is potassium hydroxide. During discharge, a chemical reaction occur producing Cadmium hydroxide at the negative electrode. During charging, discharging reaction can be reversed resulting in oxygen that can be produced at the positive electrode and hydrogen that can be produced at the negative electrode and the charging and discharging reactions need some venting and water addition. There are two types of NICD batteries, one of which is a sealed one as shown in figure (2.11), and the other is a vented one as shown in figure (2.12). Sealed batteries are commonly used for rechargeable batteries that doesn't release gases unless it breaks out, however, vented batteries release some gases if it rapidly discharged or overcharged. The Oxygen and hydrogen are released through. NiCd batteries have relatively long life of 10 to 15 years, depending on the application, charging and discharging rate and the depth of discharge must be small to allow more cycles. It has a life of 1,000 or 3500 charge/discharge cycles, depending on design. It responds within milliseconds at full power and withstands higher temperature, about $50 \mathrm{C}$. Although it is relatively expensive and has some disposal problems due the heavy and toxic Cadmium metal, it is good for small wind turbine applications, compensation of short period wind variability. [18], [19], [21]. 


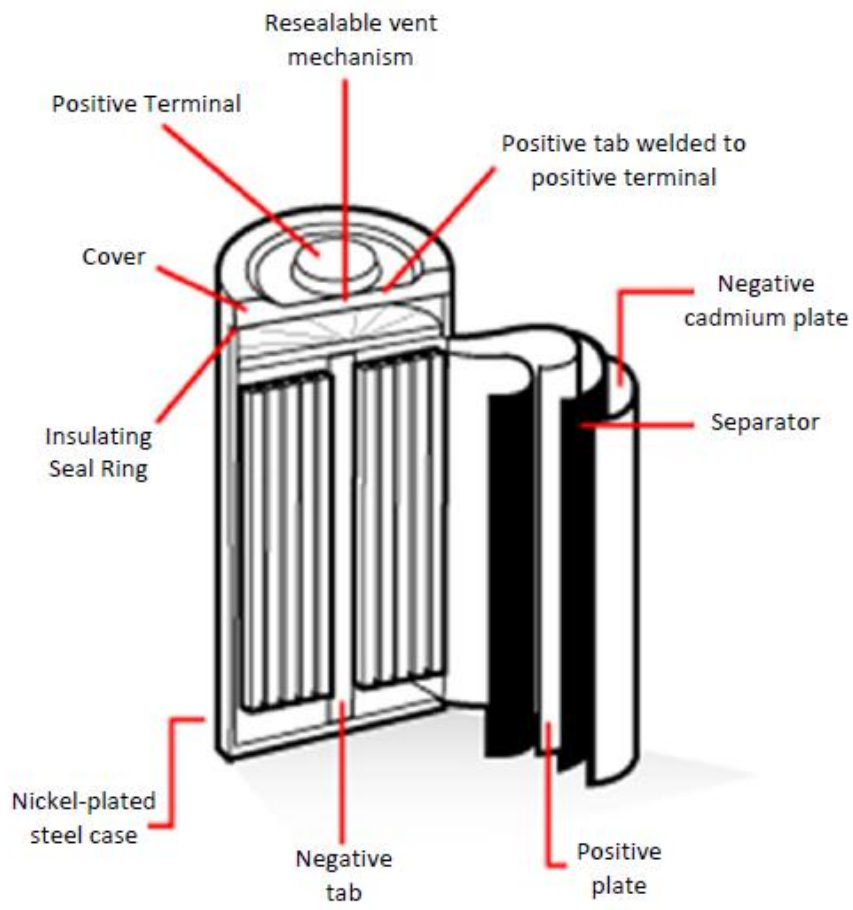

Figure 2.11 Sealed nickel cadmium battery structure. [18].

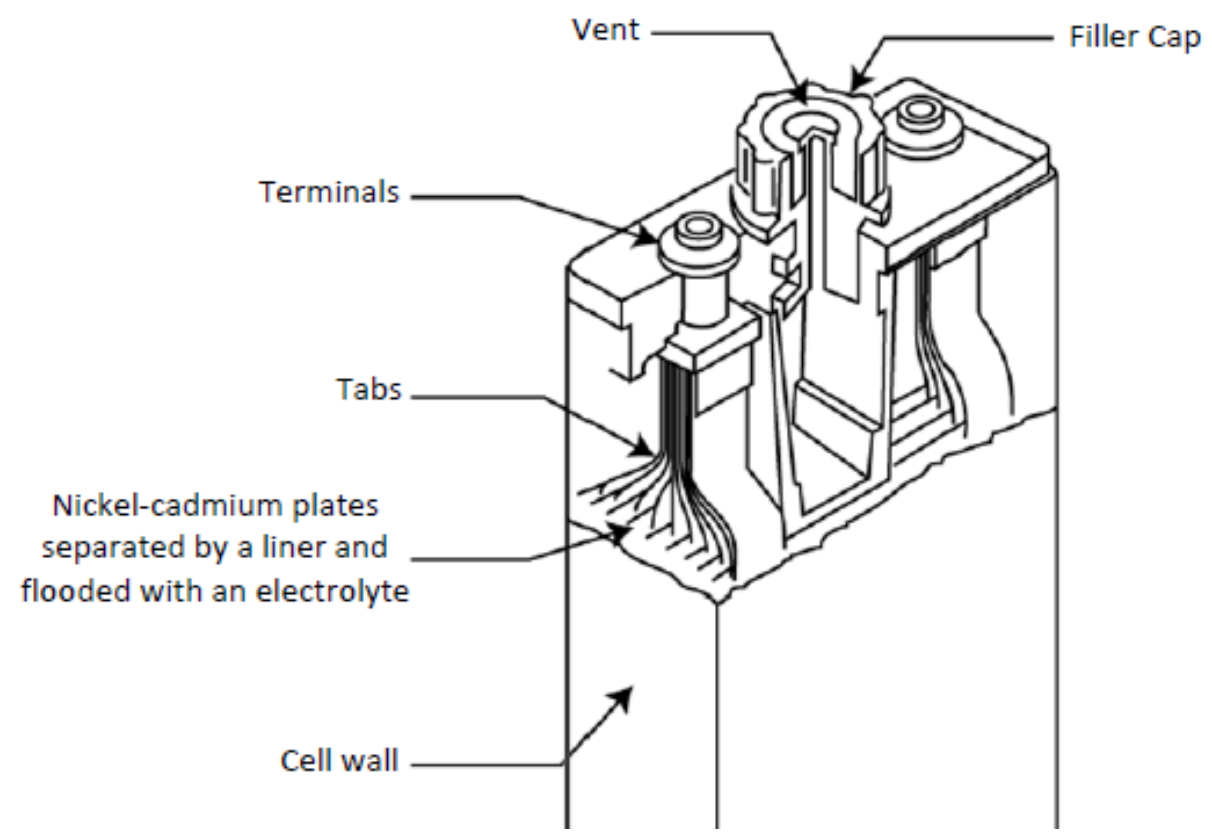

Figure 2.12 Sealed nickel cadmium battery structure. [18]. 


\subsubsection{Sodium Sulphur (NaS) Battery}

Sodium Sulphur batteries are electrochemical cell that made of molten Sodium as a negative electrode and Sulphur as a positive electrode and solid solid $\beta$-alumina as a electrolyte. During charging, chemical reactions happen and the Sodium ions pass through the electrolyte and react to form Sodium Polysulfide at the positive electrode. Discharging require reversing the reaction so that sodium polysulfide decomposes and the sodium ions are converted to sodium at the positive electrode and the electrolyte has be maintained between $320^{\circ} \mathrm{C}$ to $340^{\circ} \mathrm{C}$ to keep adequate conductivity. NaS has better energy density, long life, less maintenance and has life cycle from 2500 to 40000 depending on the depth of discharge (DOD). [18], [19], [21].

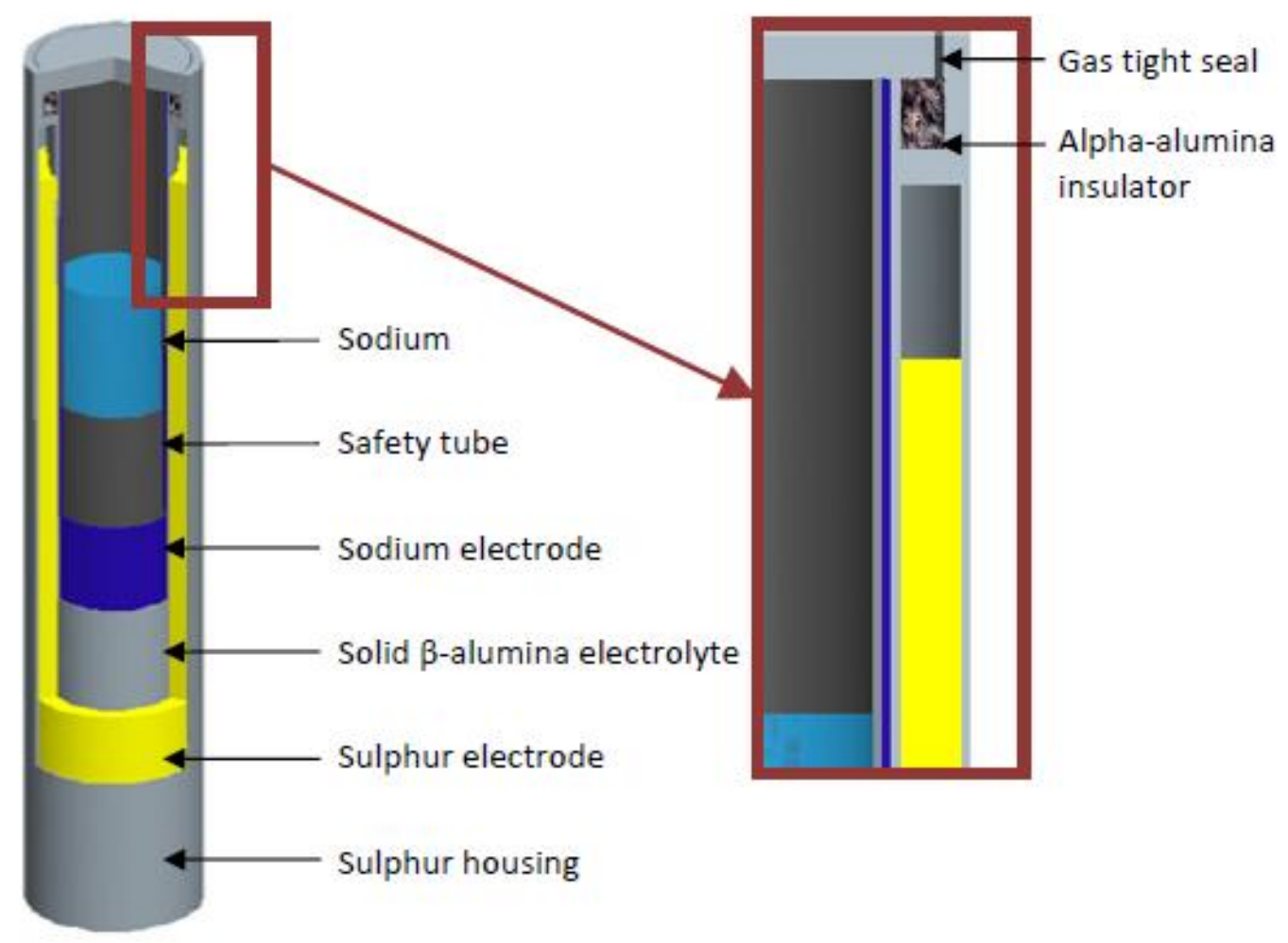

Figure 2.13 Sodium Sulphur cell structure. [18]. 


\subsubsection{Vanadium Redox (VR) Flow Battery.}

Vanadium Redox (VR) flow battery are made of two electrolyte tanks, cell stacks, and pumps to pump the electrolyte as shown in figure (2.14). Electrolytes are different kinds of vanadium ions in Sulphuric Acid; one is V2+ or V3+ as a negative electrode and V4+/ V5+ as a positive electrode. Energy is stored by the interconnection of the electrolyte ions in the cell stack. The cell stack size determines the power capacity of the battery and the volume of the electrolyte tank determines the energy capacity. When the electrolyte goes from the tank through the cell during discharging, $\mathrm{H}+$ ions will pass through the membrane between the electrolytes changing the potential energy to electrical energy and reversed process is needed to the charging process. VR batteries works on normal temperature, it has a fast response about $1 \mathrm{~ms}, 1: 1$ charge to discharge ratio, high overloaded capacity, high life cycle, about 10000 cycles, low maintenance and it can be fully discharged without affecting its performance. It reliable and needs low maintenance since it can be constructed on a site and the cell stacks are the only things have to be changed after the cycles end and the electrolyte has infinite life. VR batteries are a good storage for long and short time compensation for wind variability. [18], [19], [21].

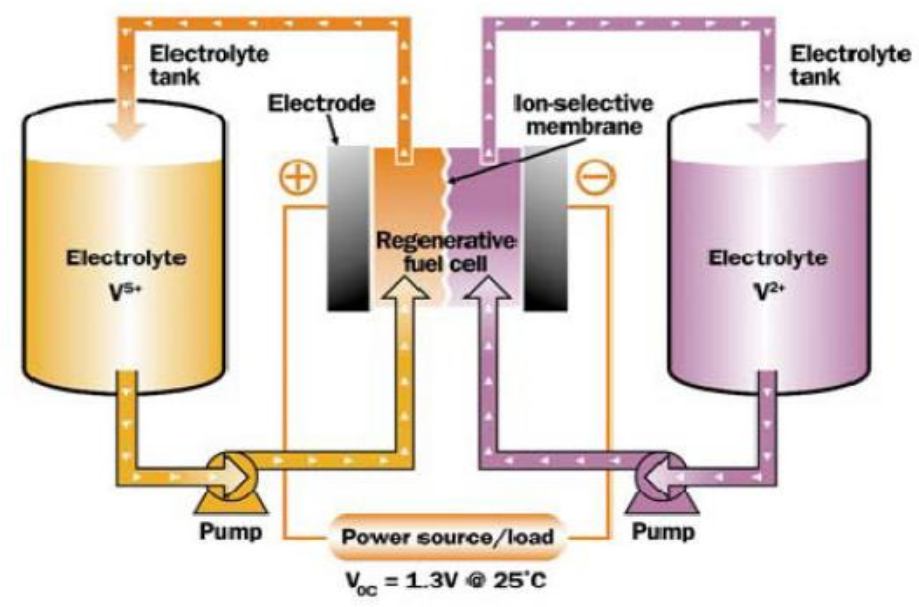

Figure 2.14 Vanadium Redox flow battery structure. [18]. 


\subsubsection{Polysulphide-Bromide (PSB) Flow Battery}

PSB batteries are made of the same structure as VR batteries. The components are a cell stack, electrolyte tank system and control pumps as in figure (2.15). Sodium Bromide is used as an positive electrolyte and Sodium Polysulphide is used as a negative electrolyte. When the electrolyte goes from the tank through the cell during discharging, Sodium ions will pass through the membrane between the electrolytes changing the potential energy to electrical energy and reversed process is needed to the charging process. The discharge ratio of the battery is $1: 1$, it operate at a low temperatures $\left(20^{\circ} \mathrm{C}\right.$ $40^{\circ} \mathrm{C}$ ) and the life cycle is estimated to be 2000 cycles depends on the application. [18], [19], [21].

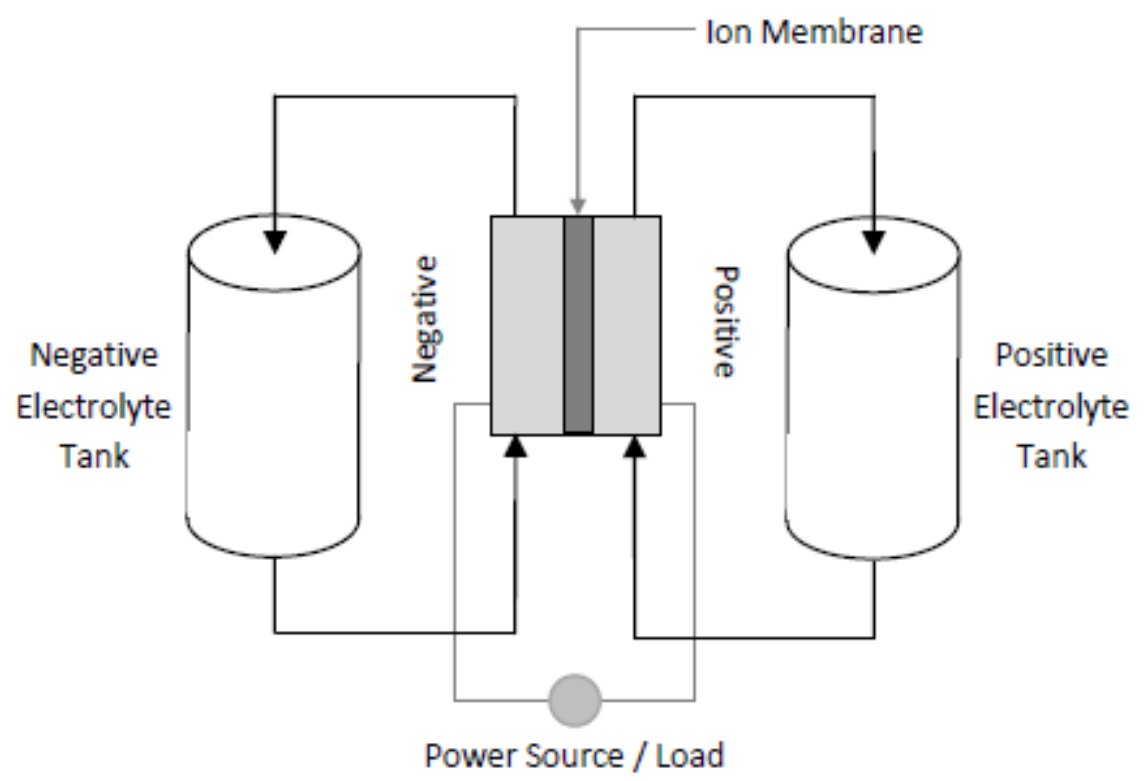

Figure 2.15 Polysulphide Bromide flow battery. [18]. 


\subsubsection{Zinc Bromine (ZnBr) Flow Battery or (ZBB).}

ZBB flow batteries has the same componentsas VR and PSB batteries are slightly different to VR and PSB flow batteries as shown in figure (2.16)but they do not operate in the same way. Electrolytes are zinc and bromine ions and they are different in concentration. During charging, ions flow to the cell stack and the are separated by microporous membrane, the electrodes act as a substrates to the reaction, once the reaction happens, zinc is electroplated on the negative electrode and Bromine is at the positive electrode and for safty purposes and self discharge reduction, an agent is added to the electrolyte to decrease the reactivity of the Bromin. Reaction is reversed for discharging, so that Zinc id dissolved from the negative electrode and Bromine is formed on the positive electrode. Electrolyte has infinite life, ZBB works at temperature between $20^{\circ} \mathrm{C}$ to $50^{\circ} \mathrm{C}$, a chiller are needed to dissipate the heat and the membrance need to be changed due to slight degradation during the operation. ZBB has a 2000 cycles, it can be fully discharged without affecting the performance, it has a 1:1 charge to discharging rate and it has the higher energy density. [18], [19], [21].

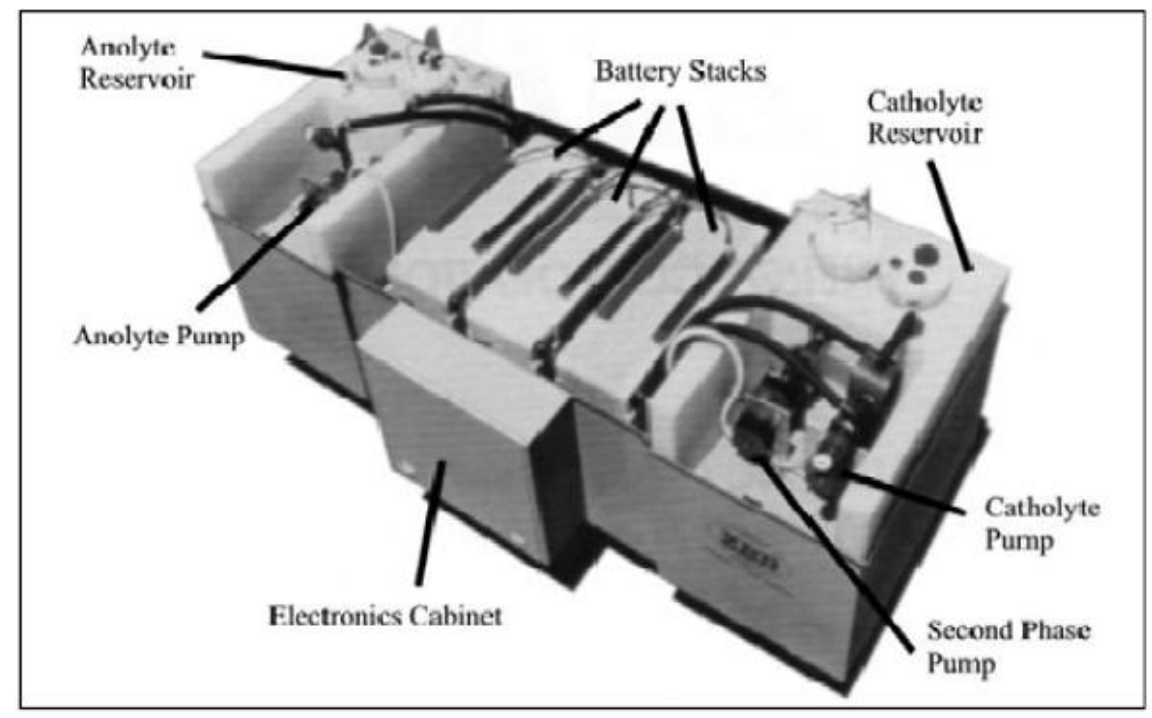

Figure 2.16 Zinc Bromine flow battery structure. [18]. 


\subsubsection{Supercapacitor Energy Storage (SCES).}

Lithium-ion supercapacitors or ultracapacitors are consisting of tow parallel metal plates, one coated with activated carbon and another one is coated with Lithium doped carbon and they are separated by an insulator as shown in figure (2.17). The plate coated with activated carbon has a positive charge and the other which is coated with Lithium doped carbon has a negative charge and both electrodes are immersed in Lithium salt solution as an electrolyte. During charging, negative ions move toward the positive electrode and positive ions move to the negative electrode and this induce an electric field so that energy can be stored. [18], [19], [21].

The energy equation is:

$$
E=\frac{1}{2} C V^{2}
$$

Where :

$\mathrm{E}$ is the energy stored within the capacitor in joules.

$\mathrm{V}$ is the voltage of the capacitor in voltage.

C is the capacitance in farads.

Capacitance can be found according to the equation below.

$$
C=\frac{A}{d} \varepsilon_{r} \varepsilon_{o}
$$

Where :

$\mathrm{C}$ is the capacitance.

$\mathrm{A}$ is area of the parallel plates .

$\mathrm{d}$ is the distance between the two plates.

$\varepsilon_{o}$ is the permittivity of free space $(8.854 \times 10 \mathrm{e} 12 \mathrm{~F} / \mathrm{m})$. 
$\varepsilon_{r}$ is the relative permittivity or dielectric constant of the material.

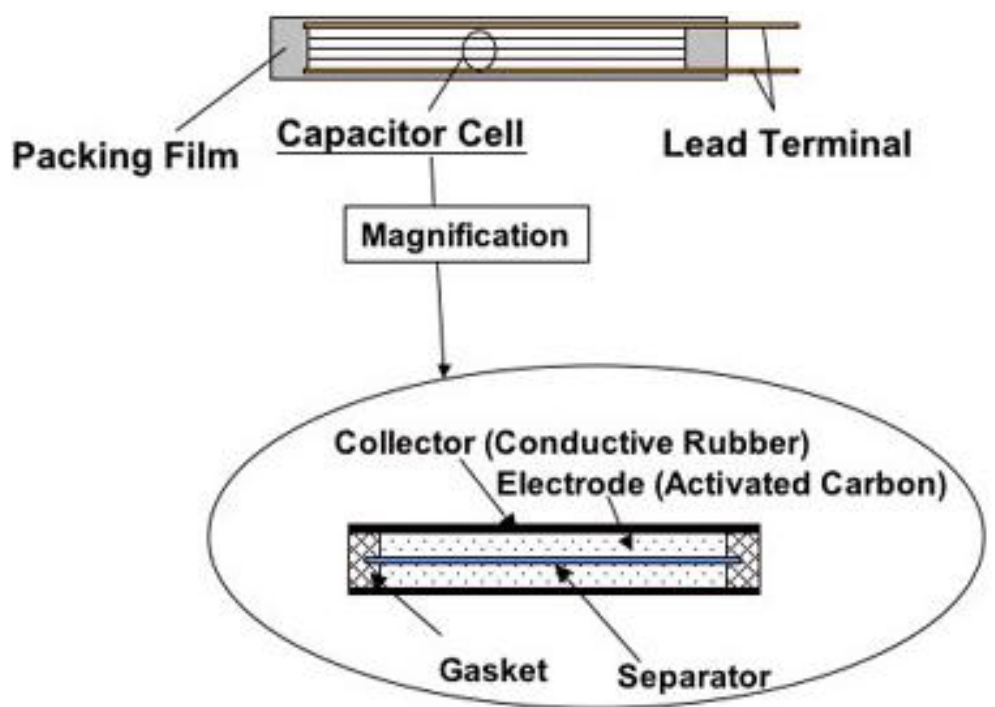

Figure 2.17 Supercapacitor energy storage device components. [17].

Supercapacitors have many advantages over the regular batteries and it can be connected either in series or in parallel. They have energy density about of $20 \mathrm{MJ} / \mathrm{m} 3$ to $70 \mathrm{MJ} / \mathrm{m} 3$ and efficiency of $95 \%$, fast charge and discharge rates and long cycle life about 1 x 106 cycles. In addition, supercapacitors show minimal degradation due to the deep discharge, no deed for heat dissipation because it does not heat up and does not produce hazardous substances. Although supercapacitos have a relatively low energy density, it is very good for short time compensation for stabilization and fluctuation and it can be rated even up to 5000F. [18], [19], [21].

Ultracapacitors and batteries as well are used to store the energy generated from the wind turbine. It store energy for power shifting which is to store energy and used when it is needed and for ramp rate limit support. In addition, it is used to store energy during grid faults since the delivered power is less than the generated wind power, and it is used to 
decouple the wind turbine from the grid side since the turbine side generates fluctuated power and voltage and it generates a frequency deviation.

\section{Chapter 3: Grid faults and requirements.}

Most of the events that occur in the electrical network are related to the network voltage. Voltage can be changed by different magnitude according to the time period of each event. Events might last from milliseconds to hours. Network events or faults can be classified in different way according to the voltage magnitude and the duration of the fault. Wind turbines connected to the grid are subjected to grid faults that might happen to the grid. Electrical network events or faults are defined as deviation from the nominal operation conditions. This deviation might happen because of short circuit in the grid, operating large motors or adding large loads and earth faults that all might lead to under voltage or voltage sage. [22], [23]

\subsection{Different types of faults.}

Grid Faults can be caused be different way, it can be caused by earthquakes, falling trees, trees contact, strong wind, or any kind of environmental incidents. Most of the faults that happens in the power lines of the electrical system and it might happen in one , two or three lines of the power system as mentioned in table (3.1). short circuit in power lines may last from milliseconds to hours until the fault is cleared by breakers of clears it self. [10], [27], [28] 


\begin{tabular}{cc}
\hline Fault Type & $\begin{array}{c}\text { \% of } \\
\text { Occurances }\end{array}$ \\
\hline \hline Single Phase-to-Ground $(\phi \mathrm{n})$ & $70-85$ \\
\hline Phase-to-Phase $(\phi \phi)$ & $8-15$ \\
\hline Phase-to-Phase-to-Ground $(2 \phi \mathrm{n})$ & $4-10$ \\
\hline Three-Phase-to-Ground $(3 \phi)$ & $3-5$ \\
\hline
\end{tabular}

Table 3.1 fault types and percentage of happens. [10]

The terminal voltage of the wind turbine during the fault can be determined according to several factors like, equivalent Thevenin network model, fault location and type, impedance, and properties of the interface transformer. For balanced $(3 \varphi)$ faults, the fault voltage during a sag event can be determined by a common voltage divider model as in figure 3.1. [10], [27], [28]

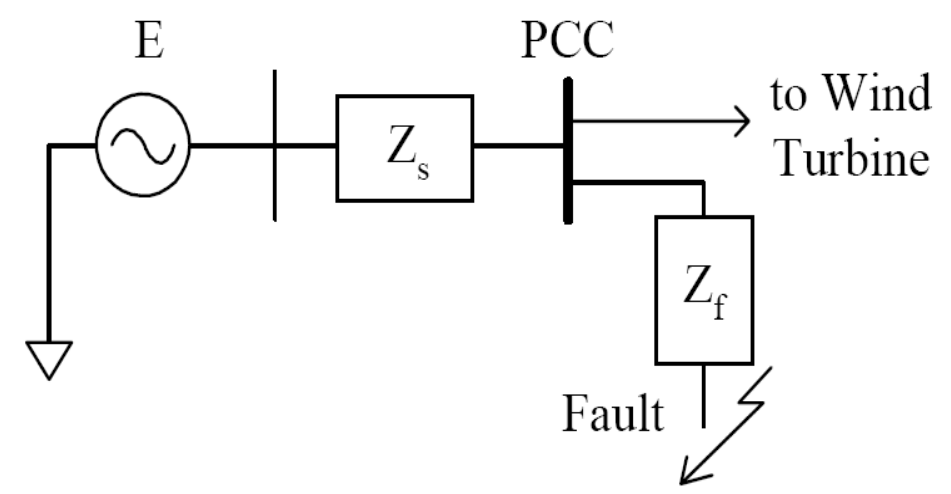

Figure 3.1 Voltage divider model for balanced fault. [27],[28].

The PCC voltage during the balanced faults is

$$
V_{p c c}=E \frac{Z_{f}}{Z_{f}+Z_{s}}
$$

The angle of the voltage at PCC can be determined if the ratio of the imaginary part to real part of the system impedance is different to the same ratio of the fault impedance. If 
there is a difference between the ratios a phase angle will be at start of the sage. Wind turbine imaginary to real part ratio of the impedance is usually consistent to the system ratio so there is no phase angle. For the unbalance faults, symmetrical component method are used to determine the phasor voltage, voltage at the wind turbine terminals will be different by the difference of the fault and the interface transformer connection between the fault and the wind turbine. [27], [29], [10]

Figure 3.2 represent a typical wind turbine transformer connection to the grid and fault analysis will be

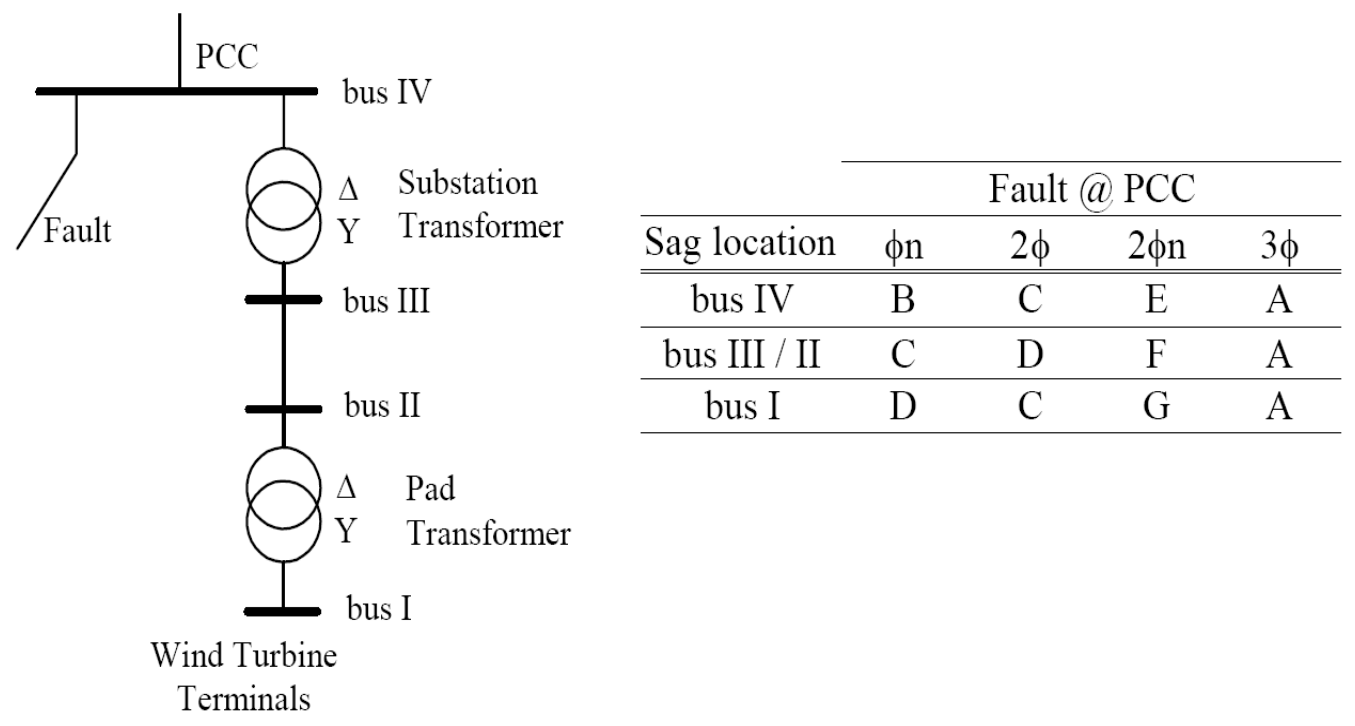

Figure 3.2 Typical transformer connections for wind turbine and the types of voltage sags for a fault on PCC . [27], [29], [10]

Since the positive, negative, and zero sequence impedances are considered equivalent, it is enough to know the voltage dip value and the fault type to find the voltage on the wind turbine terminals.

The characteristic of the voltage is the ratio of the voltage to the normal voltage.

$$
h=\frac{V}{V_{\text {nor }}}
$$




\begin{tabular}{|l|l|l|l|}
\hline Sag Type & $\boldsymbol{V}_{\boldsymbol{a}}$ & $\boldsymbol{V}_{\boldsymbol{b}}$ & $\boldsymbol{V}_{\boldsymbol{c}}$ \\
\hline $\mathbf{A}$ & $h$ & $-\frac{1}{2} h-\frac{1}{2} j h \sqrt{3}$ & $-\frac{1}{2} h+\frac{1}{2} j h \sqrt{3}$ \\
\hline B & $h$ & $-\frac{1}{2}-\frac{1}{2} j \sqrt{3}$ & $-\frac{1}{2}-\frac{1}{2} j \sqrt{3}$ \\
\hline $\mathbf{C}$ & 1 & $-\frac{1}{2}-\frac{1}{2} j h \sqrt{3}$ & $-\frac{1}{2}+\frac{1}{2} j h \sqrt{3}$ \\
\hline $\mathbf{D}$ & $h$ & $-\frac{1}{2} h-\frac{1}{2} j \sqrt{3}$ & $-\frac{1}{2} h+\frac{1}{2} j \sqrt{3}$ \\
\hline $\mathbf{E}$ & 1 & $-\frac{1}{2} h-\frac{1}{2} j h \sqrt{3}$ & $-\frac{1}{2} h+\frac{1}{2} j h \sqrt{3}$ \\
\hline F & $h$ & $-\frac{1}{2} h-\left(\frac{1}{3}+\frac{1}{6} h\right) j \sqrt{3}$ & $-\frac{1}{2} h+\left(\frac{1}{3}+\frac{1}{6} h\right) j \sqrt{3}$ \\
\hline $\mathbf{G}$ & $\frac{1}{3}(1+2 h)$ & $-\frac{1}{3}-\frac{1}{6} h-\frac{1}{2} j h \sqrt{3}$ & $-\frac{1}{3}-\frac{1}{6} h+\frac{1}{2} j h \sqrt{3}$ \\
\hline
\end{tabular}

Table 3.2 Faults types and the corresponding per unit phase voltages as a function of per unit characteristic fault voltage, $h$ [27],[29], [10].

\subsection{Grid requirements.}

As the wind energy penetration to the grid is rabidly increasing, wind power plants have a large impact on grid stability and influence on power system operation. Power system operators have increased the connection requirements to the grid and came out with different grid codes. Grid codes that cover a wide range of voltage levels require the wind turbines to have the same operation behaviors as the conventional generation and more responsibility for the network system. Wind power plants in power systems should have the capability to regulate active and reactive power, and support voltage and frequency of the grid. Grid requirements have focus on active and reactive power control, quality and low voltage ride through capability during system fault and disturbance, [22]. The main issues that have been focused on for the grid connection are: [30]. 
1) Voltage operating range:

2) Frequency operating range:

3) Active power control

4) Frequency control:

5) Voltage control:

6) Reactive power control:

7) Low voltage ride through

8) High voltage ride through (HVRT):

8) Power quality:

10) Wind farm modeling and verification

11) Communications and external control

These 11 points can be categorized under three main requirements, power control and quality, frequency control, voltage control and low voltage ride through and power plant modeling control and verification .

\subsubsection{Power control and quality capability.}

Wind turbine power has to share some of the conventional power plants duties; it has to share those duties for short or long periods. It has to support active and reactive power for the grid to share the demanded load and this support has to according to the grid power requirements. Power has to be in good quality, current and voltage with acceptable harmonics range. [22] 


\subsubsection{Frequency control capability.}

Wind turbine power plants that are integrated with power system have to operate with the frequency requirements assigned by the conventional power system. It has to have the capability to operate to operate within typical frequency variation range For example , UK grid code require the wind turbine plants to be bale to operate continuously between $47.5 \mathrm{~Hz}$ and $52 \mathrm{~Hz}$ and at least 20 seconds between $47 \mathrm{~Hz}$ and $47.5 \mathrm{~Hz}$. Operation with large frequency deviation outside these limits would damage the generating plants and lead to capacity loss that leads to blackout, [31], [30]

\subsubsection{Voltage control and Low voltage ride through capability.}

Wind turbine power plants has to produce the same voltage required by conventional power system and it has to keep that voltage constant and be able to operate with the required grid voltage variation.[30]

Voltage ride through for wind turbine power plants are imposed in order to avoid the power produced by the plant during the grid faults. Due to the rapid increase of wind power generation into the grid, low voltage ride through will help the system to avoid some of the frequency and voltage control that might happened du to disconnection of wind turbine generation. Voltage ride through addresses that wind turbines are able to remain connected to the grid during the grid faults and support reactive power to help the voltage recovery, [22]. Wind turbine grid voltage support is becoming standards for all grid code that are created by power generation agencies. Three phase, single and two phase faults voltage ride through became common requirements for voltage support. [10], [30] 


\subsubsection{Power plant modelling control and verification.}

Wind power plants have to be modelled and controlled to meet the connection requirements. Simulation tools can be used to simulate the wind power plant and to control it to keep the voltage or to keep it with a required voltage fluctuation range.

High quality power is also required to be approved by the simulation with acceptable voltage and current harmonics. [10], [30]

\subsection{Low voltage ride through (LVRT) in different grid codes.}

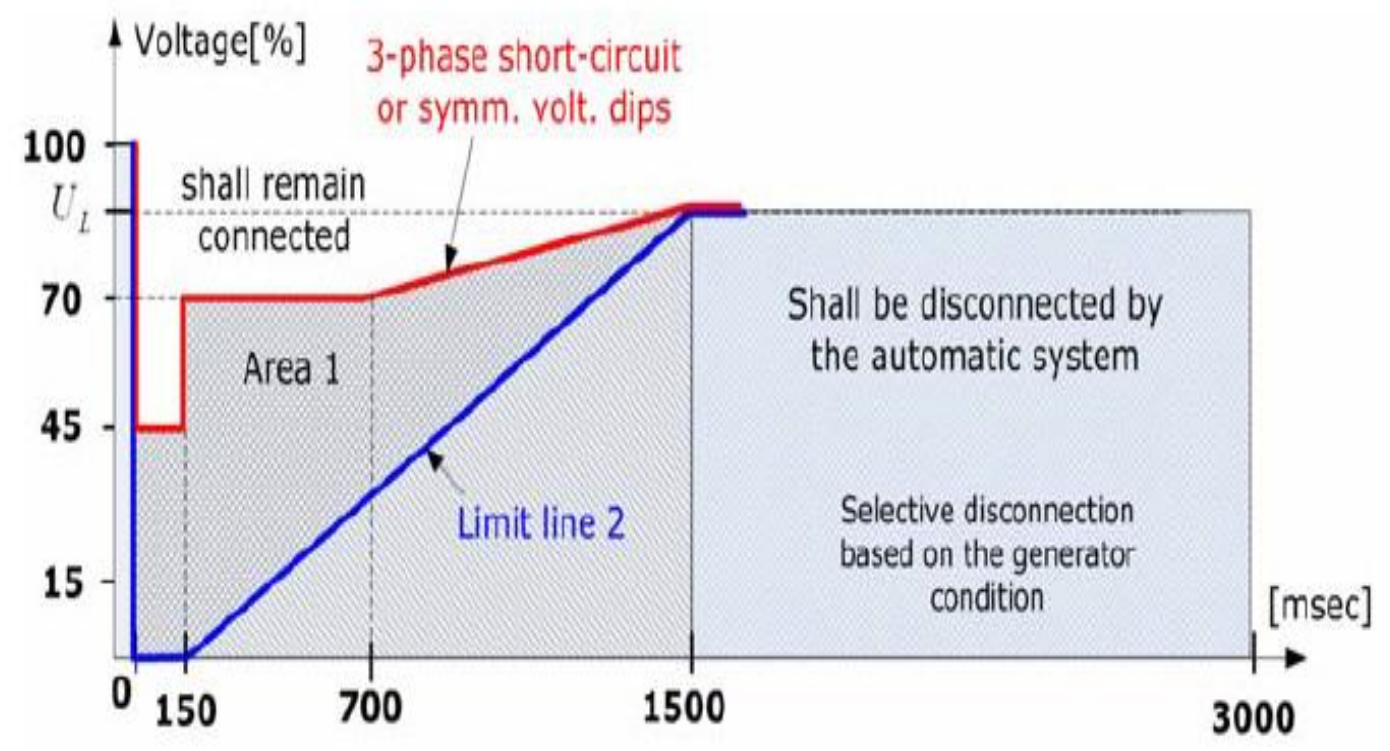

Figure 3.3 E.ON (Germany) voltage code during faults. [23] 


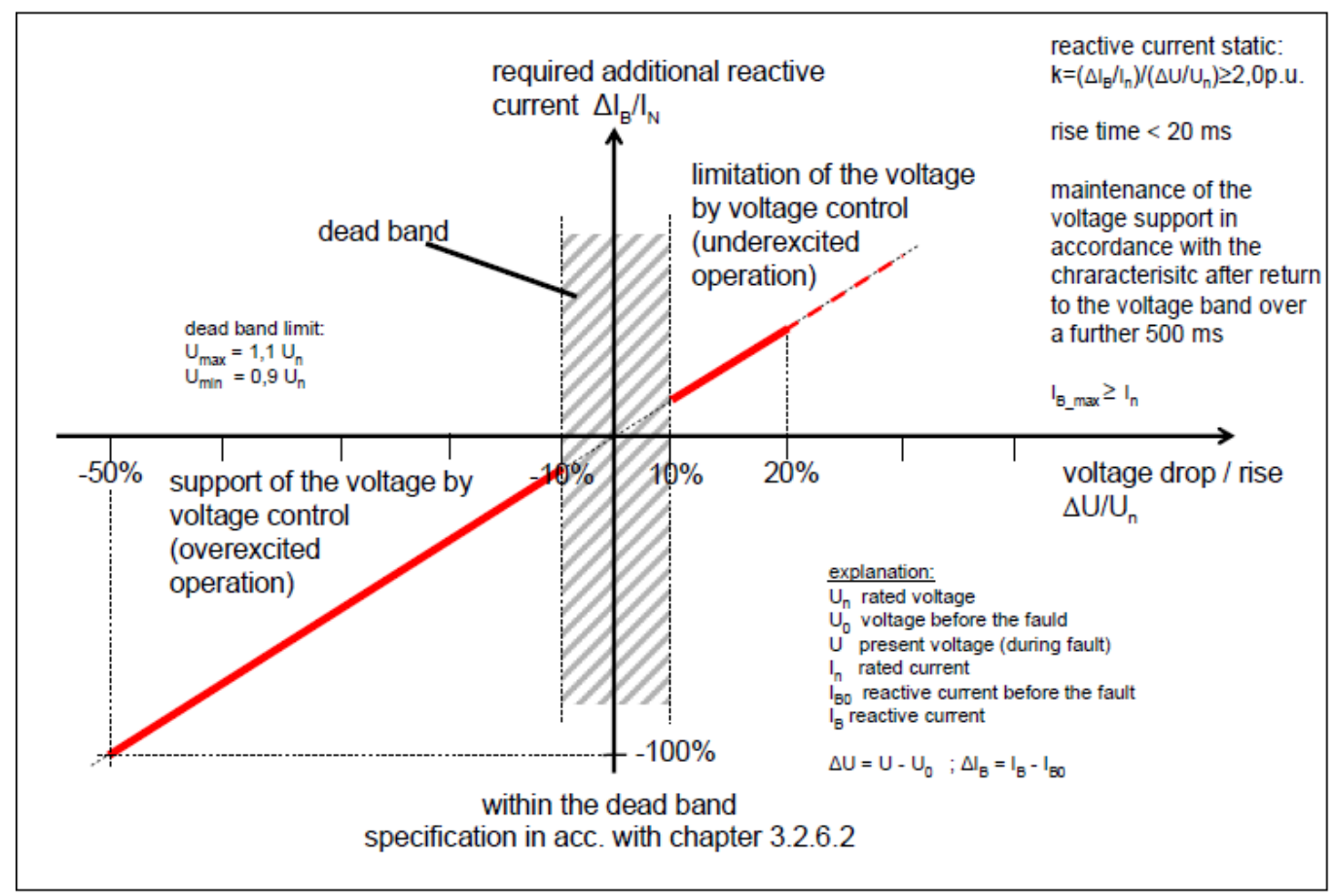

Figure 3.4 Voltage support during the grid faults, E.ON code. [32]

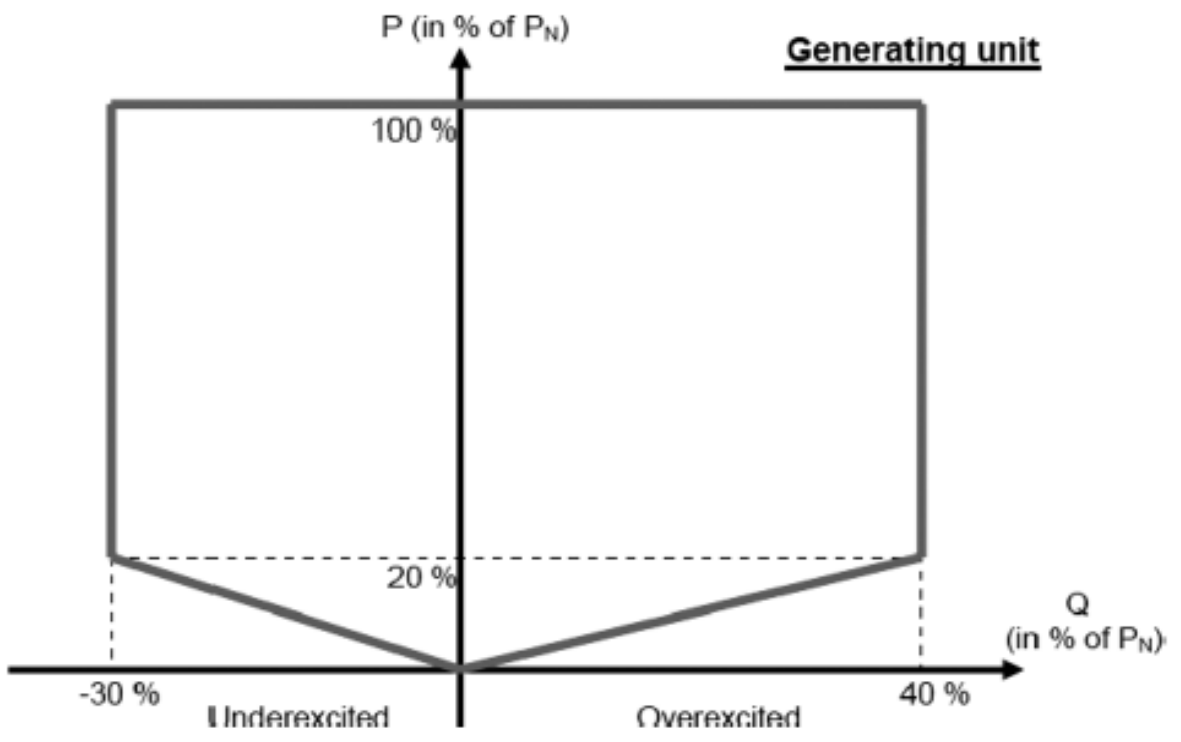

Figure 3.5 E.ON offshore requirement minimum useable P/Q-operating range of a generation unit, within a $+5 \%$ range around the nominal voltage (at the generation unit). 


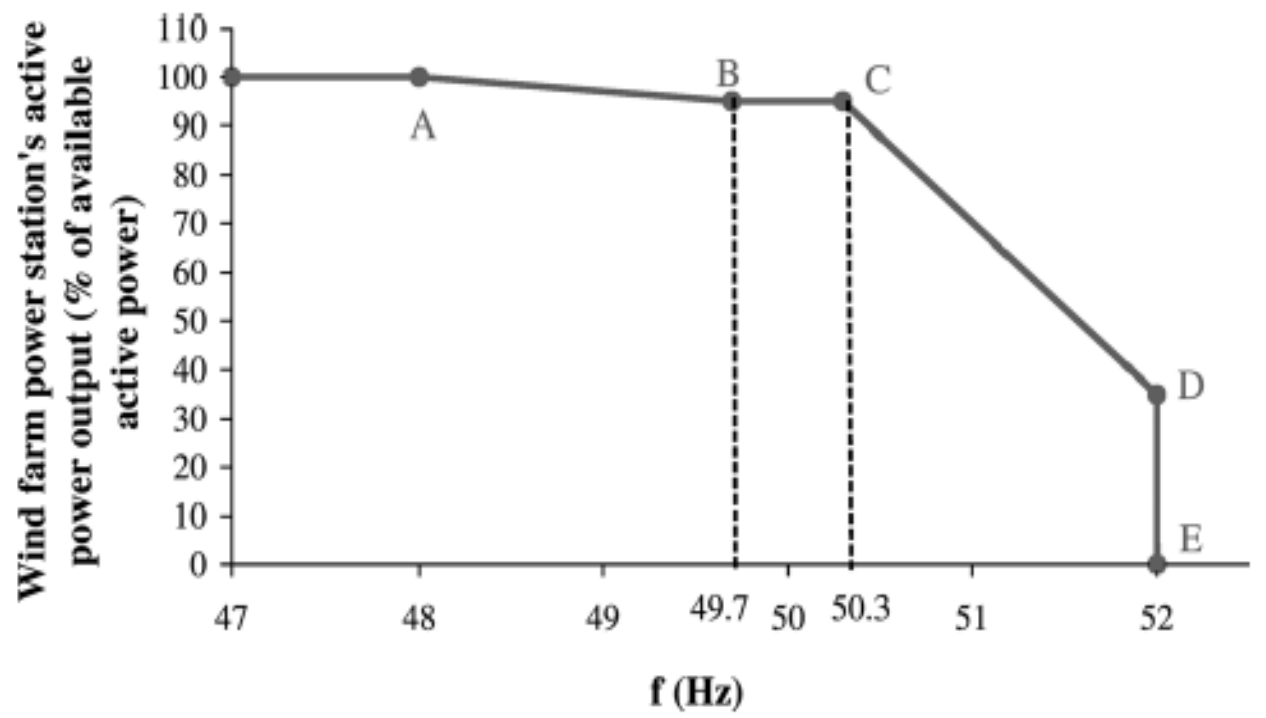

Figure 3.6 Irish grid code frequency response curve. [33]

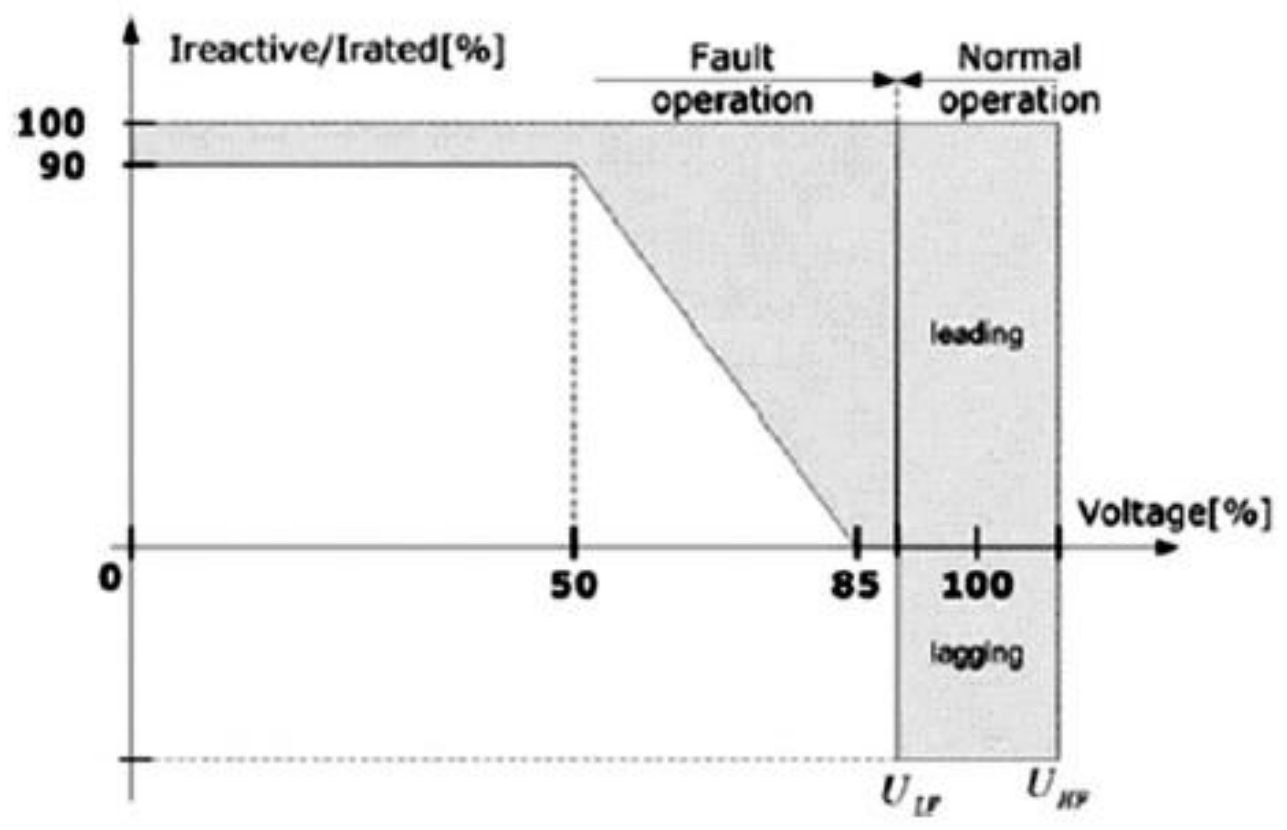

Figure 3.7 Reactive output current during voltage sage according to the Spanish grid code, [33] 


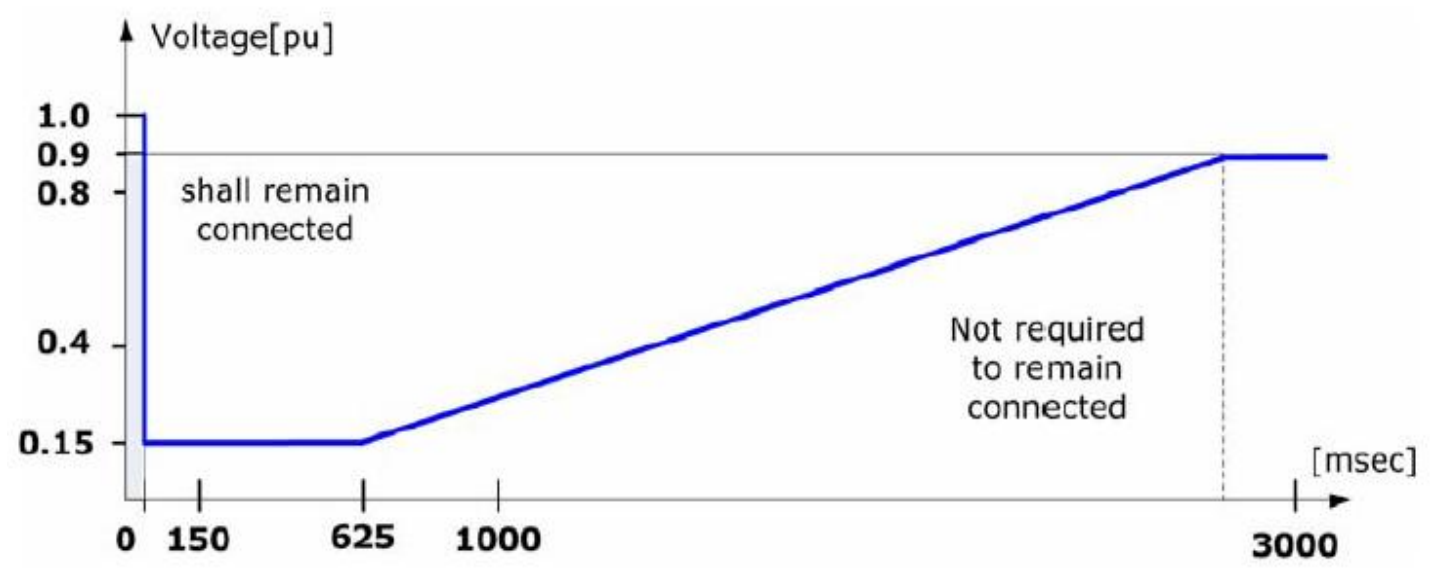

Figure 3.8 United State FERC voltage code for grid fault. [23]

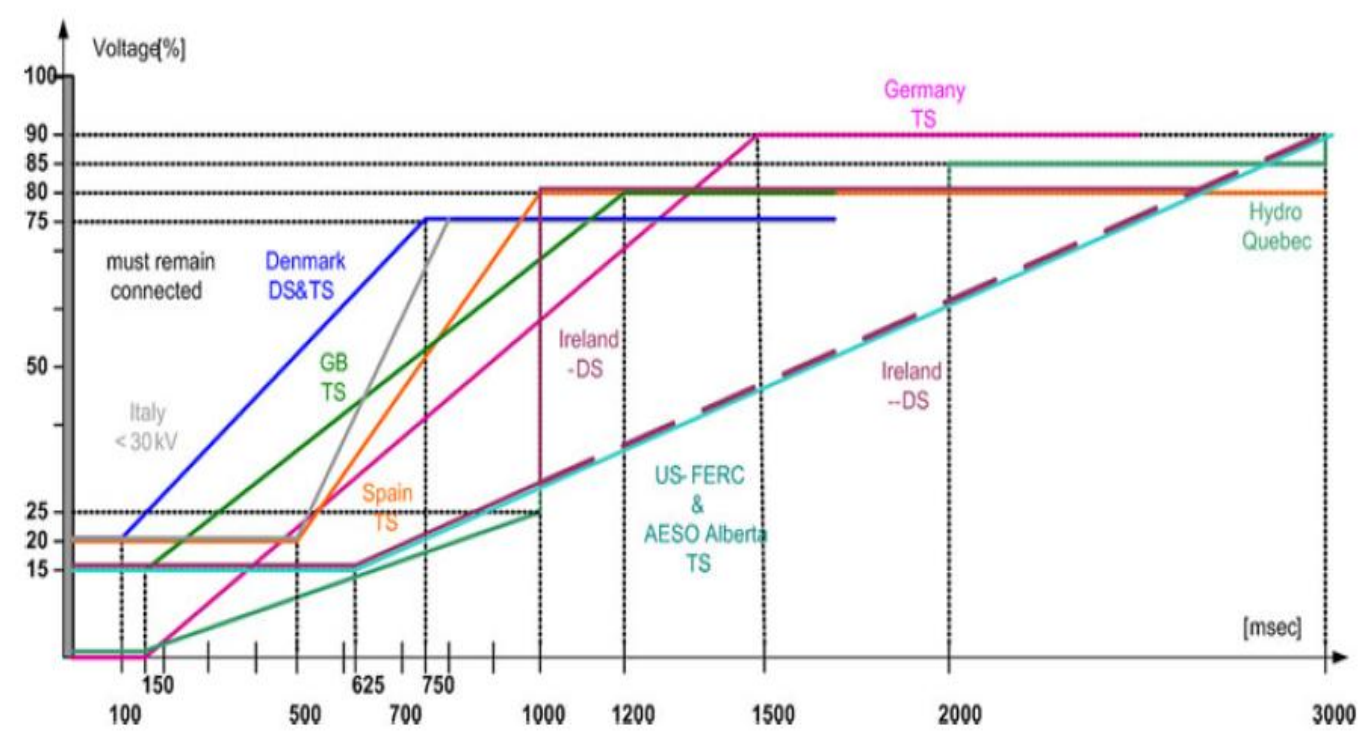

Figure 3.9 Comparison of fault ride through for different codes. [34] 


\section{Chapter 4: Wind turbine system modeling and control.}

Wind turbine system operation has been modeled and controlled using Simulink in Matlab software. The system is consisting of wind turbine mechanical system to extract the power from the wind and electrical generator to convert the extracted mechanical power to electrical power delivered to the grid. Electrical power coming from the generator needs electrical conversion system to convert the unregulated voltage and frequency coming form the wind turbine generator to constant voltage and frequency transferred to the grid. Transformer, RLC interface branches are used as a decoupling and filter to clear the signal and reduce the harmonics.

\subsection{Wind turbine modeling.}

Wind turbine used in the system is a Matlab Simulink model.

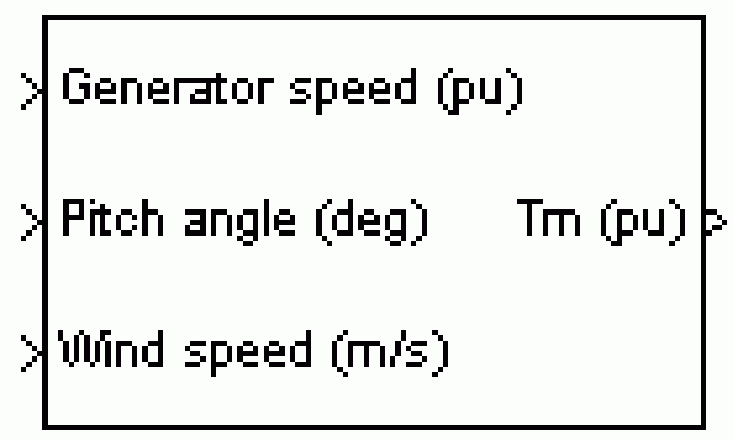

Figure 4.1 Variable pitch angle wind turbine. [35]

The above model shown in figure (4.1) is a variable pitch wind turbine model. It has three inputs and one output. The first input is the generator per unit speed of the generator rated speed. The second input is the pitch angle of turbine blades and the third input is the wind speed in $\mathrm{m} / \mathrm{s}$. The output is per unit mechanical torque of the generator ratings that will be applied to the electrical generator shaft. 
This model is a steady state model combined with a drive train. The stiffness of the drive train is infinite and the friction factor and the inertia constant are combined with the electrical generator.

The mechanical power output of this turbine can be found as:

$P_{m}=\frac{1}{2} \cdot \rho \cdot A_{b} \cdot v_{w}^{3} \cdot C_{p}(\lambda, \beta)$

Where :

$\rho$ is air density $\mathrm{kg} / \mathrm{m} 3$.

$A_{b}$ is the wept are of the wind turbine blades.

. $v$ is the wind speed in $\mathrm{m} / \mathrm{s}$.

$C_{p}(\lambda, \beta)$ is coefficient factor as a function of pitch angle and tip speed ratio.

$\beta$ is pitch angle of the blades.

$\lambda$ is tip speed ratio.

$w$ is rotational speed of the blades.

$r$ is radius of the blades.

$w r$ is the speed of the tip of the blade.

Tip speed ratio can be found as:

$T S R=\frac{w r}{v_{w}}=\lambda$

As shown in figure (4.2) performance coefficient will reach its maximum value when the pitch angle is zero and then tip speed ratio resulted from this is the nominal value. 


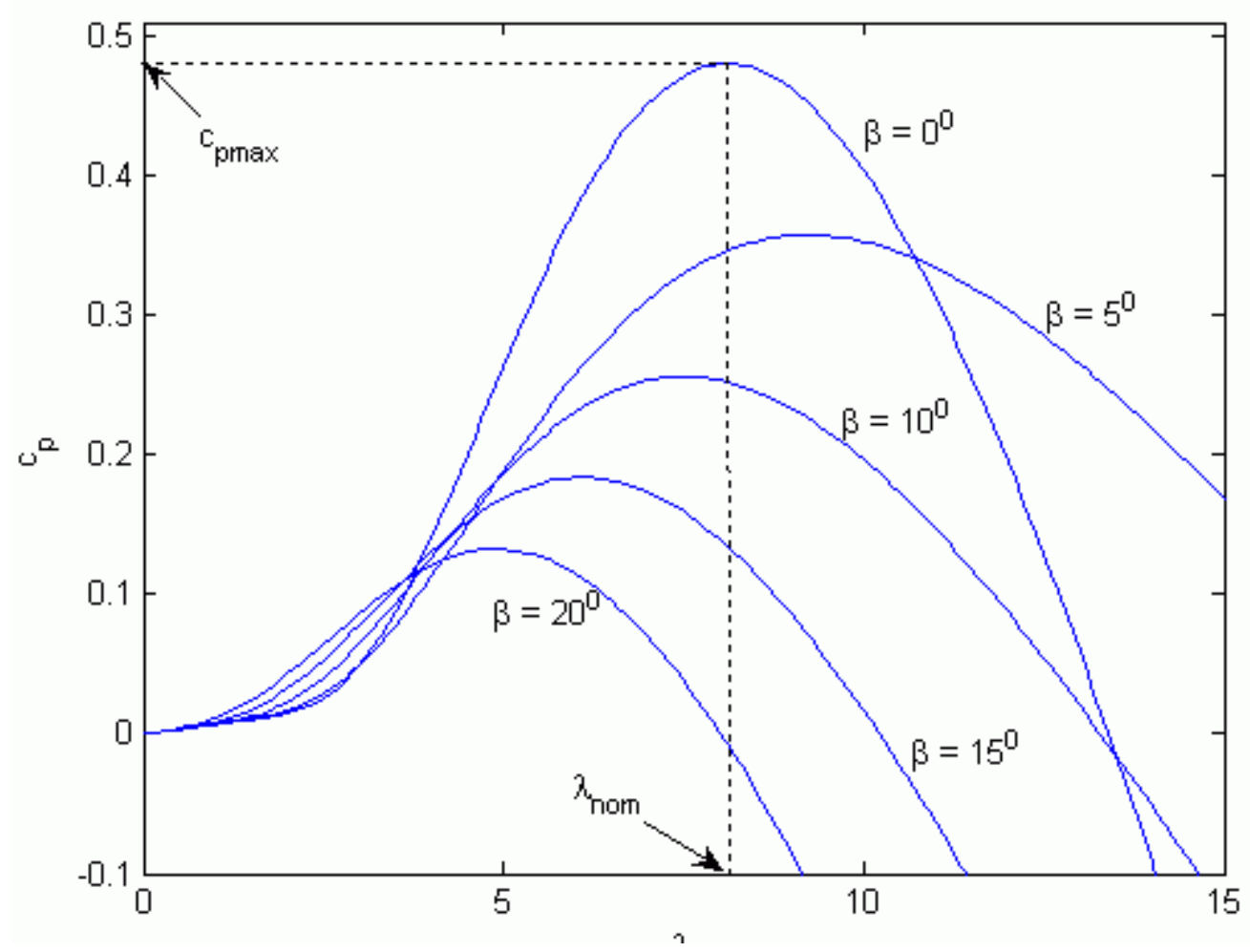

Figure $4.2 \mathrm{Cp}$ as a function of pitch angle and tip speed ratio. [35]

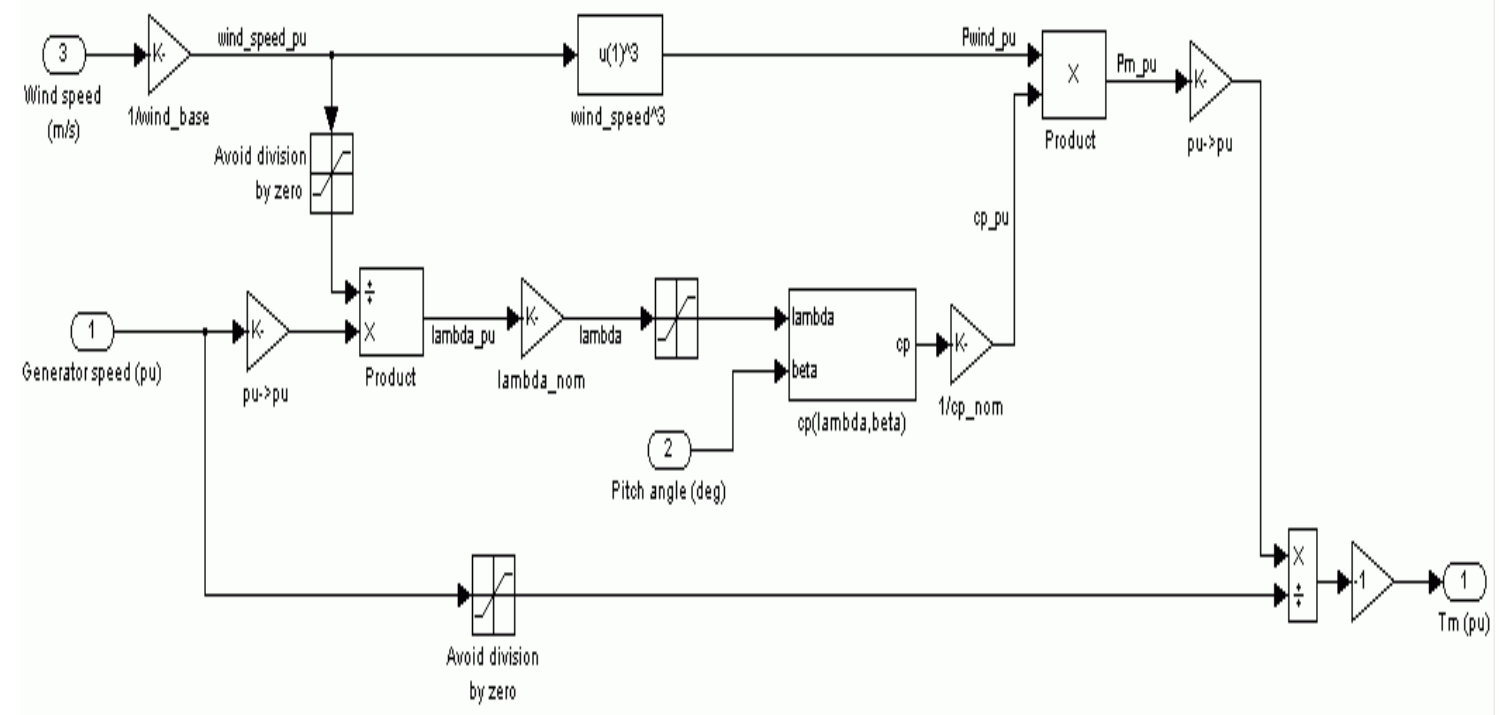

Figure 4.3 Matlab Simulink model of the wind turbine. [35] 


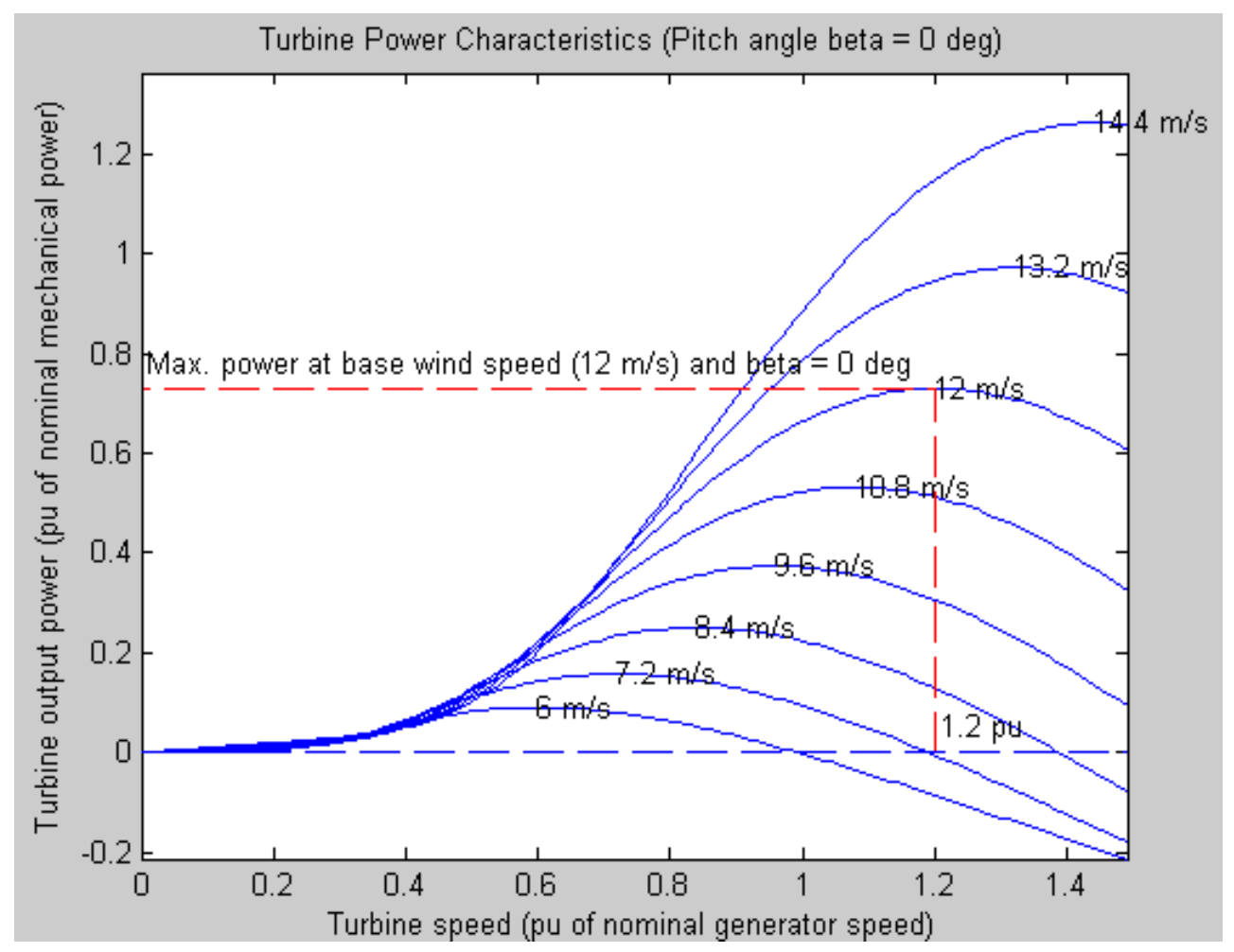

Figure 4.4 turbine output power as a function per unit turbine speed and wind speed when pitch angle is zero. [35]

\begin{tabular}{|l|l|}
\hline \multicolumn{2}{|l|}{ Wind turbine parameters } \\
\hline $\begin{array}{l}\text { Nominal mechanical } \\
\text { output power }(\mathrm{w})\end{array}$ & $1.6 \mathrm{MW}$ \\
\hline $\begin{array}{l}\text { Base power of electrical } \\
\text { generator }\end{array}$ & $(1.6 / 0.9) \mathrm{MW}$ \\
\hline Base wind speed (m/s) & $12 \mathrm{~m} / \mathrm{s}$ \\
\hline $\begin{array}{l}\text { Max pu power at base } \\
\text { wind speed }\end{array}$ & 0.73 \\
\hline Base rotational pu speed. & 1.2 \\
\hline Pitch angle & 0 \\
\hline
\end{tabular}

Table 4.1 wind turbine characteristics. 


\subsection{Generator modeling.}

Matlab Simulink synchronous generator is used in this system and it has the same electrical concept of a PMSG since the filed excitation is assumed to be constant. The generator is represented in rotationally rotor reference frame (dq frame) and all the electrical quantities are seen from the stator. The equivalent circuits of the generator in (dq frame) are show in figures (4.5) and (4.6).

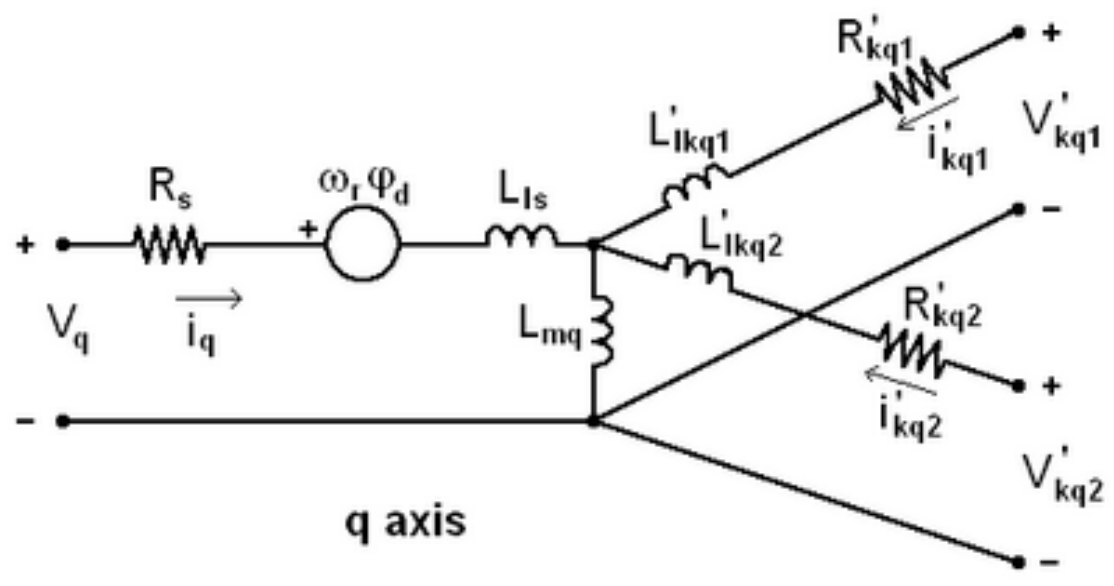

Figure 4.5 The electrical model of the generator related to q axis.

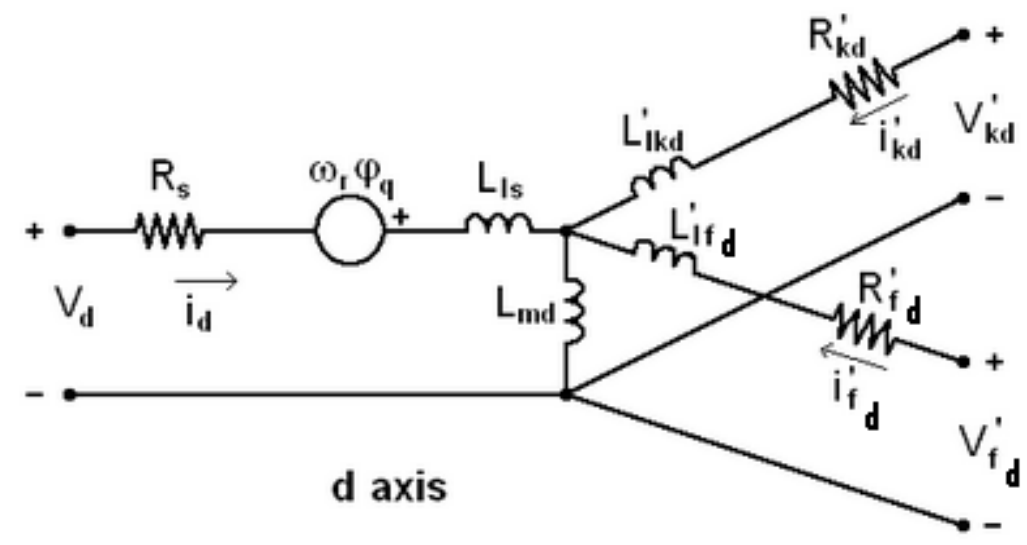

Figure 4.6 The electrical model of the generator related to $\mathrm{d}$ axis. 
Where:

$\mathrm{R}_{\mathrm{s}}=$ Stator resistance

$\mathrm{L}_{\mathrm{md}}=$ Direct-axis magnetizing inductance

$\mathrm{L}_{\mathrm{mq}}=$ Quadrature-axis magnetizing inductance

$\mathrm{L}_{\mathrm{ls}}=$ Armature leakage inductance

$\mathrm{R}_{\mathrm{fd}}=$ Field resistance

$\mathrm{L}_{\mathrm{fl}}=$ Field leakage inductance

$\mathrm{R}_{\mathrm{kd}}=$ Direct-axis damper resistanc

$\mathrm{L}_{\mathrm{kdl}}=$ Direct-axis damper leakage inductance

$\mathrm{R}_{\mathrm{kq}}=$ Quadrature-axis damper resistance

$\mathrm{L}_{\mathrm{kql}}=$ Quadrature-axis damper leakage inductance

$$
\begin{aligned}
& V_{d}=R_{s} i_{d}+\frac{d}{d t} \varphi_{d}-\omega_{r} \varphi_{q} \\
& V_{q}=R_{s} i_{q}+\frac{d}{d t} \varphi_{q}-\omega_{r} \varphi_{d} \\
& V_{f d}^{\prime}=R_{f d}^{\prime} i_{f d}^{\prime}+\frac{d}{d t} \varphi_{f d}^{\prime} \\
& V_{k d}^{\prime}=R_{k d}^{\prime} i_{k d}^{\prime}+\frac{d}{d t} \varphi_{k d}^{\prime} \\
& V_{k q 1}^{\prime}=R_{k q 1}^{\prime} i_{k q 1}^{\prime}+\frac{d}{d t} \varphi_{k q 1}^{\prime} \\
& V_{k q 2}^{\prime}=R_{k q 2}^{\prime} i_{k q 2}^{\prime}+\frac{d}{d t} \varphi_{k q 2}^{\prime}
\end{aligned}
$$




$$
\begin{aligned}
& \varphi_{d}=L_{d} i_{d}+L_{m d}\left(i_{f d}^{\prime}+i_{k d}^{\prime}\right) \\
& \varphi_{q}=L_{q} i_{q}+L_{m q} i_{k q}^{\prime} \\
& \varphi_{f d}^{\prime}=L_{f d}^{\prime} i_{f d}^{\prime}+L_{m d}\left(i_{d}+i_{k d}^{\prime}\right) \\
& \varphi_{k d}^{\prime}=L_{k d}^{\prime} i_{k d}^{\prime}+L_{m d}\left(i_{d}+i_{f d}^{\prime}\right) \\
& \varphi_{k q 1}=L_{k q 1}^{\prime} i_{k q 1}^{\prime}+L_{m q} i_{q}^{\prime} \\
& \varphi_{k q 2}=L_{k q 2}^{\prime} i_{k q 2}^{\prime}+L_{m q} i_{q}^{\prime}
\end{aligned}
$$

The synchronous generator has two inputs and two outputs as shown in figure (4.7). The inputs are the per unit mechanical power coming from the wind turbine and field voltage applied on the rotor for excitation. The outputs are three phase electrical output source and measurements to measure different electrical quantities like, voltage, current electromagnetic torque, speed and angle.

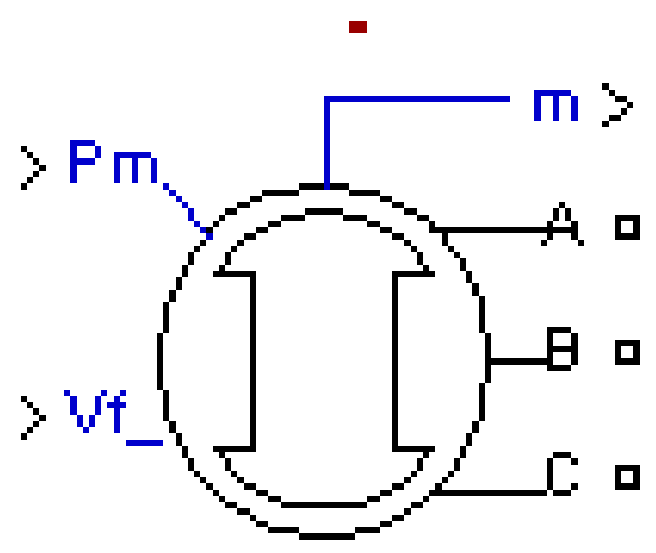

Figure 4.7 Synchronous generator used in Matlab Simulink. 
The synchronous generator parameters used in the simulation model are shown I table (4.2).

\begin{tabular}{|l|l|}
\hline \multicolumn{2}{|l|}{ Synchronous generator parameters } \\
\hline Nominal power & $(1.6 / 0.9) \mathrm{MW}$ \\
\hline Nominal Vl-1 & $480 \mathrm{v}$ \\
\hline frequency & $60 \mathrm{~Hz}$ \\
\hline Inertia constant & 3.7 \\
\hline Friction factor & 0.01 \\
\hline Poles pair & 1 \\
\hline $\begin{array}{l}\text { synchronous reactance Xd } \\
\text { transient reactance Xd' } \\
\text { subtransient reactance Xd" } \\
\text { leakage reactance Xl } \\
\text { synchronous reactance Xq } \\
\text { subtransient reactance Xq" }\end{array}$ & $0.305 \mathrm{pu}$ \\
& $0.252 \mathrm{pu}$ \\
\hline $\begin{array}{l}\text { transient open-circuit(Tdo') } \\
\text { subtransient open-circuit (Tdo") } \\
\text { subtransient open-circuit (Tqo") }\end{array}$ & $0.18 \mathrm{pu}$ \\
\hline Stator resistance Rs & $0.064 \mathrm{pu}$ \\
& 0.0513 \\
\hline
\end{tabular}

Table 4.2 synchronous generator parameters.

\subsection{Back to back converter (AC/DC/AC) modeling and control.}

Back to back converter is consisting of a rectifier (AC/DC) which is on the wind turbine generator side, DC energy storage and inverter (DC/AC) which is on the grid side. The rectifier rectifies the AC power source coming from the wind turbine generator to a DC power that is stored in the DC bus energy storage. Inverter converts the DC power coming from the $\mathrm{DC}$ bus to $\mathrm{AC}$ with specific voltage and frequency to meet the grid requirements. The rectifier and the inverter are mad up of three arm bridges with an $\mathrm{RC}$ snubber circuit connect in parallel with each switch which are an IGBT diodes. 


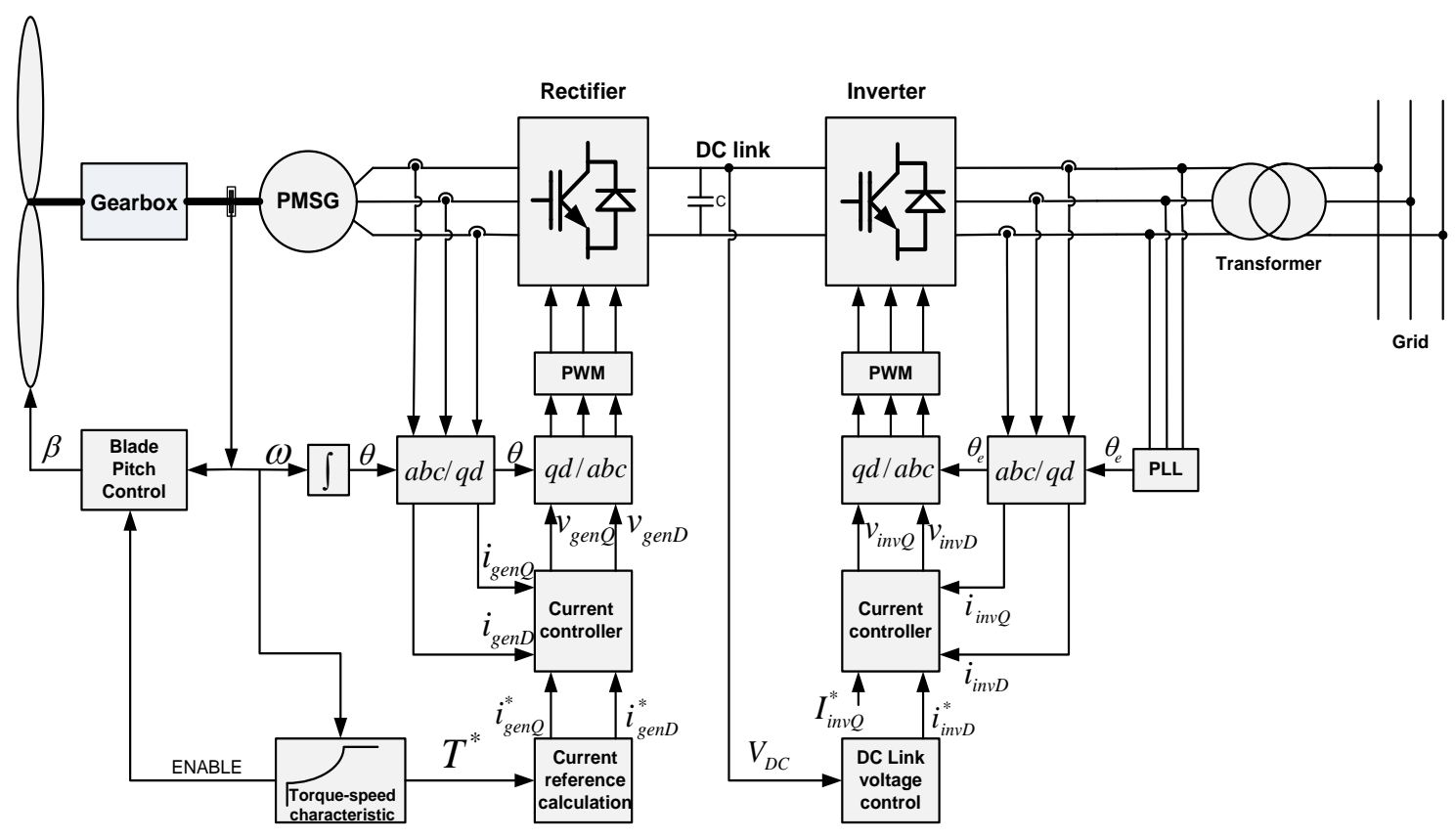

Figure 4.8 Back to back converter complete control.

\subsubsection{Generator side converter (AC/DC) and MPPT control.}

Generator side converter is done to satisfy a maximum wind power point tracking (MPPT). Maximum power point tracking allow the wind turbine to extract the maximum power from the wind.

According to the wind turbine power characteristics that shown in figure (4.4) a lookup table is constructed with wind speed as an input and the output is the generator reference speed that will meet the maximum power point from the wind. Controlling the generator speed to be equal the reference speed is done by close the loop control, taking the generator speed as a feedback signal and subtracting it form the reference speed will result in an error that will be compensated using a PI compensator that will give us $\mathrm{d}$ axis reference current. Using the actual d axis current as a feedback signal and subtracting it from the $\mathrm{d}$ axis reference current will result in an error that will be also compensated using a PI compensator to create the $\mathrm{d}$ axis reference voltage. 
Q axis voltage can be found using a close loop control, which uses the $\mathrm{q}$ axis actual signal and subtracting it form reference and compensating that error using a PI compensator. Subtracting the actual id from the id reference and compensating for the error using a PI compensator will result in vq component.

Converting vd and vq from the rotor two axis reference frame to stator reference frame using a reverse park transformation will result in three phase control voltage signal that will be fed to a pulse width modulator (PWM) to create pulses to control the converter.

Phase locked loop (PLL) block in Matlab is used to measure frequency and phase angle for a three phase signal source. Phase angle is used in abc-dq transformation box that uses park transform to transform the signal from three phase signal to 2 phase rotating signal.

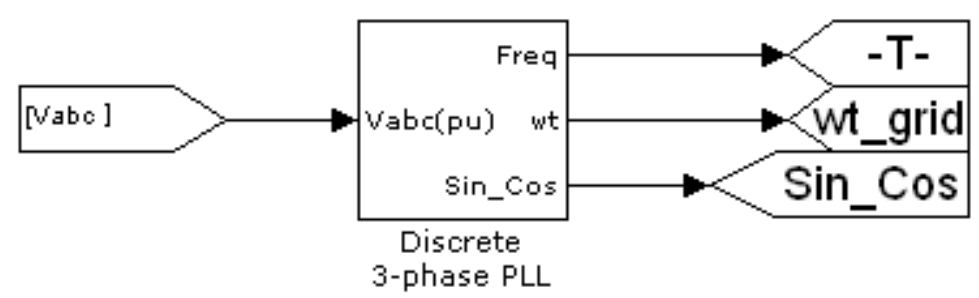

Figure 4.9 PLL for frequency and phase angle measurements.

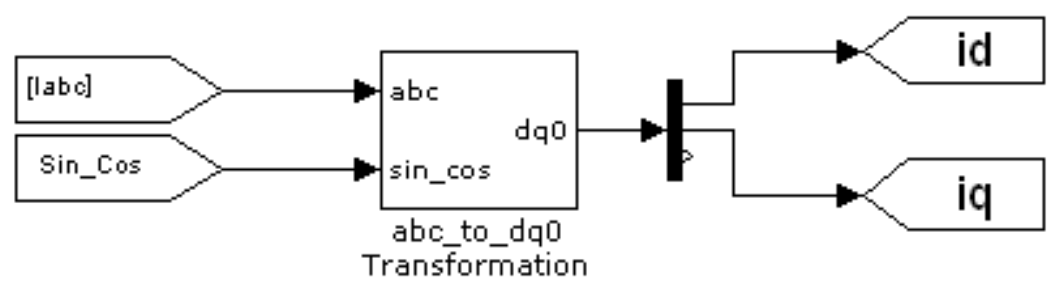

Figure 4.10 abc-dq park transformations. 

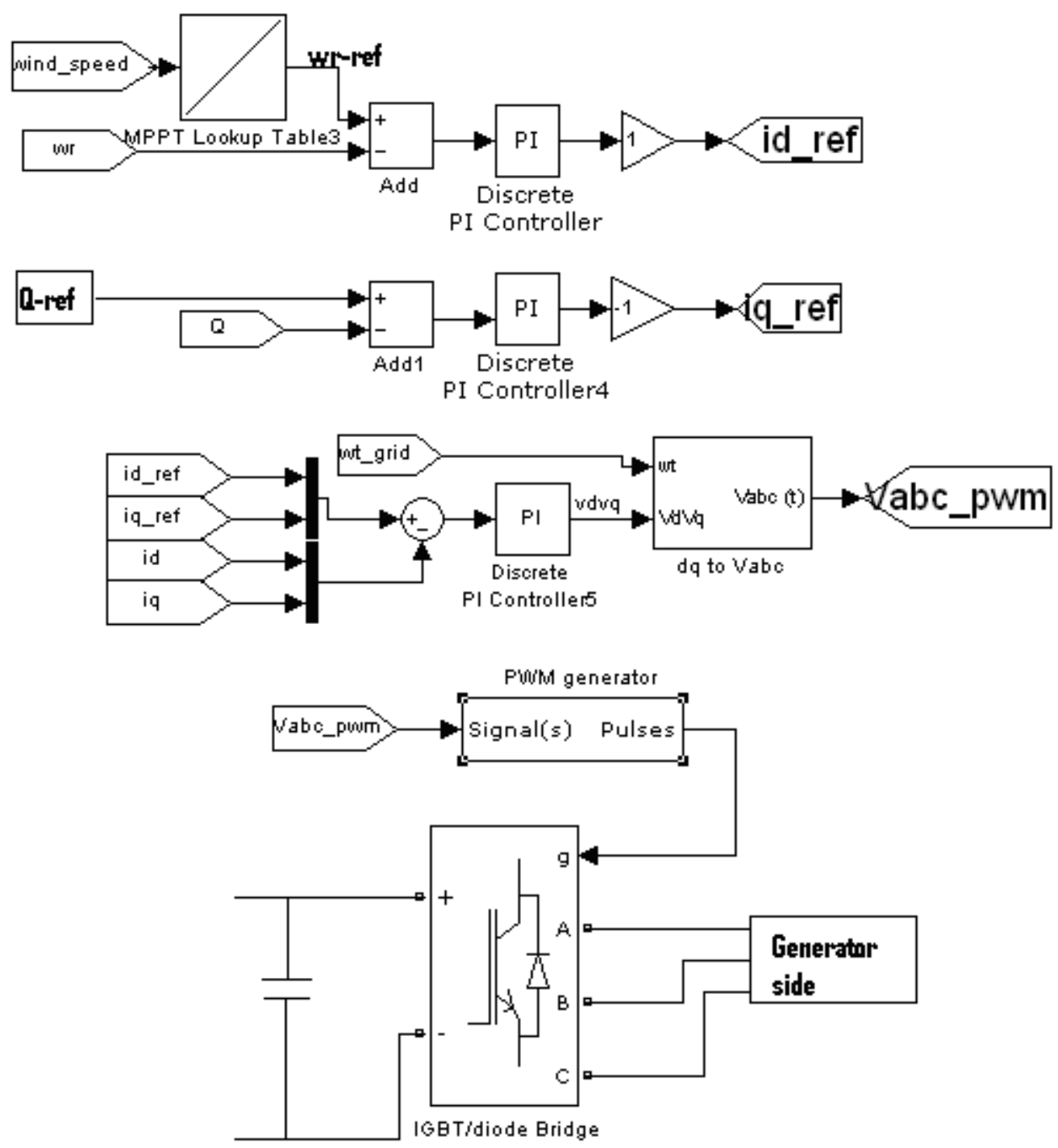

Figure 4.11 Generator side converter simulations for MPPT control.

\subsubsection{Grid side converter (DC/AC) control.}

Gird side converter is an DC/AC converter. The control is done in three different ways, the first is for normal operation without power smoothing, so that whatever power coming from the wind will be delivered to the grid. The second one is normal operation with power smoothing so you deliver a higher quality smoothed power to the grid. The third way is control for low voltage ride through (LVRT) support. 


\subsubsection{Normal operation in DC bus voltage control.}

In normal operation as shown in figure (4.12), The DC bus voltage are required to constant so that all the power coming from the wind can be delivered to the grid. A closed loop control for the DC bus is done bye taking the required DC bus voltage as a reference voltage value and the actual DC bus value as a feedback. The error resulting form subtracting the two voltages will be compensated using a PI compensator to produce the $\mathrm{d}$ axis reference current.

The $\mathrm{q}$ axis reference current can be found be a closed loop control for the reactive power that must be delivered to the grid. Taking zero reactive power as a reference value so we can deliver maximum active power and taking the actual reactive power as a feed back signal. The error resulting from subtracting both signals will be compensated using a PI compensator to produce the $\mathrm{q}$ axis reference current.

Measuring the actual $\mathrm{d}$ axis and $\mathrm{q}$ axis currents and using the $\mathrm{d}$ axis and $\mathrm{q}$ axis reference currents as a feedback signal that will be compensated by PI compensator that creats $\mathrm{v} d$ and $\mathrm{q}$ axis that are converted to abc stator axis using reverse park transformation as an input for a PWM generator to generate the pulses as shown in figure (4.12).

Phase locked loop (PLL) is used from for grid synchronization since it measure the frequency and the phase angle of the three phase signal of the grid. The phase angle is used in abc - dq park transformation as in figure (4.10) to find the actual d and q axis components. 

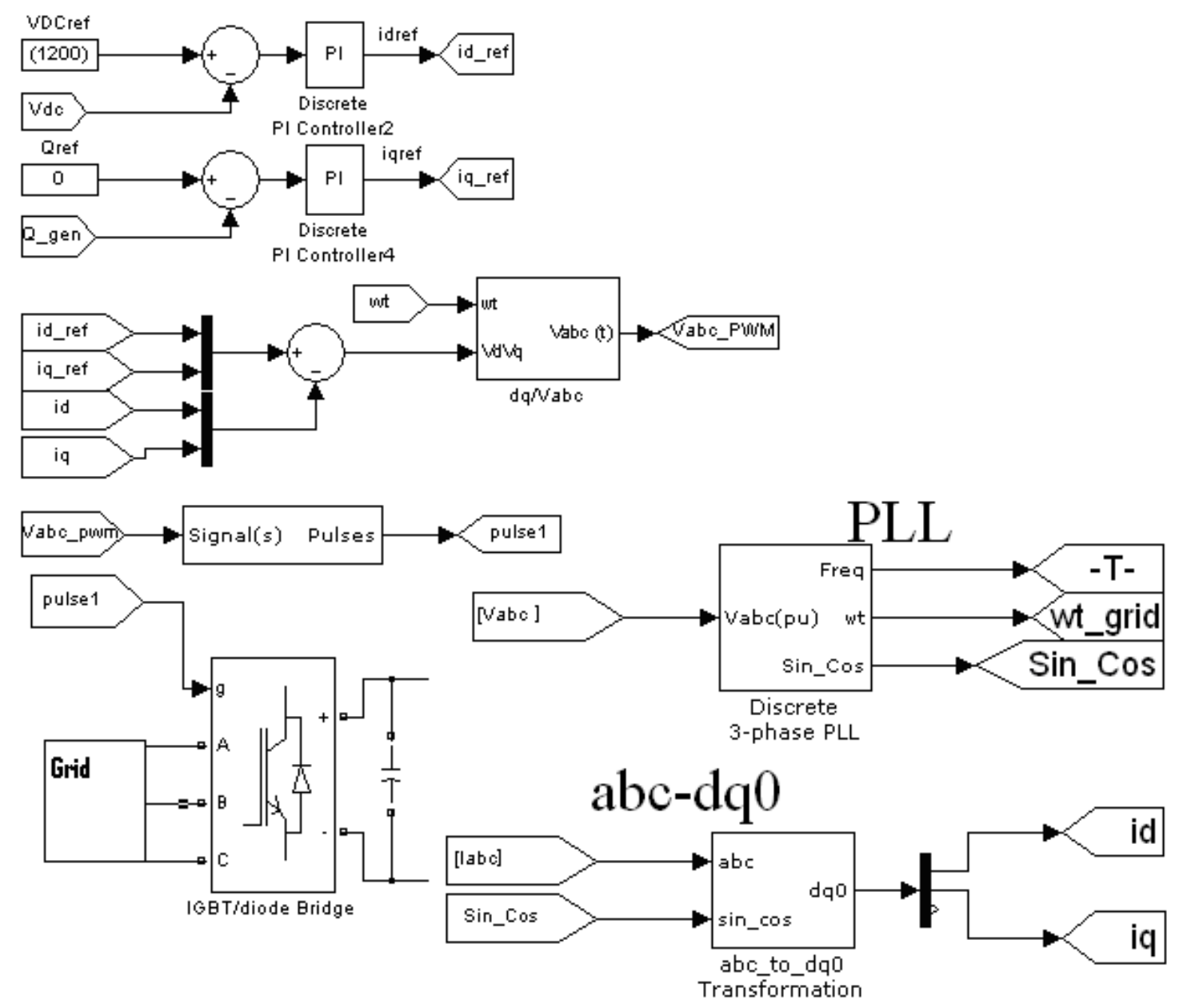

Figure 4.12 Grid side converter control under normal operation.

\subsubsection{Normal operation adaptive filter control for power smoothing.}

Adaptive filter control strategy as shown in figure (4.11) is used for power quality purposes so a smoothed power can be delivered to the grid. Closed loop control for the DC bus voltage will result in an error that will be multiplied by a small factor to reduce the DC bus voltage variation effect on the control. DC bus variation in voltage multiplied by a small factor will be added to the maximum power that will be delivered to the grid. The summation signal will be an input to the adaptive filter and the output will be the $d$ axis current reference. 
The adaptive filter is low pass filter with variable frequency depends on the voltage that is implemented by a lookup table. This variable frequency filter will smooth the power in different rates in order to keep the voltage varied with the desired limit which is (10001400).

When the DC bus voltage increases or decreases to reach the limits, the frequency will increase allowing more power fluctuation and less power smoothing so all the power coming from the wind will be delivered to the grid and this by it self will keep the DC voltage constant or variable with a small change depend on the frequency related to voltage limits.

When the DC bus is around $1200 \mathrm{~V}$ which is the mid value of the DC voltage variation band. The frequency will be small allowing a less power fluctuation that lead to a smoothed power.

The small error coming form the DC bus closed loop control makes the DC bus voltage variation with a small band around $1200 \mathrm{v}$ by acting like a compensator for the deviation in the generated power coming from the wind and the smoothed power delivered to the grid. If the power coming from the turbine increases in a relatively high step the power delivered to the grid will be less do to the low pass filter, thus there is an amount of energy that will be stored in the DC bus so that the DC bus voltage will increase and this increase in voltage will be taken care of by the DC bus closed loop to keep it around $1200 \mathrm{v}$. 


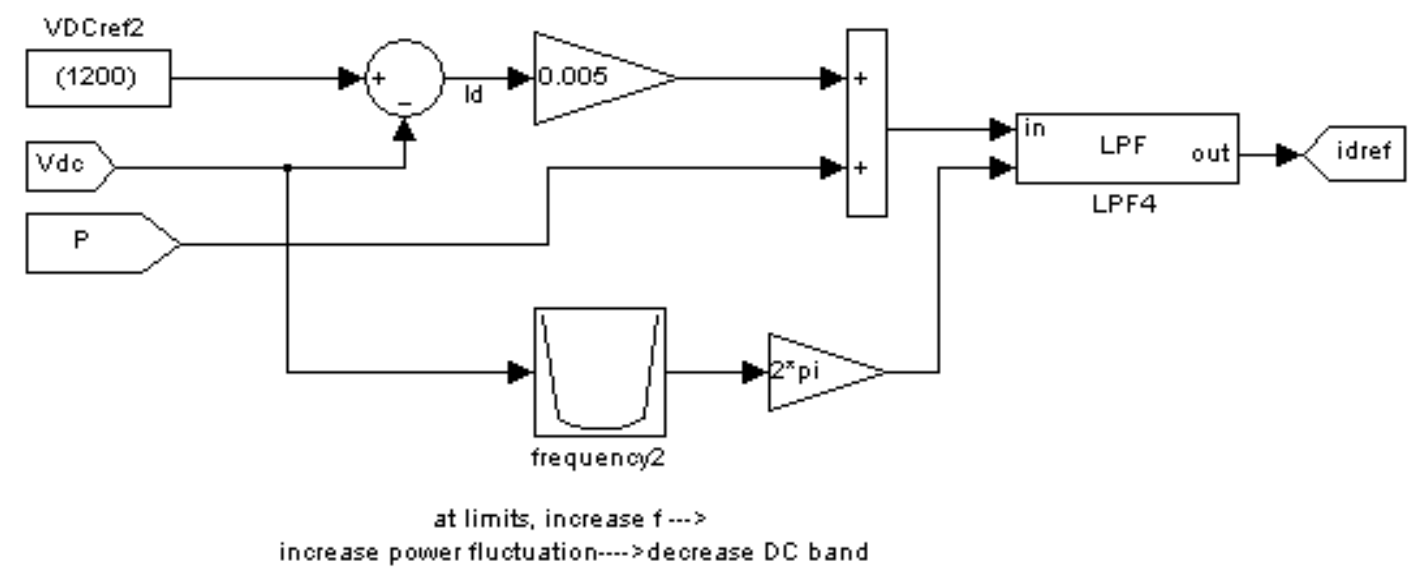

Figure 4.13 Adaptive filter and control for power smoothing.

\subsubsection{Grid side control for low voltage ride through.}

The proposed control is according to E.ON voltage code of Germany. When the voltage drops due to short circuit or any other issues in the power system, the active power delivered to the grid will be controlled to almost zero until the grid voltage recovers to $0.9 \mathrm{pu}$ and then the power will ramp up to $90 \%$ of the available generated power in 1 second. The reactive current injection to the grid is $1 \mathrm{pu}$ of the system capacity to support recovering the voltage until the grid voltage recovers to $0.9 \mathrm{pu}$ and it might reach up to 2 pu for a short period of time like less than 2 seconds.

According to the equation below (4.15), for 1 pu reactive power injection, the current injected will stay one $1 \mathrm{pu}$ until the grid voltage more than 0.9 according to the LVRT code. For 2 pu reactive current injection the reactive current will stay 2 pu until the grid voltage reaches $0.5 \mathrm{pu}$ and will start decreasing according to the voltage value.

$$
S=V I
$$

Where $\mathrm{S}$ is apparent power, $\mathrm{v}$ is voltage and I is the current.

For I pu reactive current injection: 
$V=\frac{S}{I}=\frac{1 p u}{1 p u}=1 p u$

The above result tells that the reactive current can be 1 per unit until the grid recovers.

For 2 pu reactive current injection:

$V=\frac{S}{I}=\frac{1 p u}{2 p u}=0.5 p u$

The above result tells that the reactive current is 2 until the grid voltage reaches $0.5 \mathrm{pu}$.
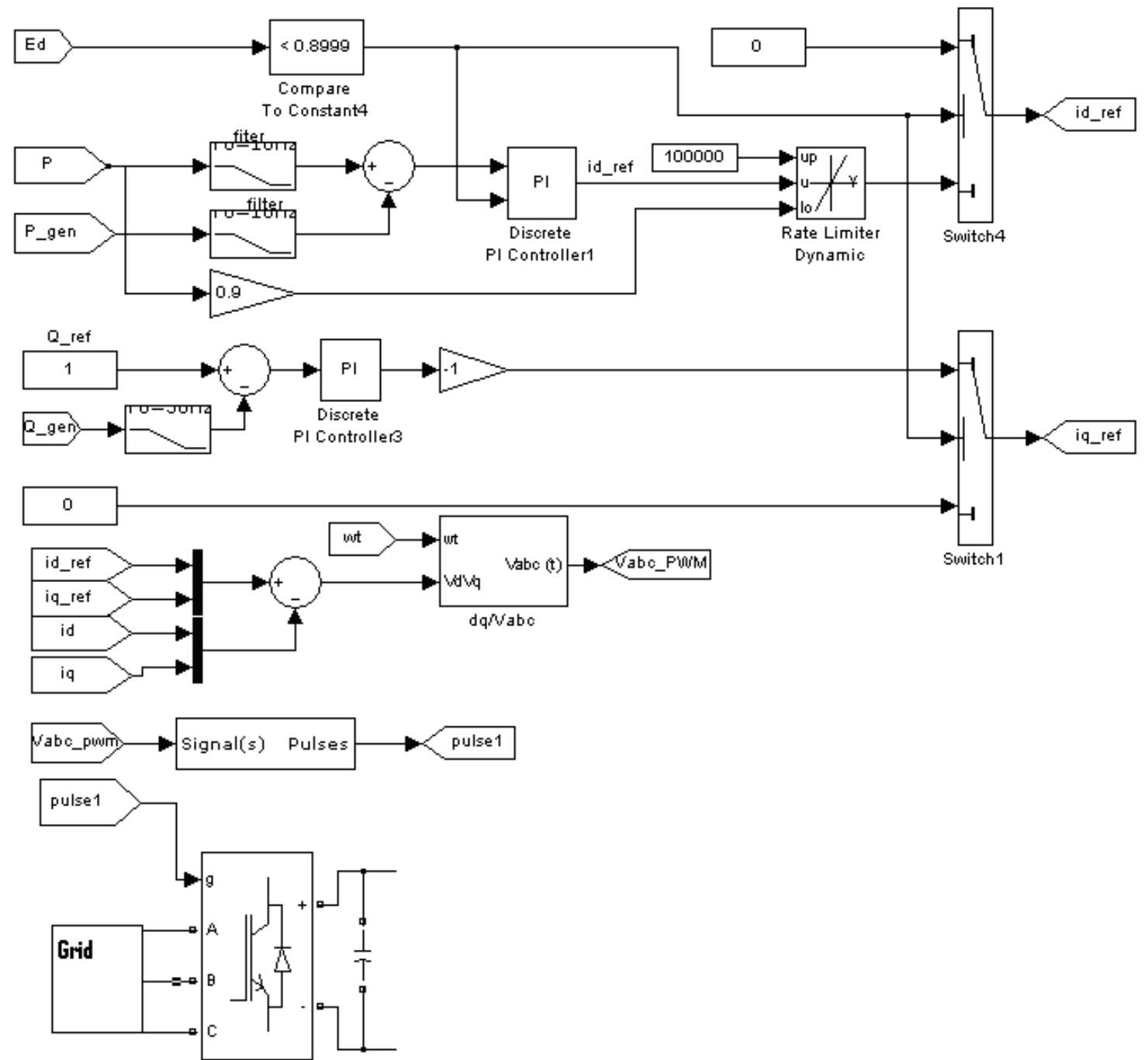

Figure 4.14 Grid side converter control for LVRT. 


\subsection{Ultracapacitor Energy storage level for LVRT.}

The proposed control is an ultracapacitor energy storage in the DC bus of the Back to back converter and it is used either to store or support energy. It is used to store the energy coming from the wind during the LVRT period since the active power deliver to the grid during LVRT is zero. The incoming power is equal to the wind turbine generated power and the delivered is almost zero so that the power will be stored in the ultracapacitors and lead to increases the voltage.

According to equation (2-1) in chapter 2, the energy that can be stored in the ultracapacitor is a functinon of the capacity of the capacitor and the square of the capacitor voltage.

$E=\frac{1}{2} C V^{2}$

Since the voltage of the capacitor is controlled to be around 1200 volt in normal operation, the voltage band of the capacitor becomes from (1200-1400) $\mathrm{v}$ and the capacitor value used is 5.86 farad. According to this voltage lower and upper band, the energy storage level will be as calculated below.

$E=\frac{1}{2} * 5.86 *\left(1400^{2}-1200^{2}\right)=1.52 M J$

According to the wind turbine power characteristics that shown in figure (4.4), the maximum power at the base wind speed which is $12 \mathrm{~m} / \mathrm{s}$ is $0.73 \mathrm{pu}$ of the electrical generator power and according to the E.ON voltage code, the maximum time the required the grid to recover after low voltage is $1500 \mathrm{~ms}$.

If we assume that the wind turbine is running at bass wind speed the energy produced within LVRT according to the equation below will be: 


$$
E=\int_{0}^{t} P d t=\int_{0}^{t} V * i * d t=P * \Delta t
$$

$$
E=P^{*} \Delta t=0.73 *(1.5 / 0.9) M W * 1.5 s=1.825 M J
$$

After the voltage recovers to $90 \%$, the active power will ramp up to $90 \%$ of the generated wind turbine within 1 second. So if we also assume the wind turbine is running at bass wind speed, the generated power will be $0.73 \mathrm{pu}$ of the electrical generator power. And the energy storage level during that period will be according to the following equations.

$$
\begin{aligned}
& E=0.9 * P_{\text {base }} * t=0.9 * 0.73 *(1.5 / 0.9) * t=1.1 t \mathrm{Mj}, \quad \mathrm{t} \text { is from } 0 \text { to } 1 . \\
& E=0.9 * P_{\text {base }} * t=0.9 * 0.73 *(1.5 / 0.9) * 1=1.1 \mathrm{Mj}
\end{aligned}
$$

Maximum total energy $=1.1 \mathrm{Mj}+1.825 \mathrm{Mj}=2.925 \mathrm{Mj}$ which is more than the total power capabilities of the ultracapacitor within the voltage band of (1200-1400)v but it is almost the (1000-1400) v storage capability which is $2.812 \mathrm{Mj}$. These calculation shows that the DC bus voltage will go above the $1400 \mathrm{v}$. 


\section{Chapter 5: Simulation results for LVRT support.}

This chapter shows different signals for the system under different operating conditions. Different operation topologies are normal operation with DC voltage control, normal operation with adaptive filter for power smoothing and low voltage ride through operation. All the operation techniques will be done on various wind speed profile.

\subsection{Normal operation with DC bus voltage control.}

This section control is done as described in chapter 4 section 3.2.1. The DC bus voltage is controlled to equal a reference DC bus voltage. This control is done for fixed wind speed and for variable wind speed profiles.

\subsubsection{Fixed wind speed profile.}

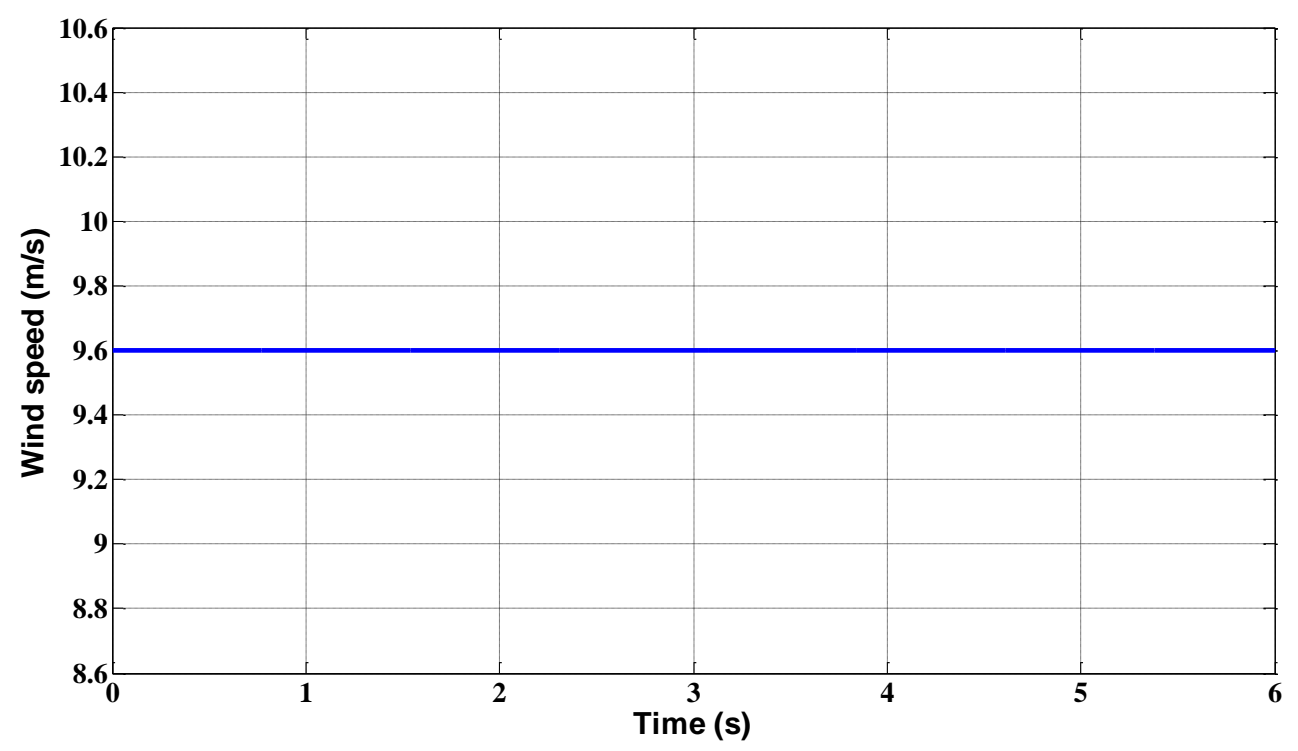

Figure 5.1 Fixed wind speed. 


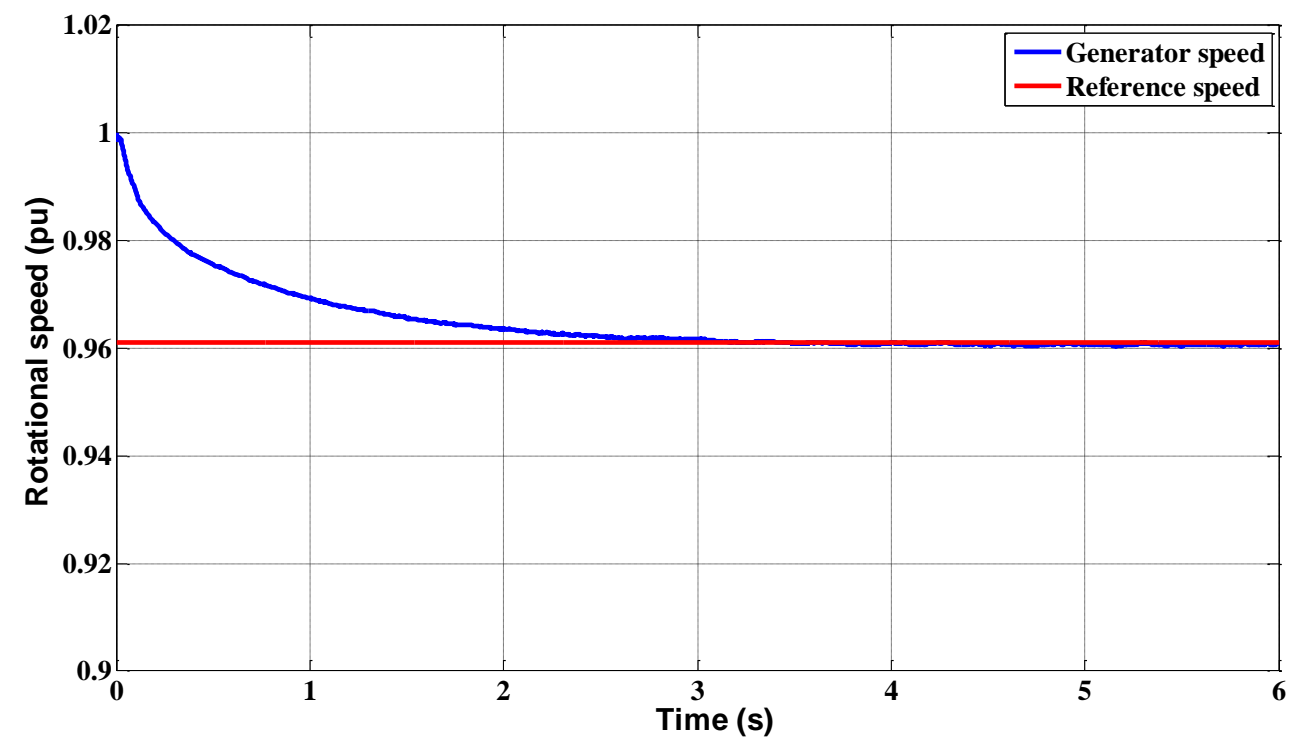

Figure 5.2 Generator speed and generator reference speed for fixed wind speed.

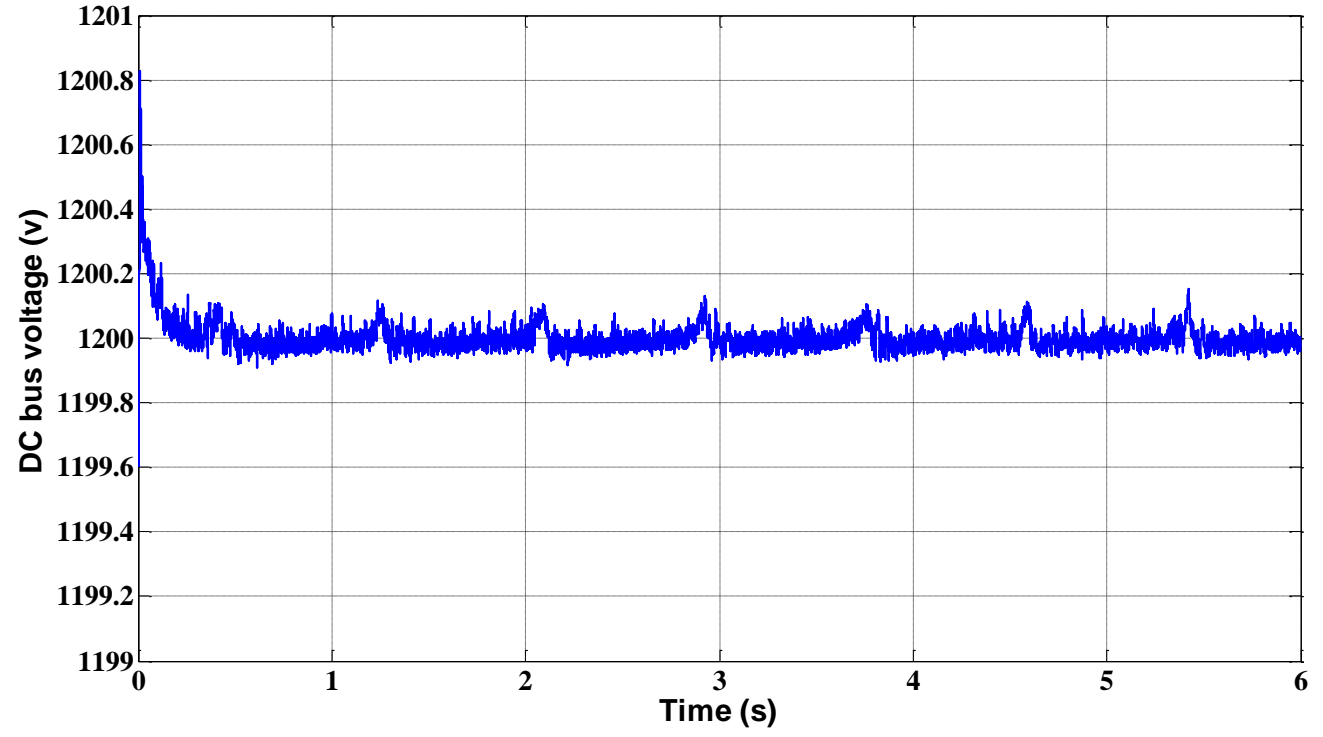

Figure 5.3 DC bus voltage for fixed wind speed. 


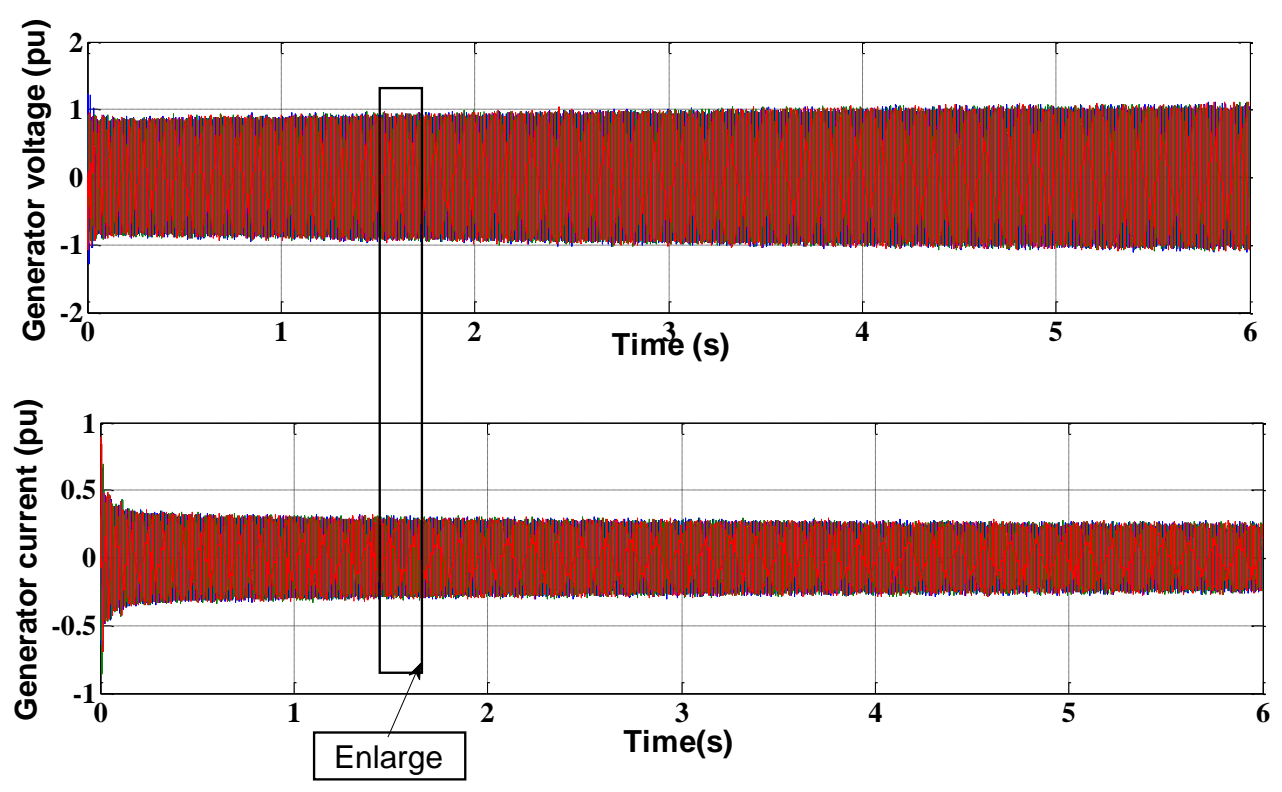

Figure 5.4 Generator voltage and current for fixed wind speed .
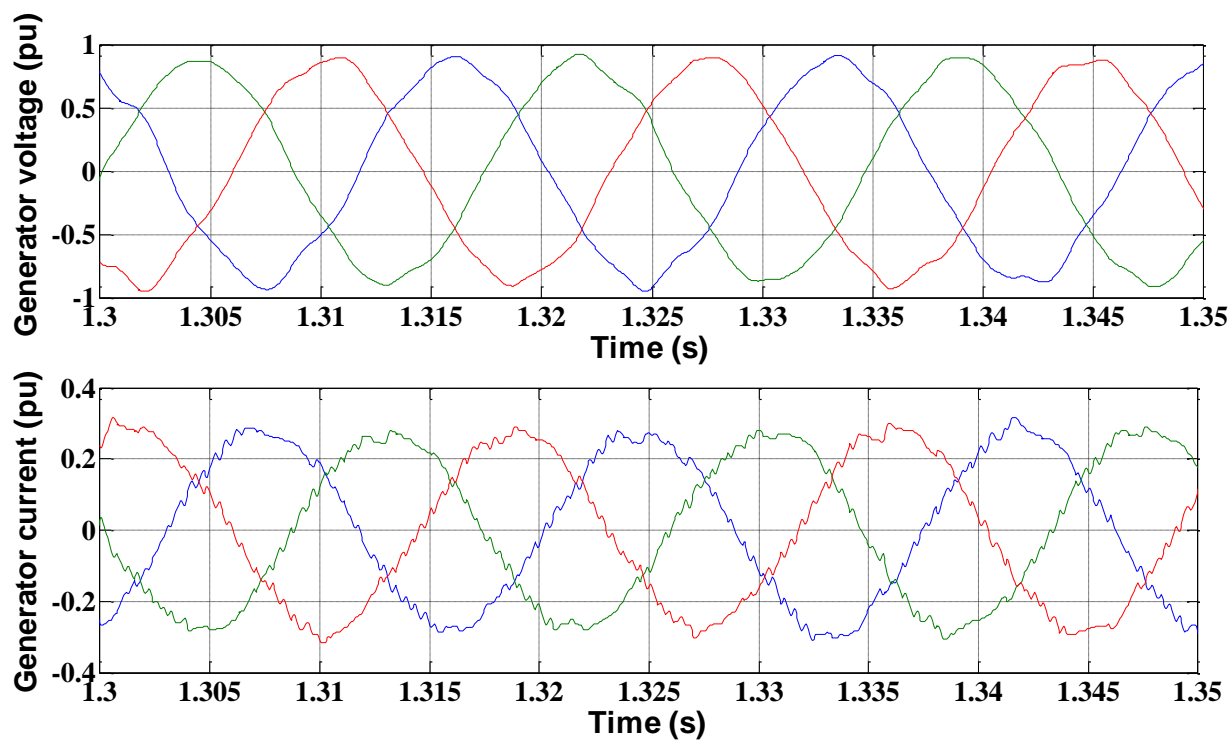

Figure 5.5 Generator voltage and current over a small enlarged period with fixed wind speed . 


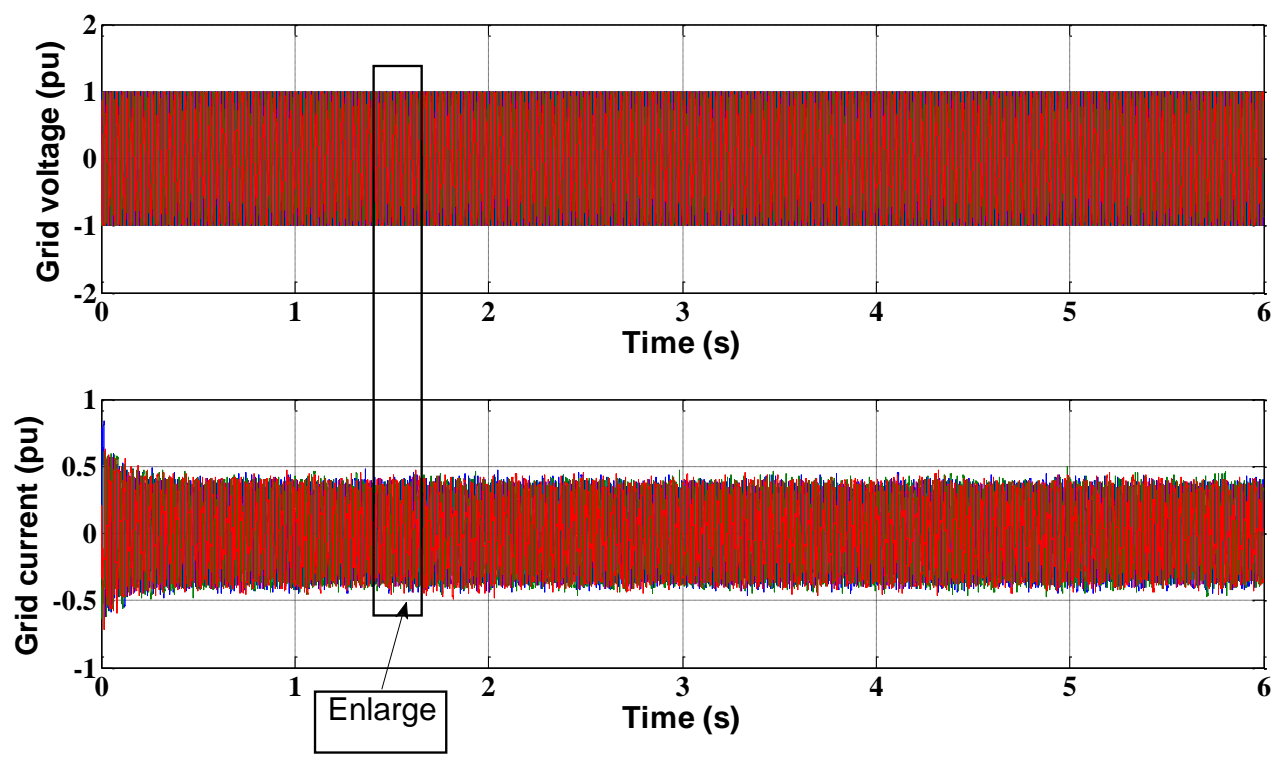

Figure 5.6 Grid voltage and current for fixed wind speed.
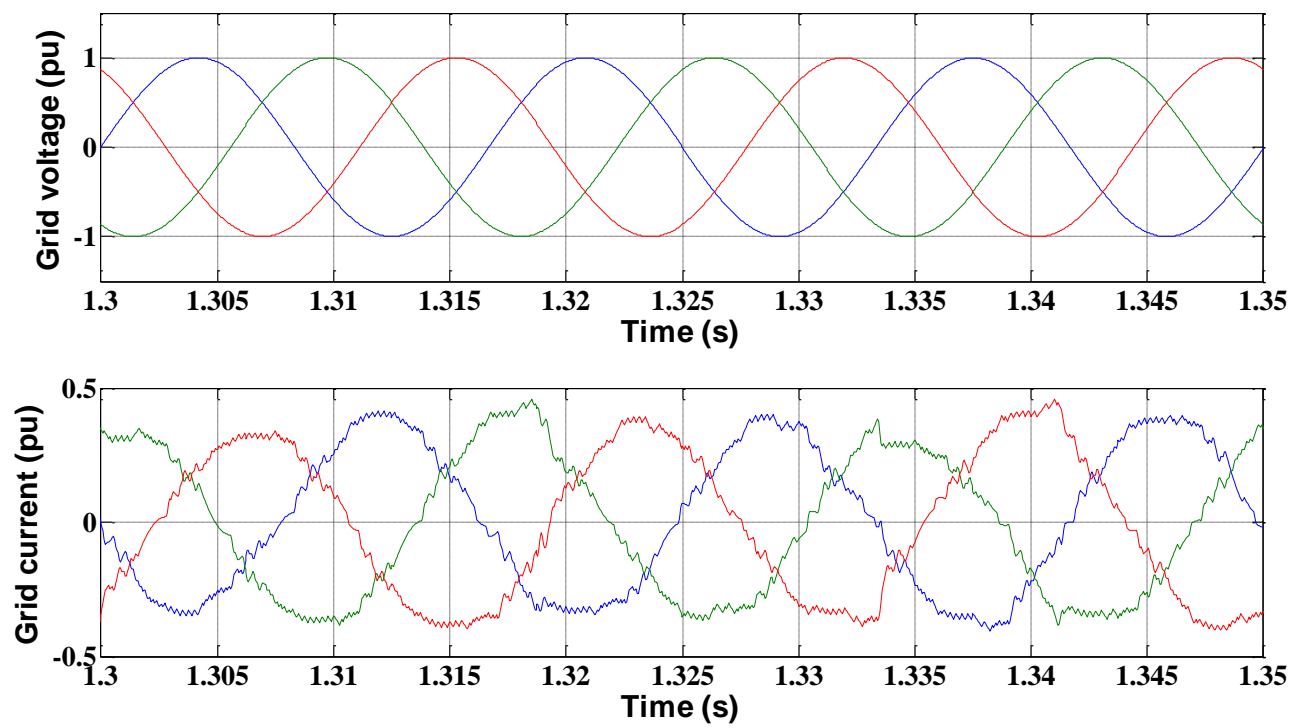

Figure 5.7 Grid voltage and current over a small enlarged period for fixed wind speed. 


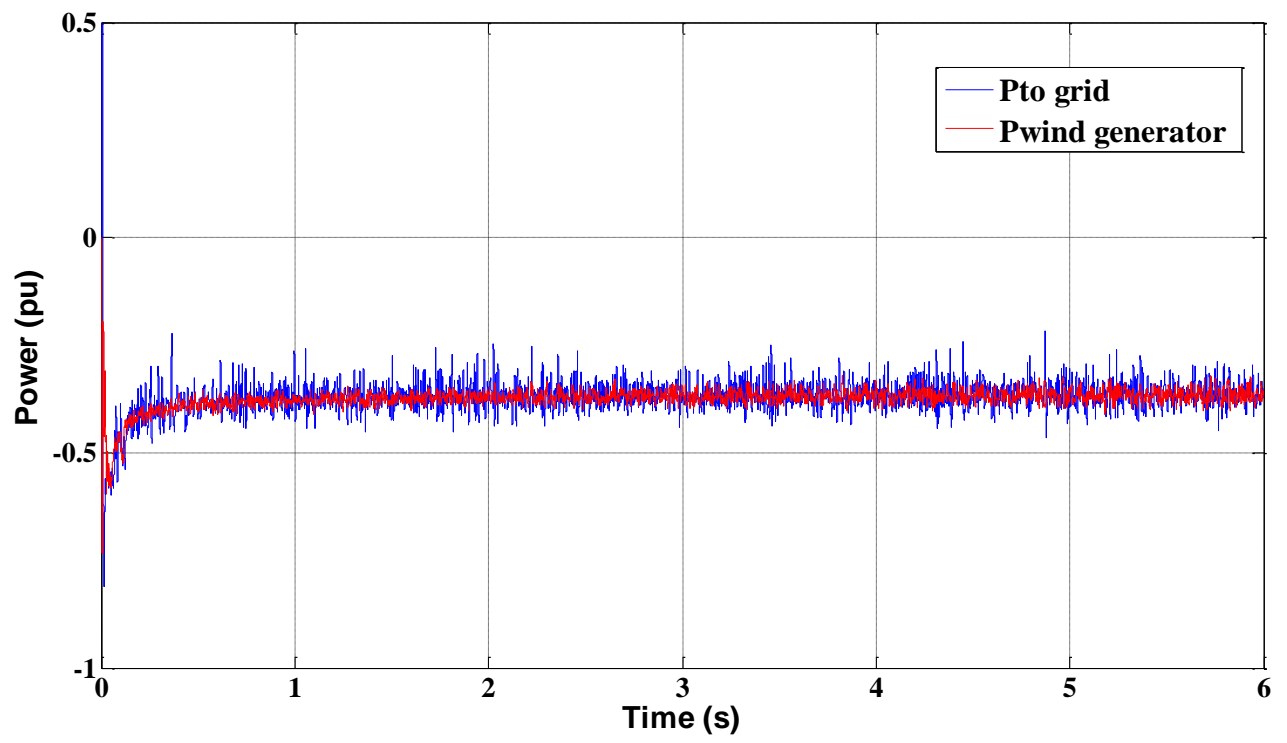

Figure 5.8 Active power delivered to the Grid and wind generator active power for fixed wind speed.

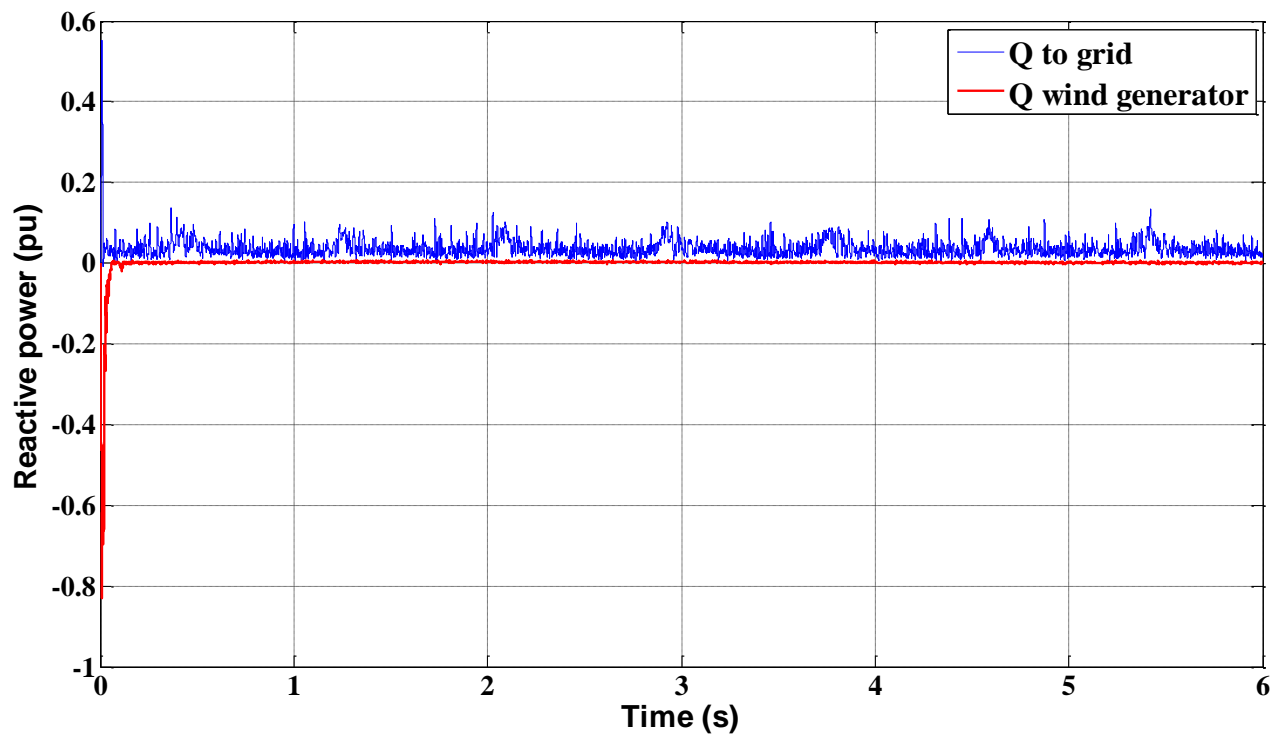

Figure 5.9 Reactive power delivered to grid and wind generator reactive power for fixed wind speed. 


\subsubsection{Variable wind speed profile.}

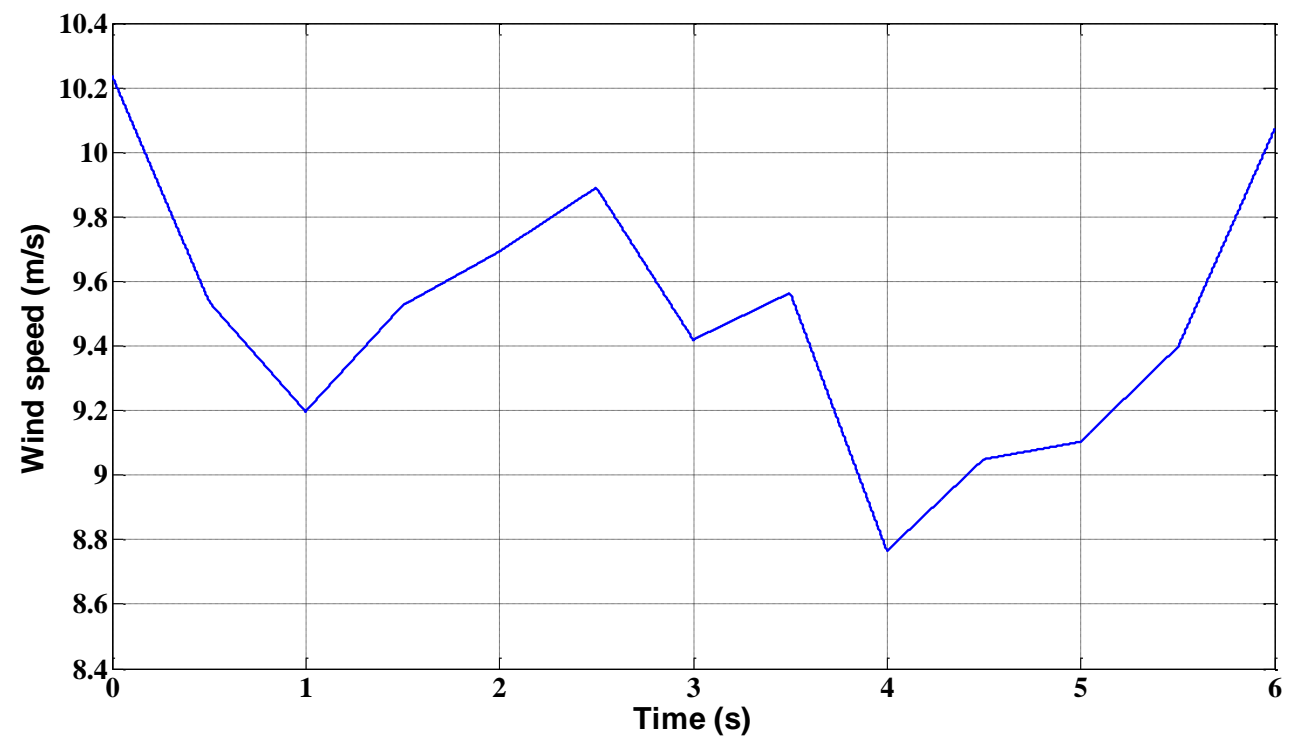

Figure 5.10 Variable wind speed profile.

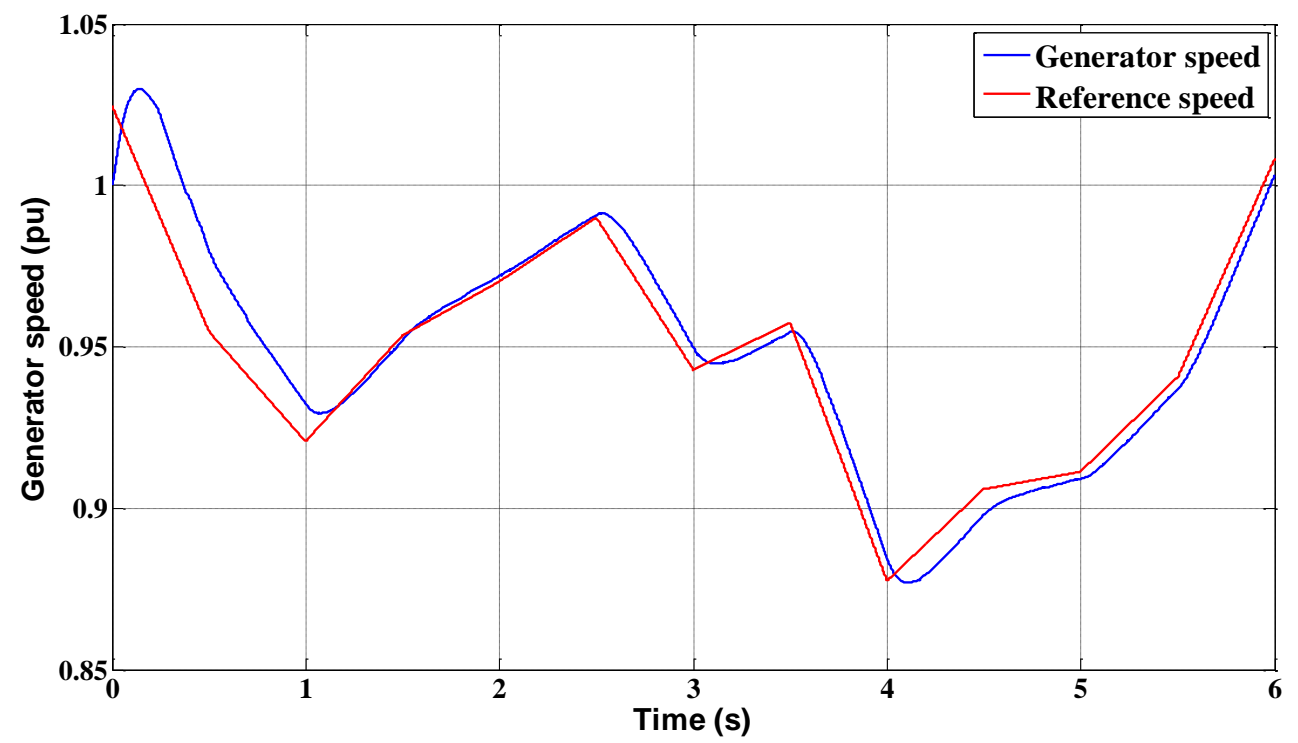

Figure 5.11 Generator speed and generator reference speed for variable wind speed. 


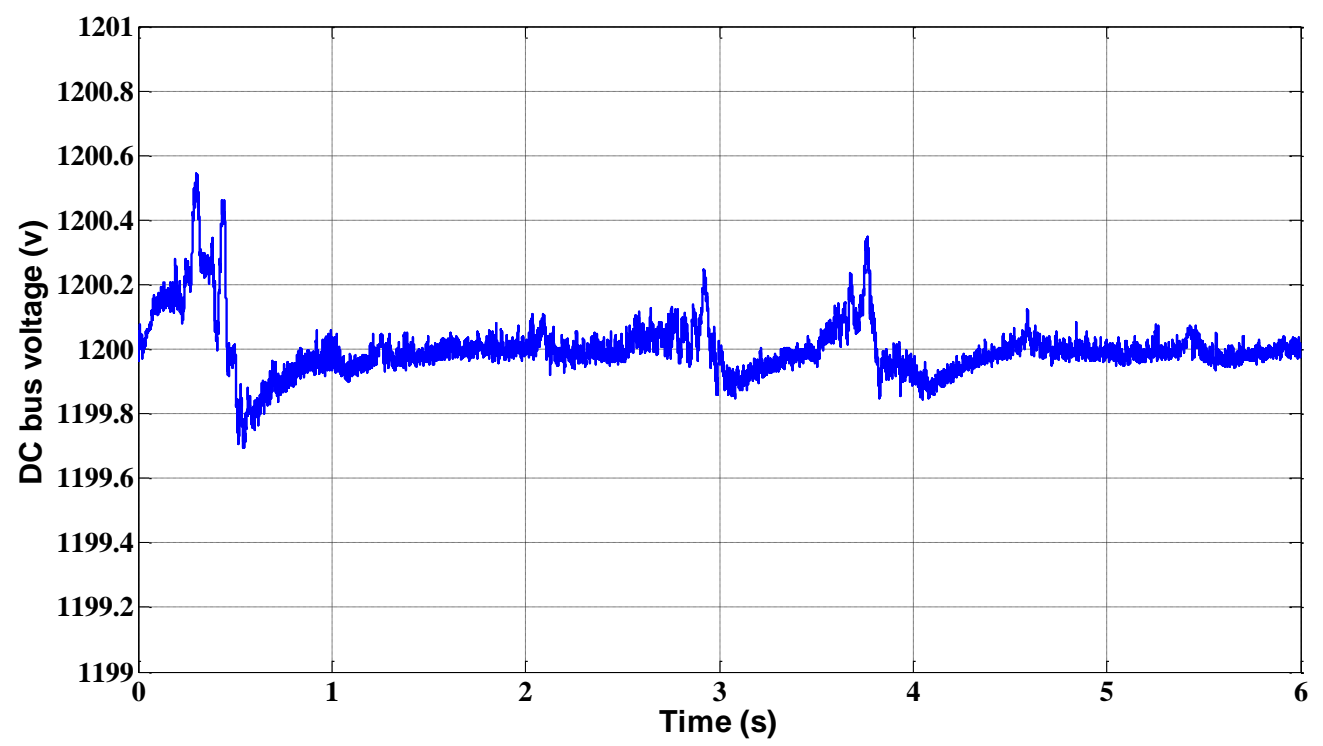

Figure 5.12 DC bus voltage for variable wind speed.

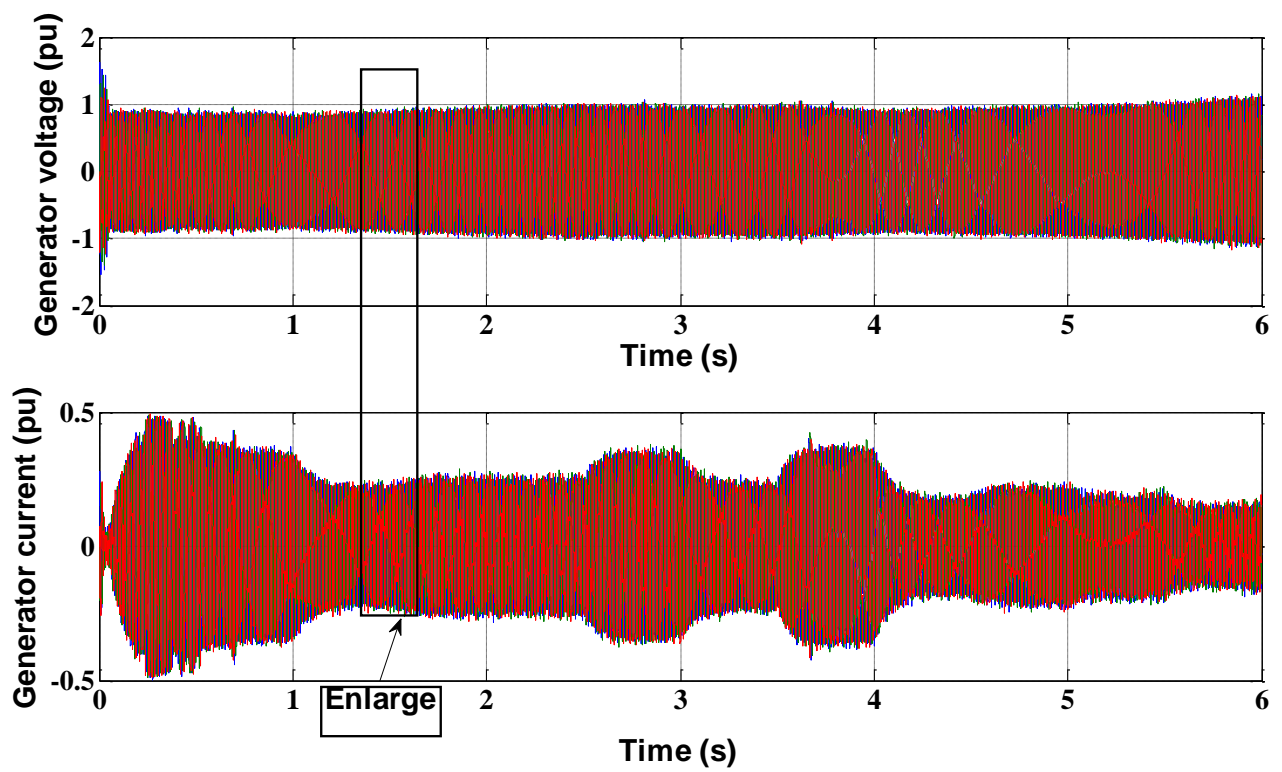

Figure 5.13 Generator voltage and current for variable wind speed. 

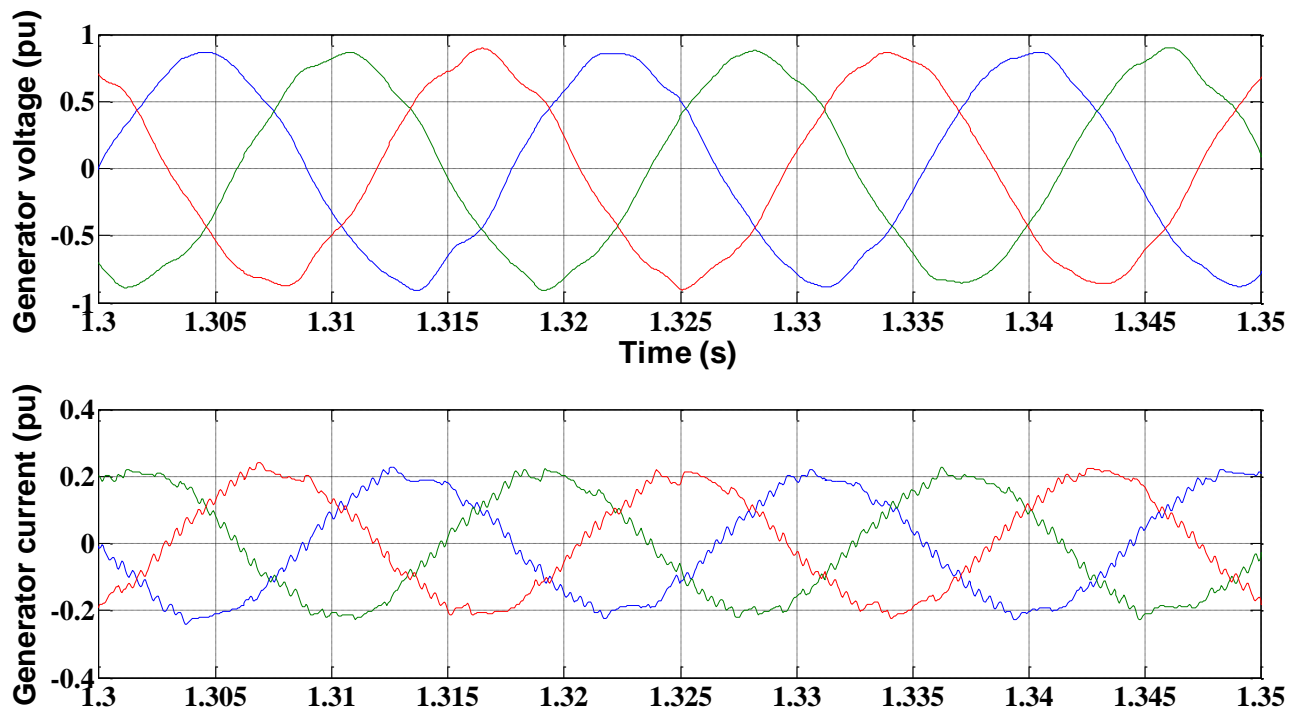

Figure 5.14 Generator voltage and current over a small enlarged period of time for variable wind speed.

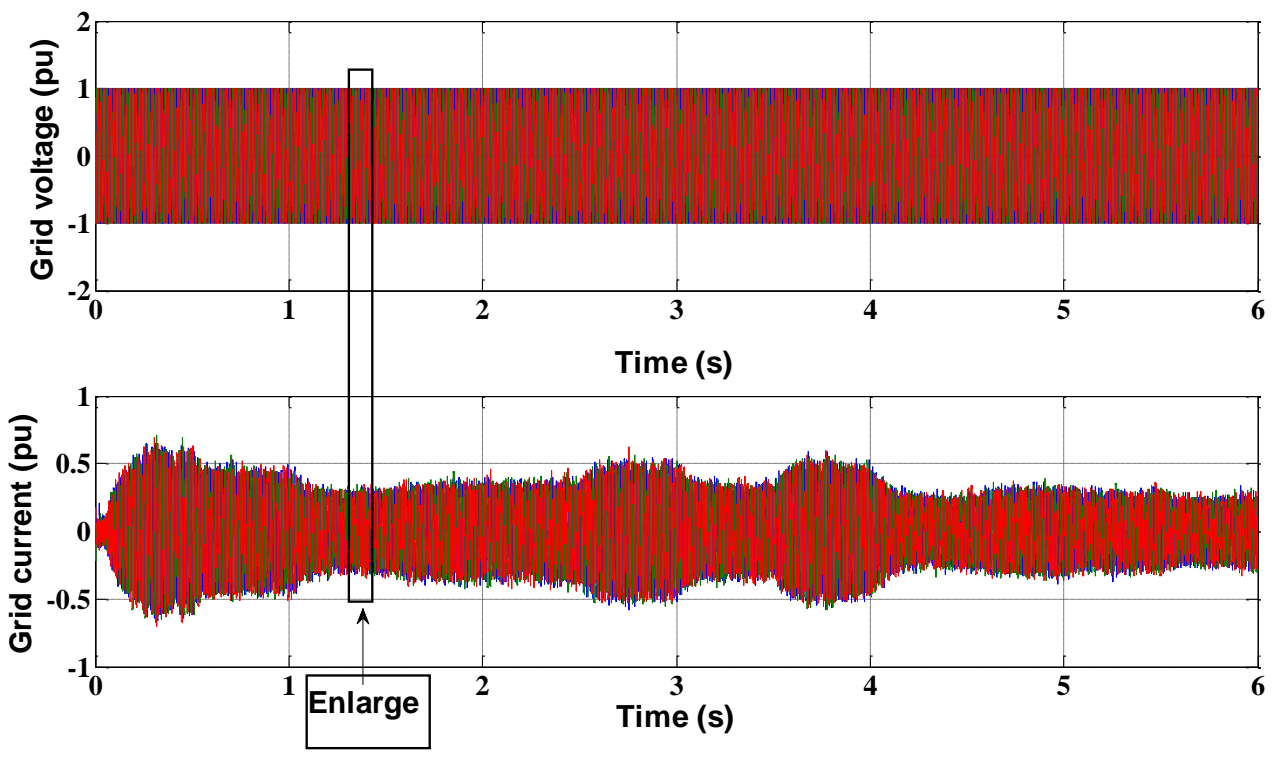

Figure 5.15 Grid voltage and current for variable wind speed. 

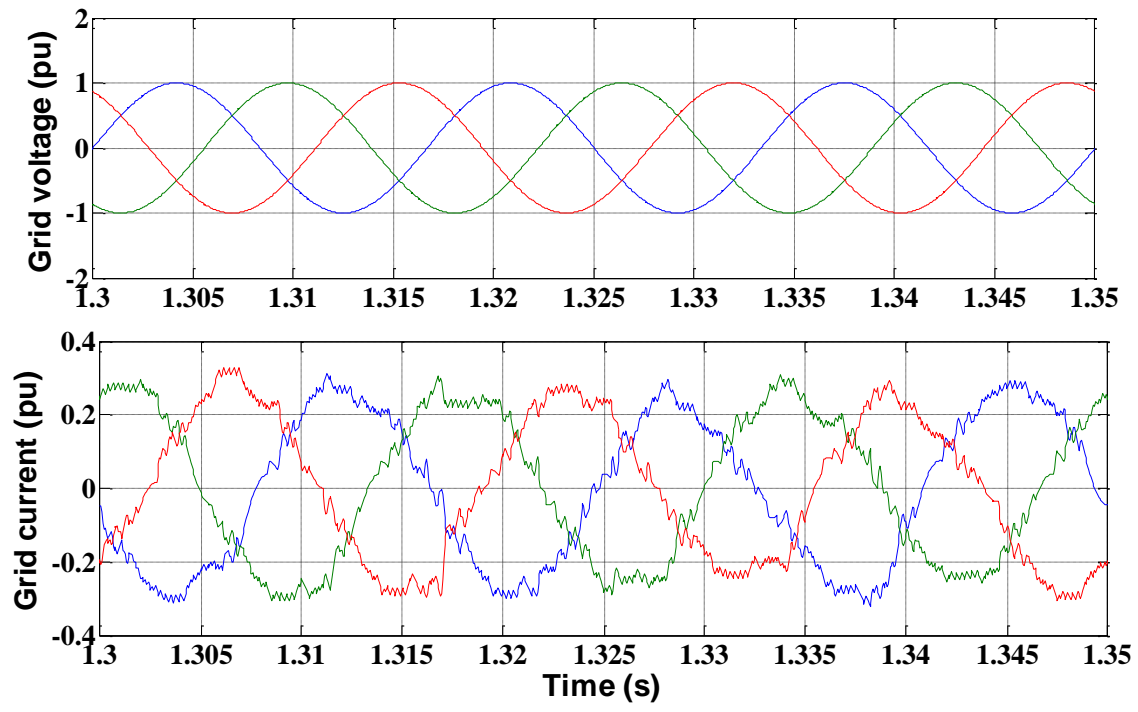

Figure 5.16 Grid voltage and current over a small enlarged period of time for variable wind speed.

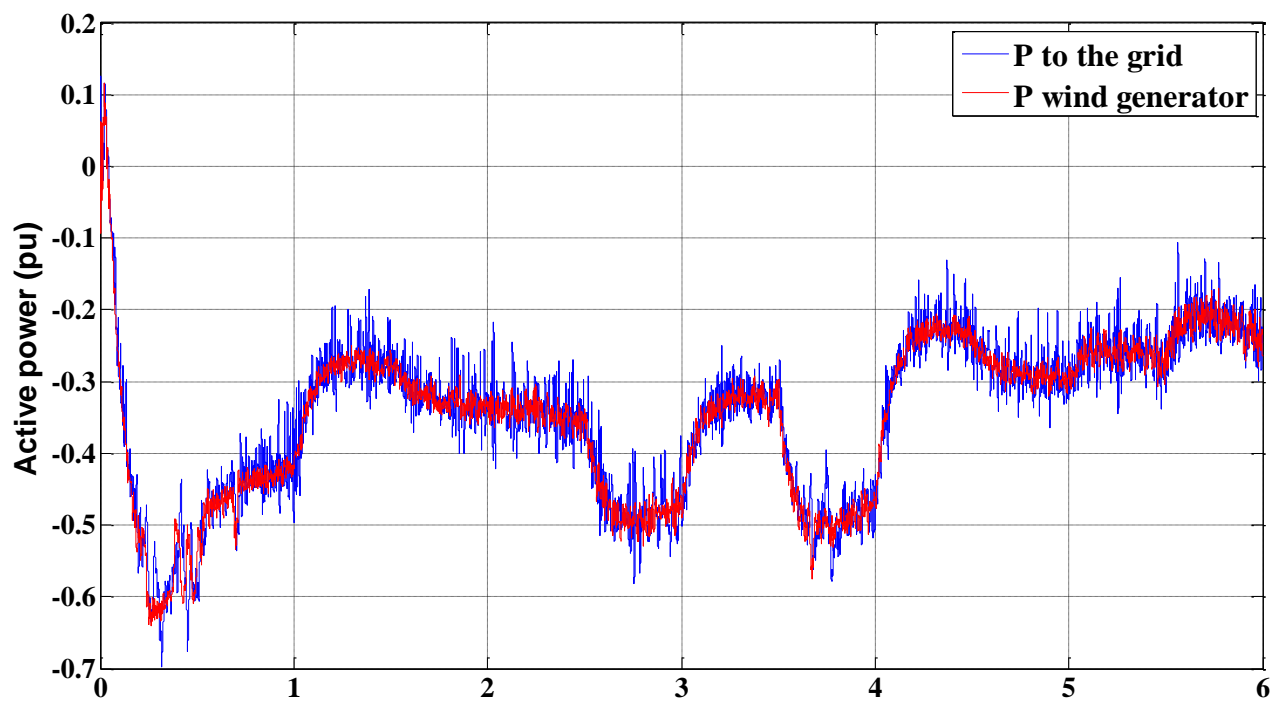

Figure 5.17 Active power delivered to the grid and wind generator active power for variable wind speed. 


\subsection{Normal operation with adaptive filter for power smoothing.}

Adaptive filter as descried in chapter 4 section 3.2.2 is used to smooth the output power to the grid within desired DC bus voltage variation.

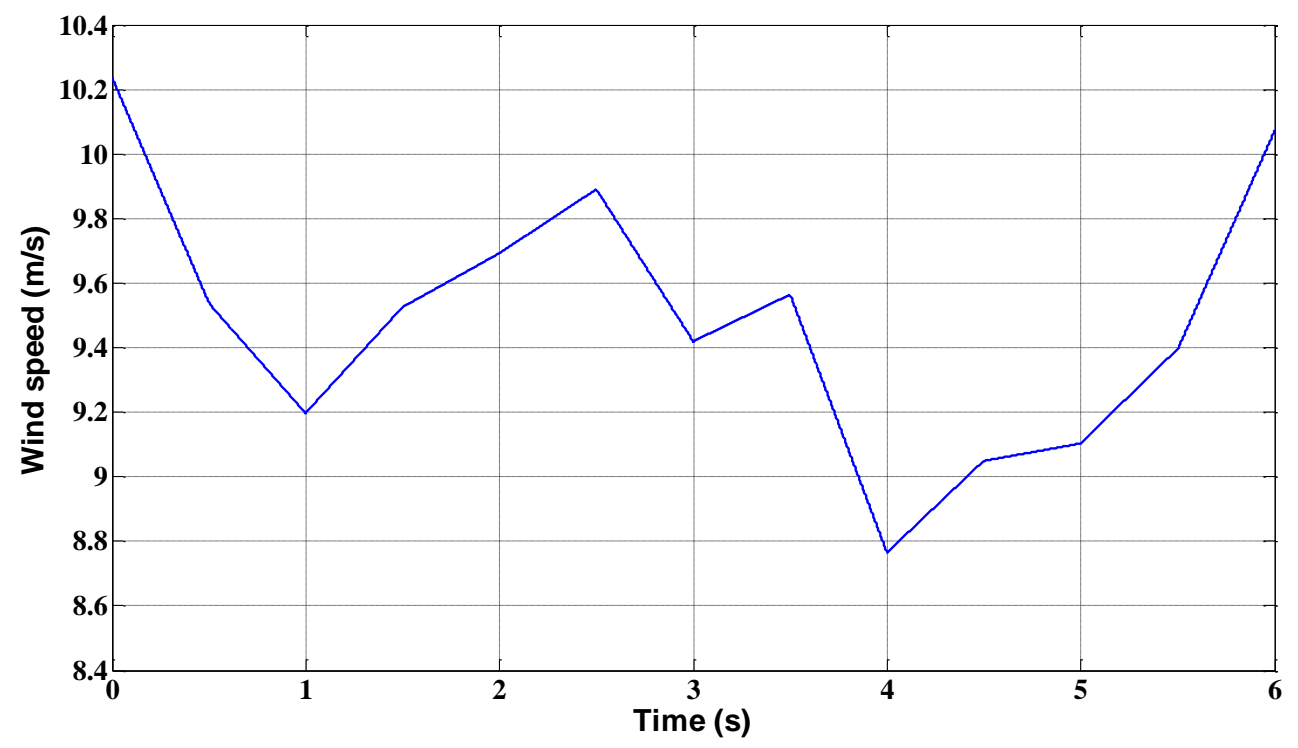

Figure 5.18 Variable wind speed profile in power smoothing.

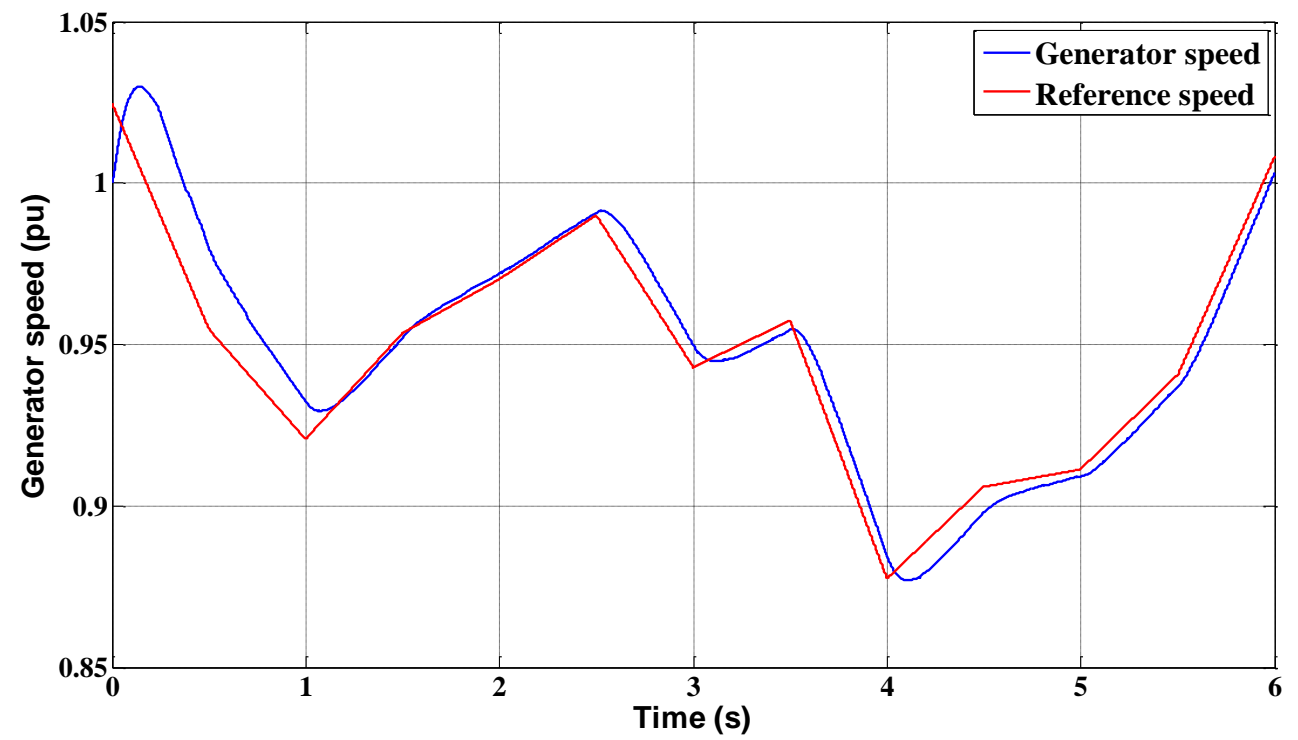

Figure 5.19 Generator speed and generator reference speed within power smoothing. 


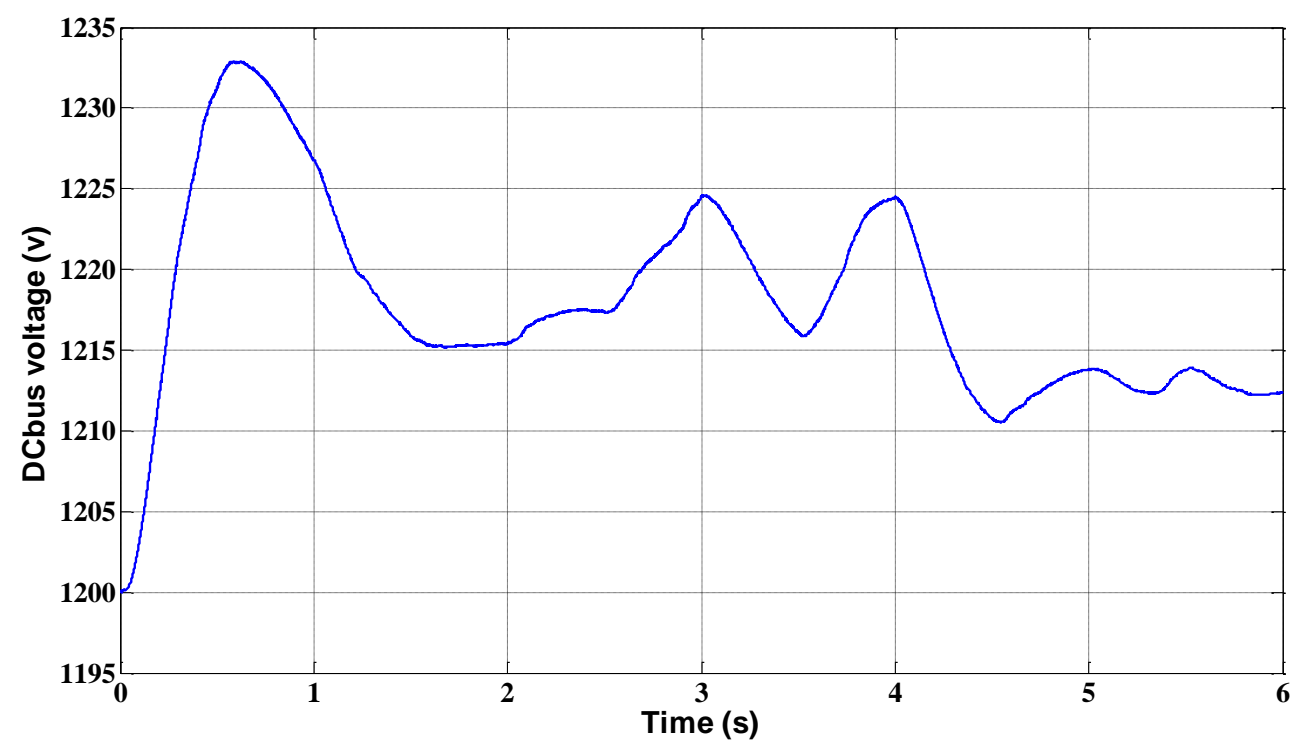

Figure 5.20 DC bus voltage within power smoothing.

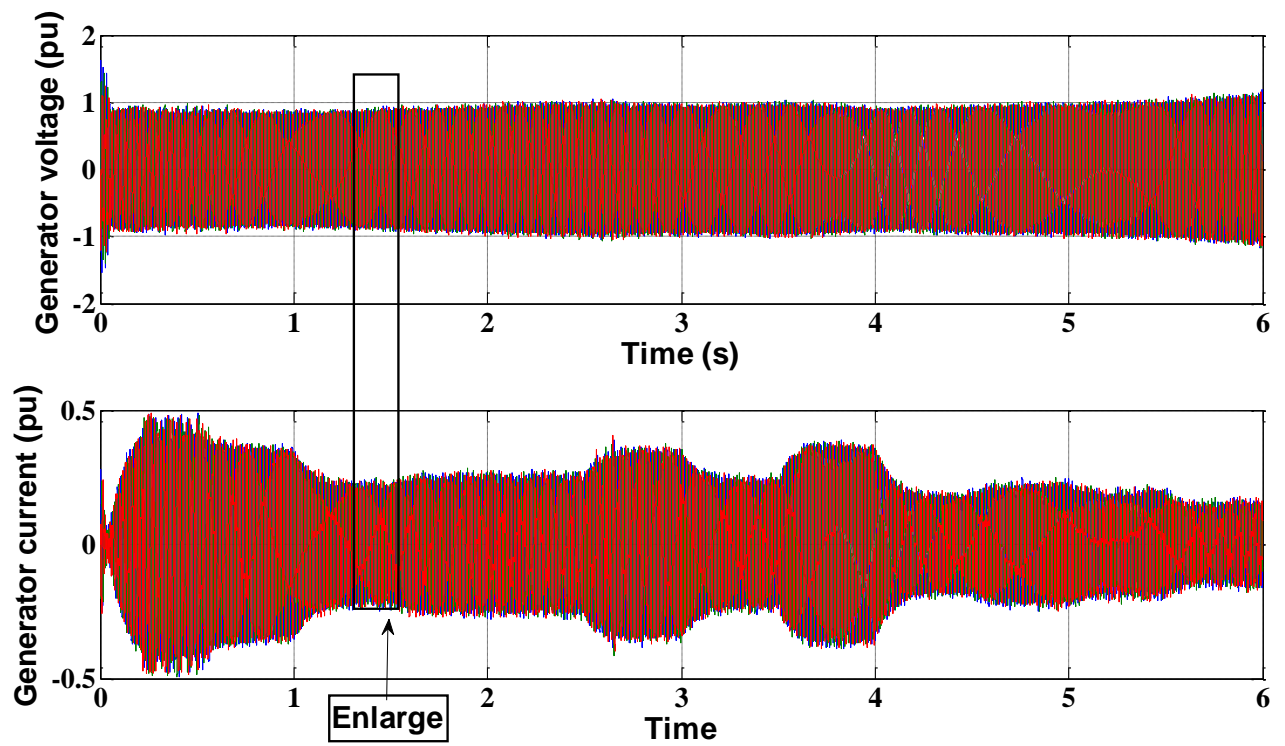

Figure 5.21 Generator voltage and current within power smoothing. 

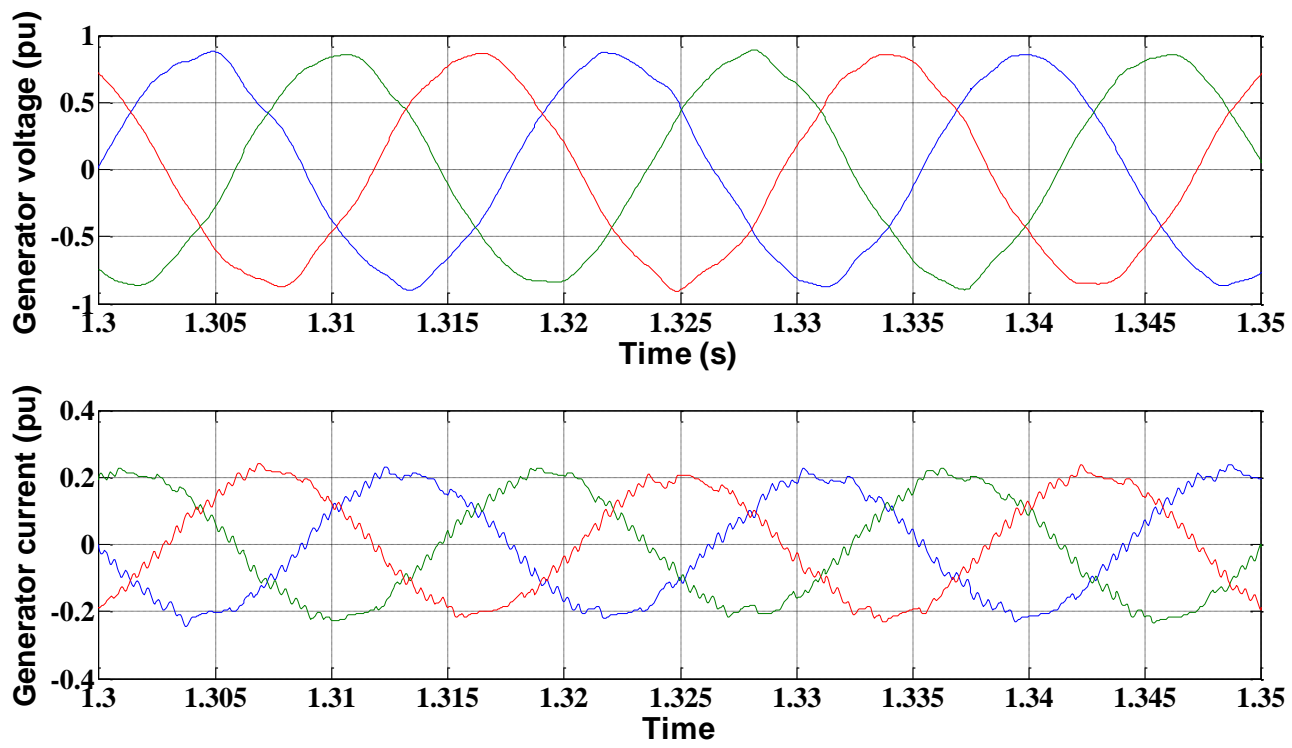

Figure 5.22 Generator voltage and current or a small enlarged period of time within power smoothing.

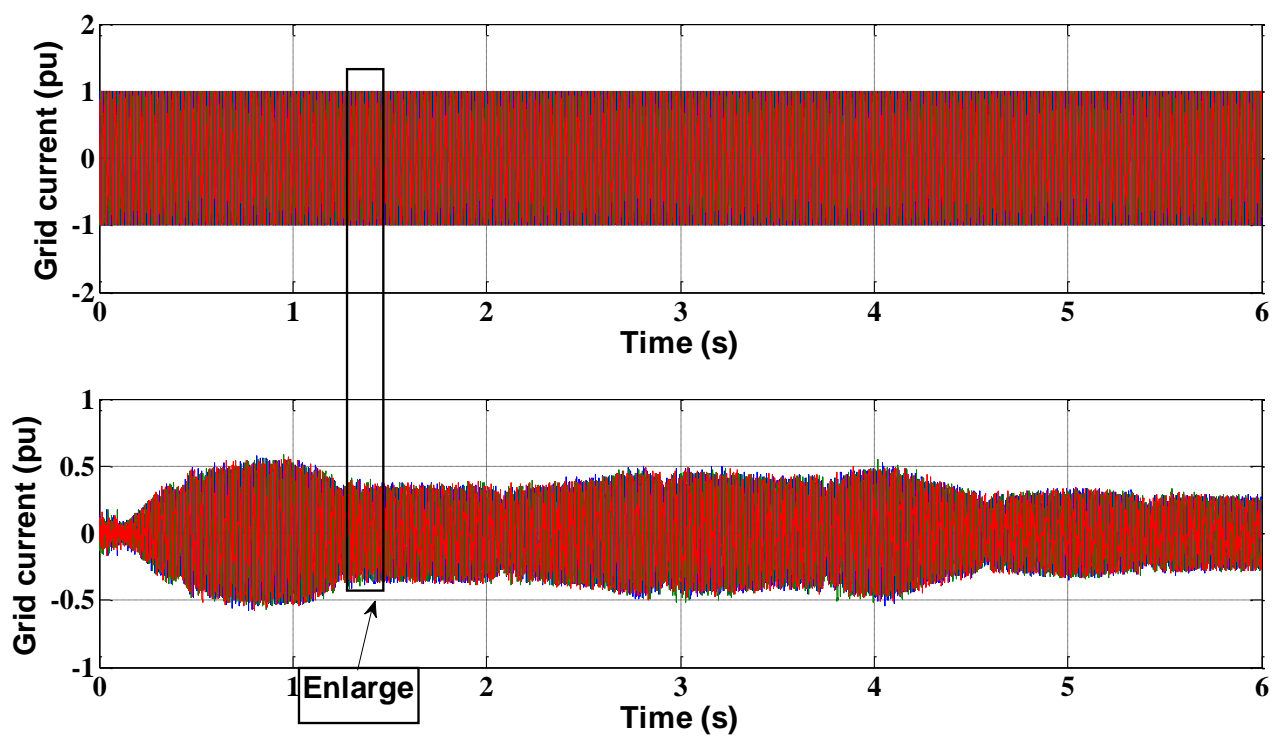

Figure 5.23 Grid voltage and current within power smoothing. 

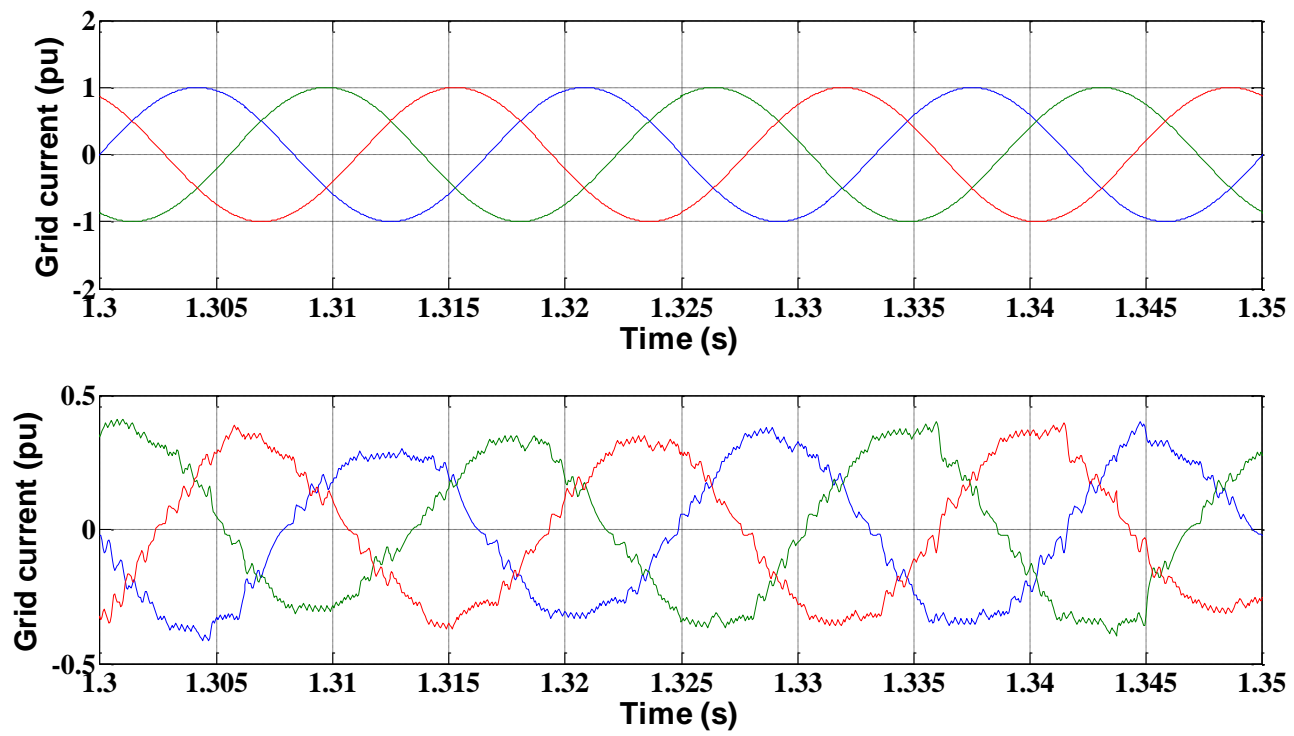

Figure 5.24 Grid voltage and current over a small enlarged period of time within power smoothing.

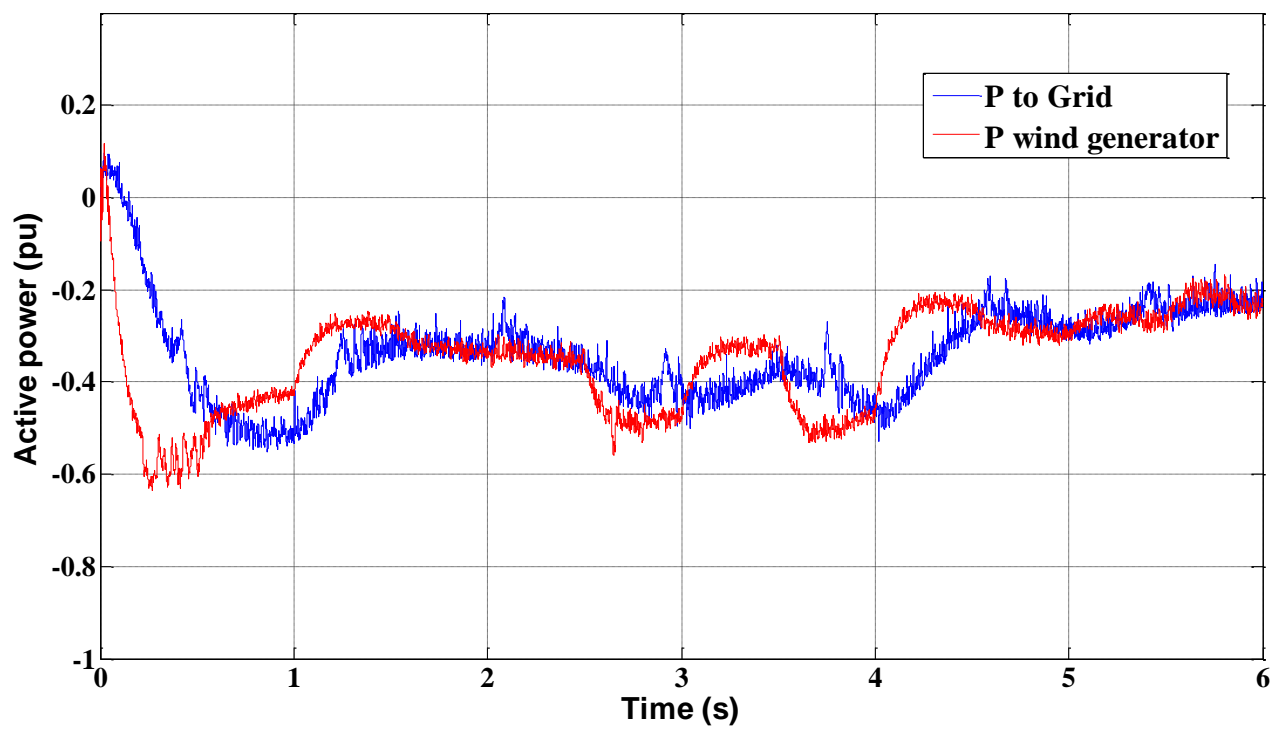

Figure 5.25 Active power delivered to the grid and wind generator active power within power smoothing. 


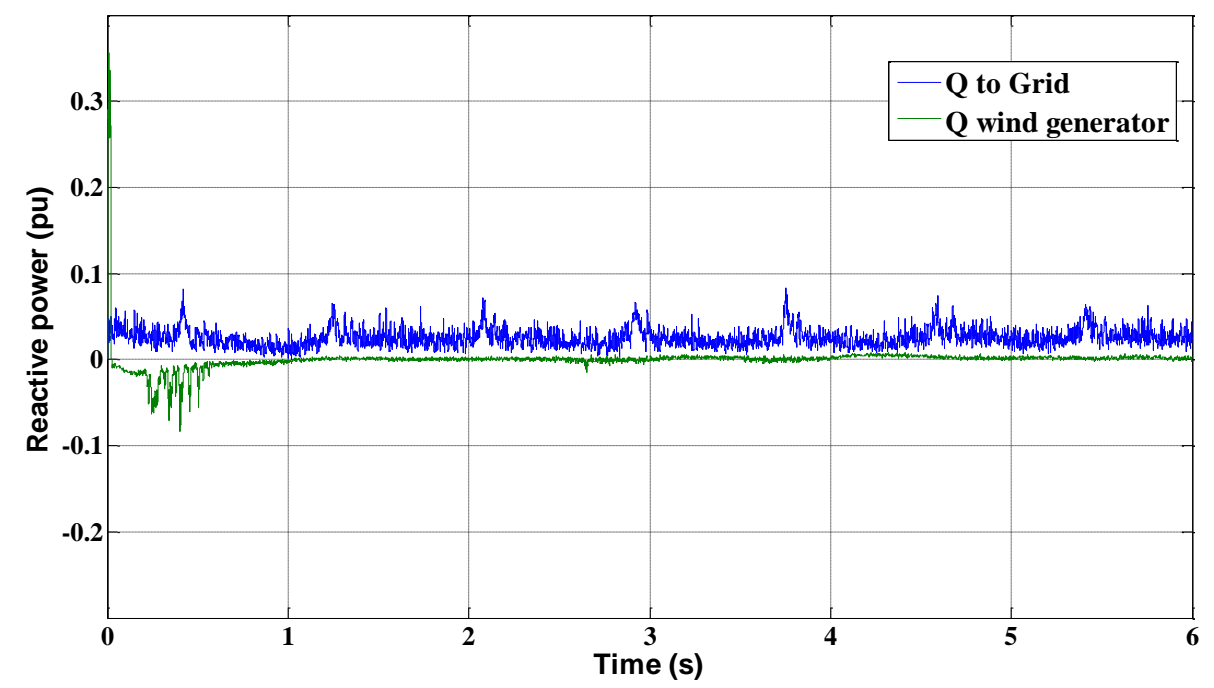

Figure 5.26 Reactive power delivered to grid and wind generator reactive power within power smoothing.

\subsection{LVRT operation.}

LVRT period is very small period, it's less than 2 seconds, so the wind speed is assumed constant and taken equal to $9.6(\mathrm{~m} / \mathrm{s}$.

\subsubsection{LVRT reactive current support up to 2(pu).}
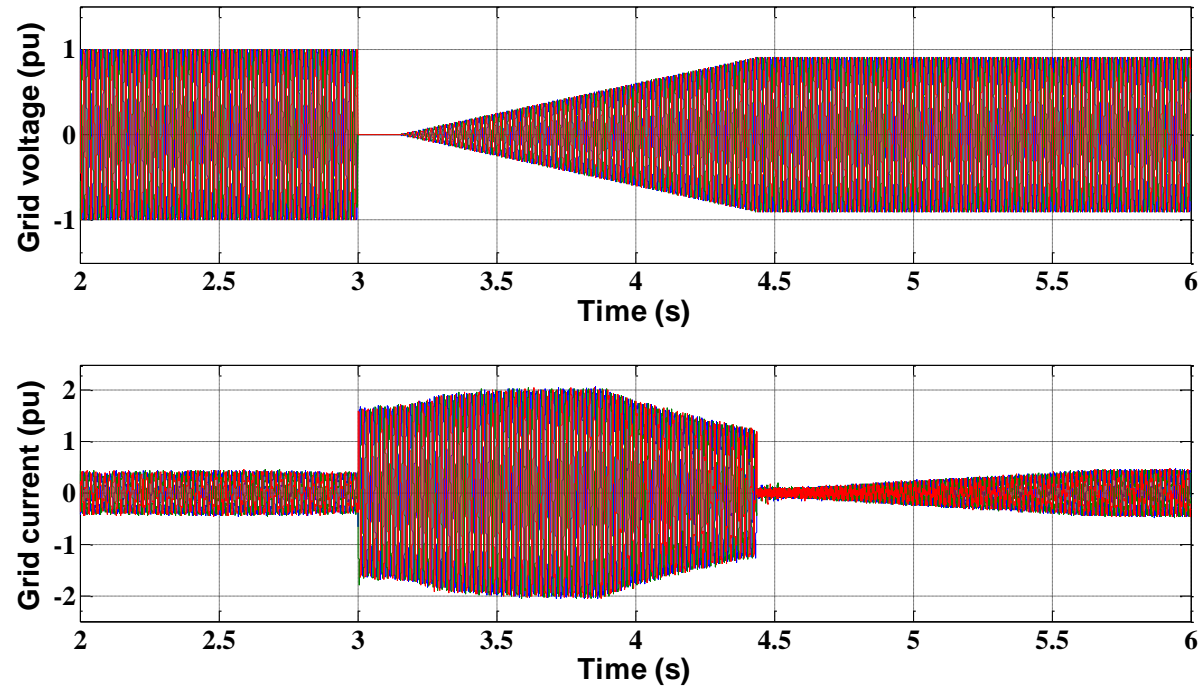

Figure 5.27 Grid voltage and current for (2) pu reactive power support. 


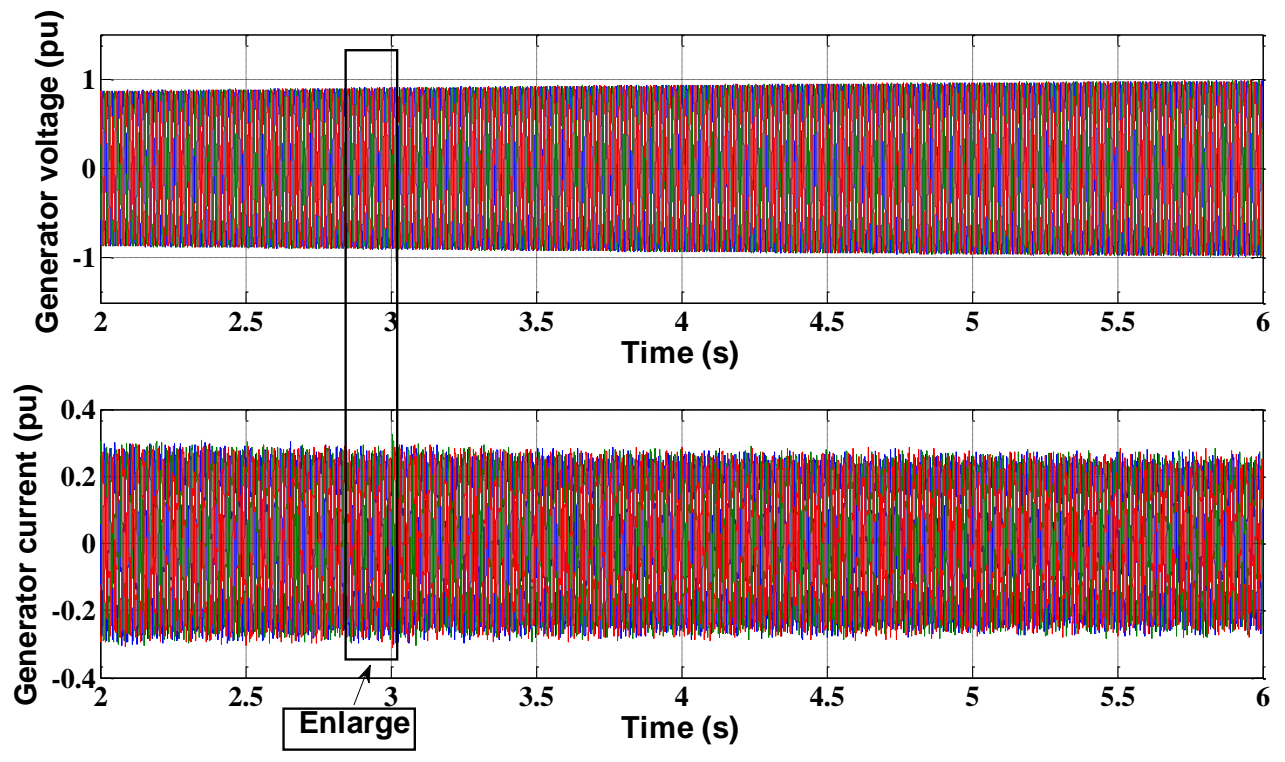

Figure 5.28 Generator voltage and current for (2) pu reactive power support.
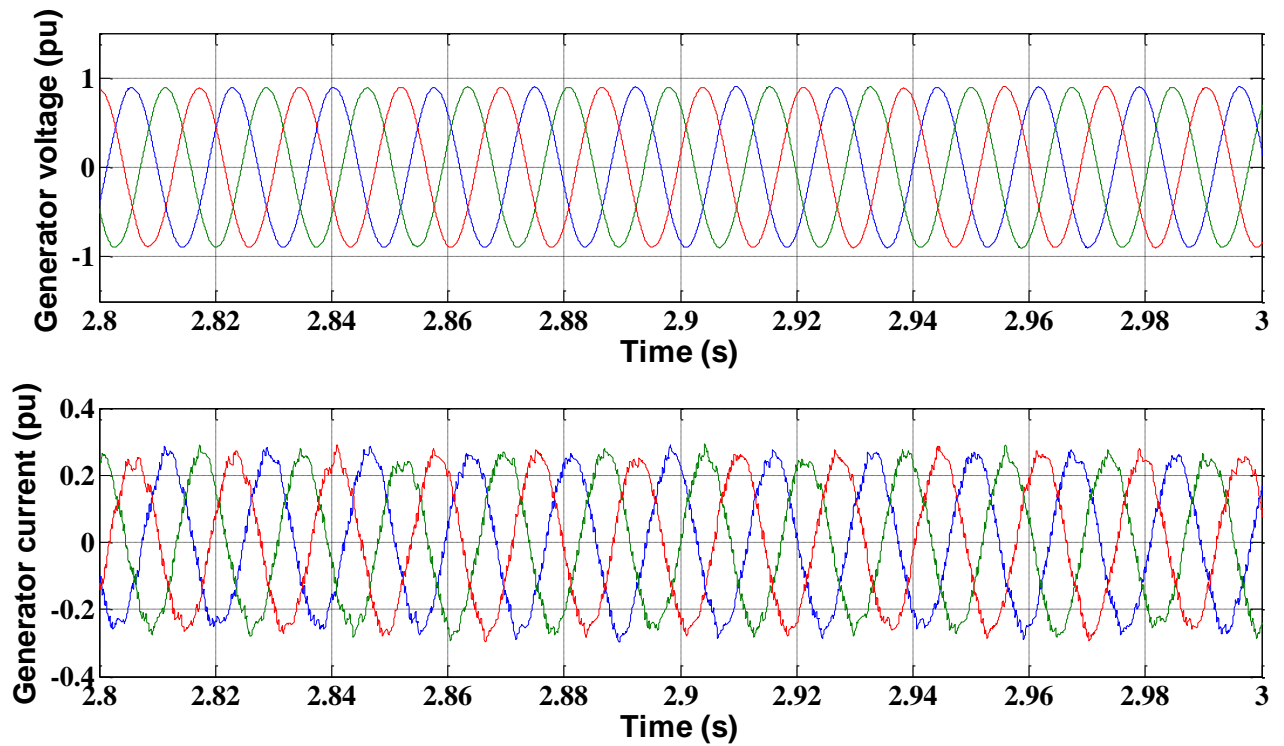

Figure 5.29 Generator voltage and current for (2) pu reactive power support over a small enlarged period of time.. 


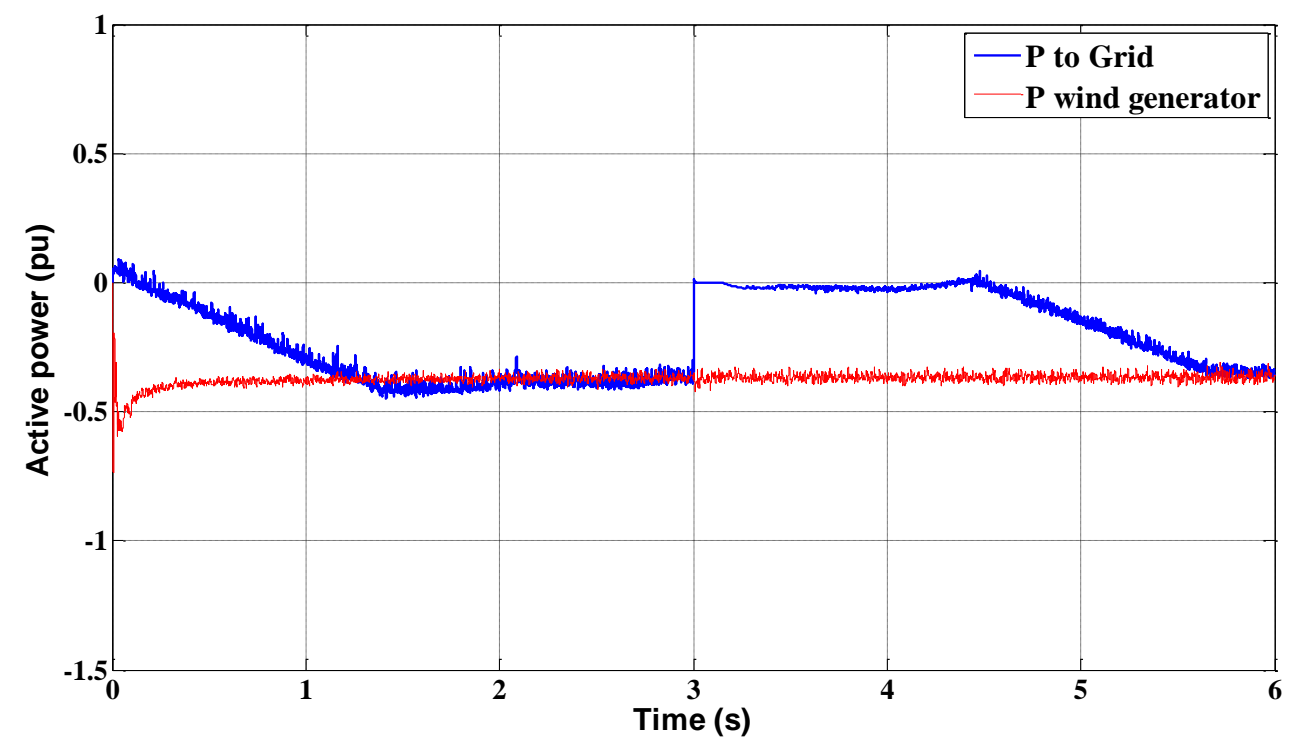

Figure 5.30 Active power delivered to the grid and generator active power for (2) pu reactive power support.

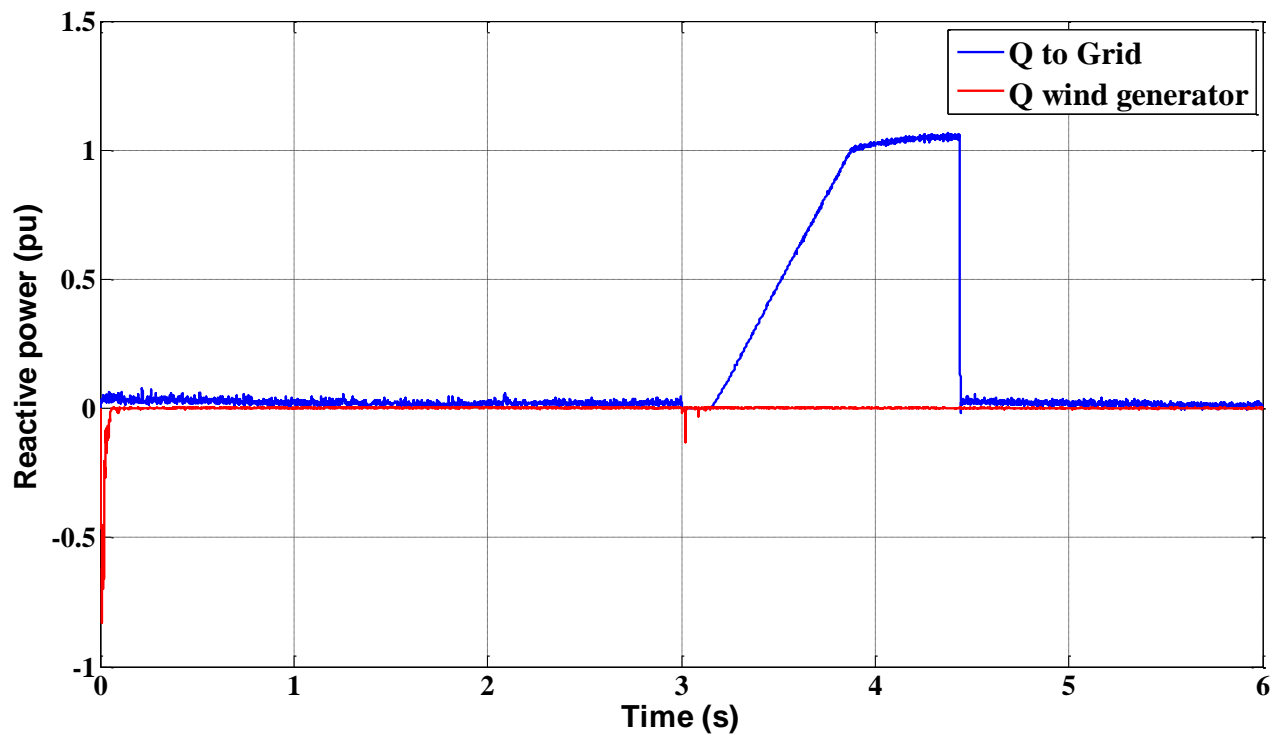

Figure 5.31 Reactive power delivered to the grid and wing generator reactive power for (2) pu reactive power support. 


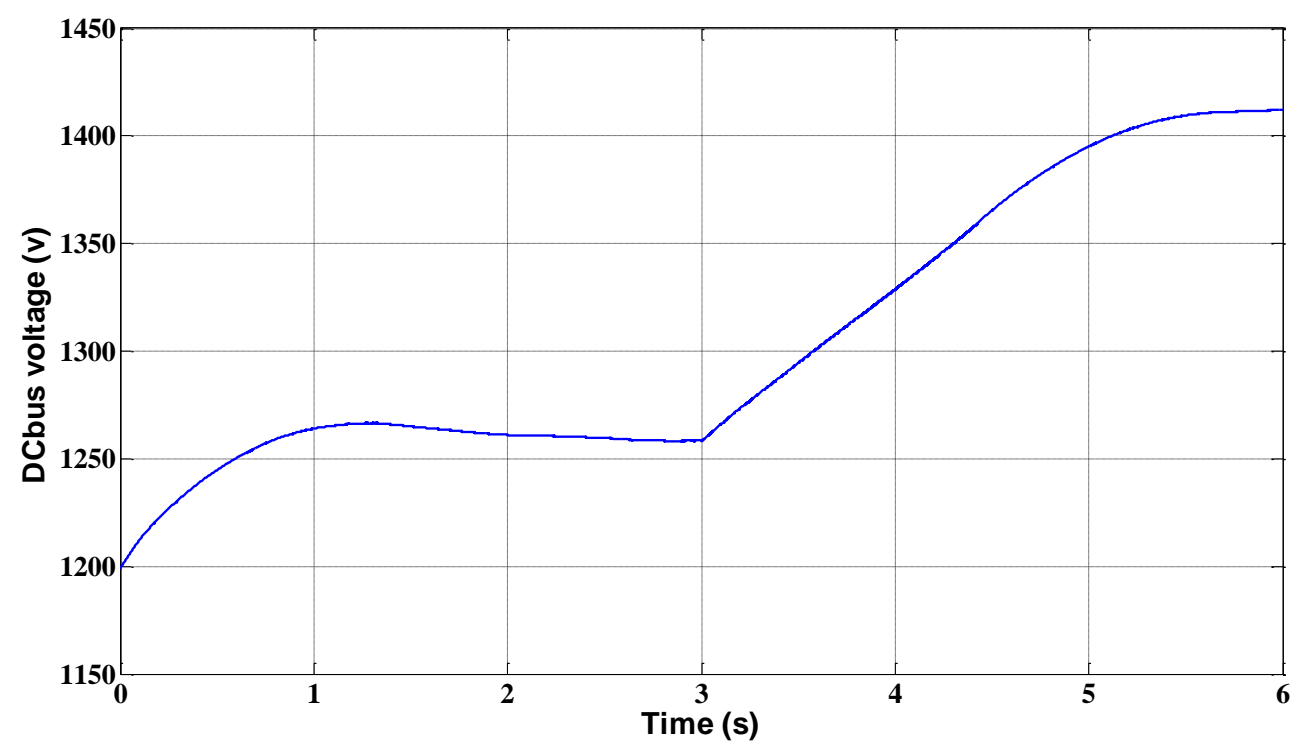

Figure 5.32 DC bus voltage for (2) pu reactive power support.

\subsubsection{LVRT 1 (pu) reactive current support.}
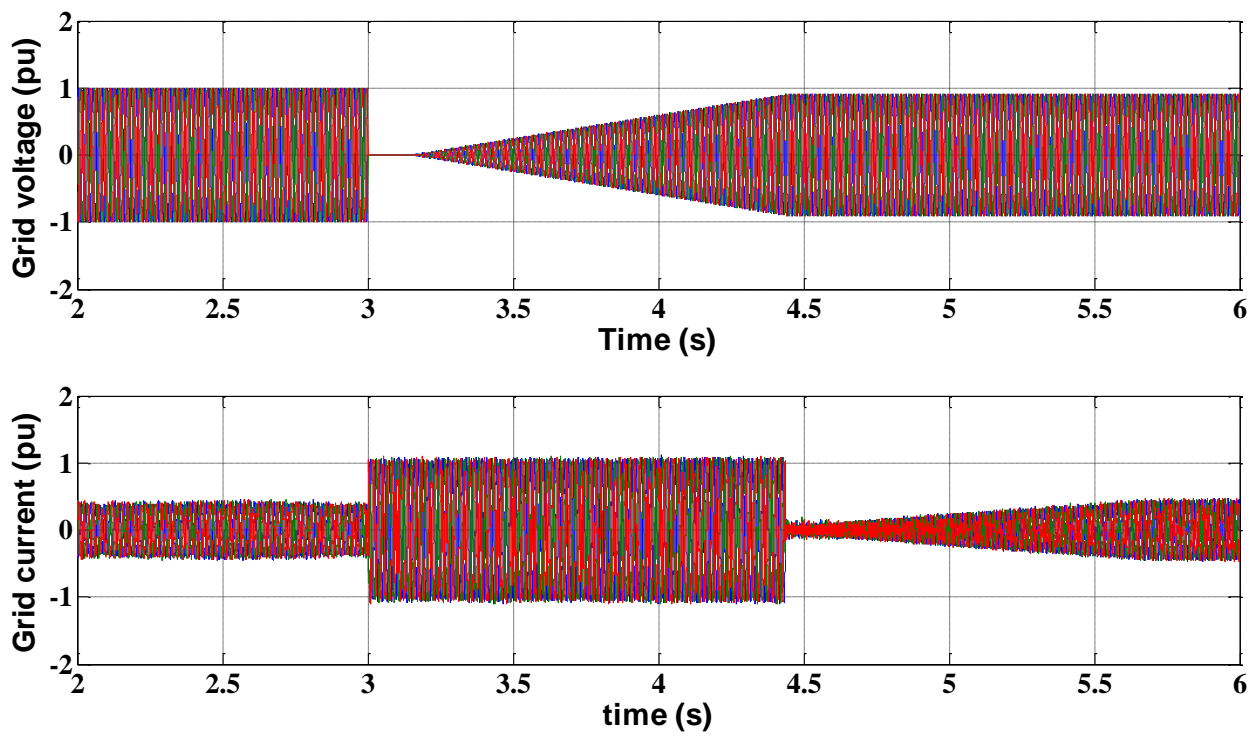

Figure 5.33 Grid voltage and current for (1) pu reactive power support. 


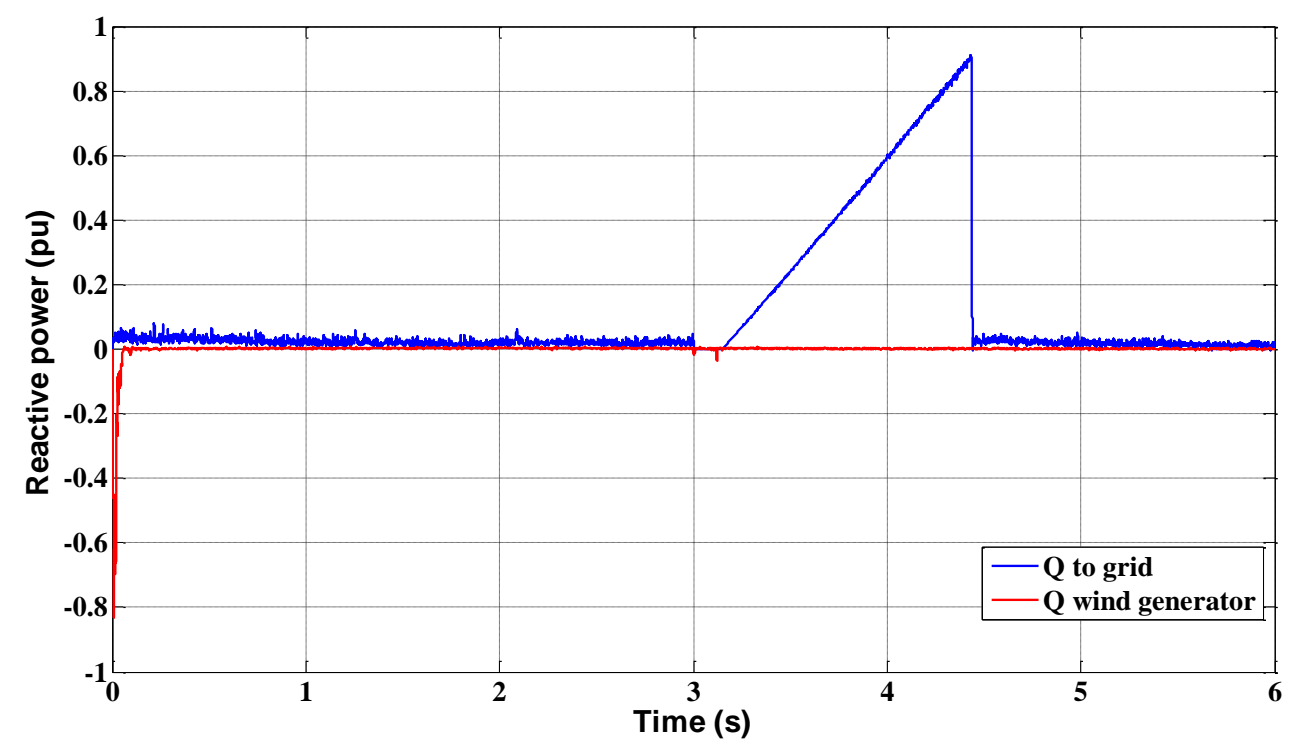

5.34 Reactive power delivered to the grid and wind generator reactive power for (2) pu reactive power support.

\section{Chapter 6: Conclusion and Future Work.}

Double conversion wind energy system was simulated in Matlab Simulink and achieved the desired results through out different control techniques. MPPT control was done showing that the generator speed runs at the reference speed that achieves MPPT for the generator. Active and reactive power control on both side of the Back to back converter are done to maximize the power delivered to the grid.

Under normal operation, active and reactive powers delivered to the grid were controlled in different wind turbine operation. Simulation of Wind turbine running at fixed wind speed was done showing good active and reactive power control; it was also simulated using a variable wind speed profile which generates variable and fluctuated power. Variable power delivered to the grid either with DC bus voltage control to keep it equal to a reference value or using an adaptive filter so you deliver a smoothed power. 
The adaptive filter technique makes the DC bus voltage fluctuate within a desirable band related to the filter design.

Under low voltage ride through (LVRT), active and reactive powers were controlled according to E.ON grid code of Germany. Wind turbine system was integrated with a grid voltage profile that will dip to zero and recover to 0.9 pu within the none trip zone of the E.ON voltage code. During the low voltage period, simulation shows a good results in active an reactive power control. Active power goes to zero when voltage dips and reactive power support should take a place to support the grid voltage. Reactive current was controlled to be 1 pu unit or up to 2 per unit during the LVRT. After the voltage recovers to 0.9 , active power was controlled to achieve a ramp rate of $90 \%$ of the available wind generated power in 1 second.

For future consideration, wind energy conversion system simulations was showing good control results however it might need more tuning for the grid side converter since it was relatively showing rough current due to harmonics and tuning issues. More grid faults can be analyzed by applying different grid voltages and notice the efficiency of the control. Build actual simulation setup and get actual data and results and compare it with the simulation results. 


\section{$\underline{\text { References }}$}

[1] http://www.awea.org/learnabout/utility/One-Fifth-Wind-Energy-by-2030.cfm

[2] Dewei Xu, Bin Wu, Zargari, N.R. "Unified DC-Link Current Control for LowVoltage Ride-Through in Current-Source-Converter-Based Wind Energy Conversion Systems” ,IEEE TRANSACTIONS ON POWER ELECTRONICS, VOL. 26, NO. 1, JANUARY 2011.

[3] http://en.wikipedia.org/wiki/History_of_wind_power.

[4] http://en.wikipedia.org/wiki/Wind_power_in_the_United_States.

[5] http://www.awea.org/learnabout/publications/upload/20percent_Wind_factsheet.pdf.

[6] http://centurionenergy.net/types-of-wind-turbines.

[7] http://me1065.wikidot.com/types-of-wind-turbines-and-associated-advantages.

[8] http://www1.eere.energy.gov/wind/inside_a_wind_turbine.html\#e

[9] $\mathrm{Yu}$ Zou, "MODELING, CONTROL AND MAXIMUM POWER POINT TRACKING (MPPT) OF DOUBLY-FED INDUCTION GENERATOR (DFIG) WIND POWER SYSTEM" A Dissertation Presented to The Graduate Faculty of The University of Akron, August, 2012.

[10] Abdelbaqi, omar." LVRT for DFIG" university of Wisconsin Milwaukee, august 2010

[11] Z. Chen," Issues of Connecting Wind Farms into Power Systems", Transmission and Distribution Conference \& Exhibition, IEEE/PES, Asia and Pacific Dalian, China, 2005.

[12] A. Abedini, A. Nasiri." Applications of Super Capacitors for PMSG Wind Turbine Power Smoothing",IEEE Annual Conference of Industrial Electronics, Page(s): 3347 3351, November 2008. 
[13] Rajveer Mittal, K. S. Sandhu and D. K. Jain,”

LOW VOLTAGE RIDE-THROUGH (LVRT) OF GRID INTERFACED WIND DRIVEN PMSG”,ARPN Journal of Engineering and Applied Sciences, VOL. 4, NO. 5, JULY 2009

[14] Hyong Sik Kim, Dylan Dah-Chuan Lu.” Review on wind turbine generators and power electronic converters with the grid-connection issues", Australasian Universities Power Engineering Conference (AUPEC), Page(s): 1 - 6, Dec 2010

[15] http://www.dolcera.com/wiki/index.php?title=Wind_Energy_Background

[16] Andrew Kusiak, “Turbine Generators” Intelligent Systems Laboratory, The University of Iowa, 2/25/2010

[17] George Alin RADUCU." Control of Grid Side Inverter in a B2B Configuration for WT Applications”, Master Thesis, Aalborg University, 2008.

[18] David Connolly," A Review of Energy Storage Technologies

For the integration of fluctuating renewable energy", University of Limerick, 11 October 2010.

[19] EPRI_DOE handbook supplemet,1008703” Energy storage for grid connected wind generation application”,US , Dec 2004.

[20] Paul Denholm, Erik Ela, Brendan Kirby, and Michael Milligan," The Role of Energy Storage with Renewable Electricity Generation”, Technical Report NREL/TP6A2-47187, January 2010

[21] R. Teodorescu, C.N. Rasmussen, P. Rodriguez, H. VikelgaSwierczynski," Overview of the Energy Storage Systems for Wind Power Integration Enhancement", IEEE, Symposium on Industrial Electronics (ISIE), Page(s): 3749 - 3756 , 2010. 
[22] Anca D. Hansen, Nicolaos A. Cutululis, Helen Markou, Poul Sørensen, Florin Iov,” Grid fault and design-basis for wind turbines - Final report”, Risø-R-1714(EN), January 2010

[23] Anca D. Hansen, Nicolaos A. Cutululis, Poul Sørensen, Florin Iov,” Mapping of grid faults and grid codes”, Risø-R-1617(EN) Risø National Laboratory Technical University of Denmark.Roskilde, Denmark July 2007

[24] Kaiyuan Lu, Lars Helle,” Reactive power control and fault ride through capabilities of synchronous generator”, Aalborg University, 2010-2011.

[25]Vicente León-Martínez „Joaquín Montañana-Romeu,” Active and Reactive Power Formulations for Grid Code Requirements Verification" Universidad Politécnica de Valencia ,Spain.

[26] Willi Christiansen \& David T. Johnsen," Analysis of requirements in selected Grid Codes", Lyngby den 20.01.2006.

[27] M.H.J. Bollen, G. Olguin, M. Martins, "Voltage Dips at the Terminals of Wind Power Installations", Wind Energy, vol. 8, pp. 307-318, Jul. 2005.

[28] M.H.J. Bollen, "Voltage Recovery After Unbalanced and Balanced Voltage Dips in Three-Phase Systems”, IEEE Trans. on Power Delivery, vol. 18, pp. 1376- 1381, Oct. 2003.

[29] M.H.J. Bollen, “Understanding Power Quality Problems”, IEEE Press, New York, NY, 2000.

[30] Wei Qiao, Ronald G. Harley," Grid Connection Requirements and Solutions for DFIG Wind Turbines",IEE Energy 2030 Conference, Atlanta, GA USA 17-18 November, 2008 
[31] O. S. Adagha," Review of grid connection requirements for wind farms in the UK", school of engineering, university of Aberdeen King's College, Aberdeen,AB243FX.UK. [32] E.on net Gmbh,Bayreuth ,"requirements for offshore grid connection",1April 2008. [33] M. Tsili S. Papathanassiou," Review of grid code technical requirements for wind farms", IET Renewable Power Generation, pp. 1-25, 2009 [34] Ki-Hong Kim, Yoon-Cheul Jeung, Dong-Choon Lee, Heung-Geun Kim," LVRT Scheme of PMSG Wind Power Systems Based on Feedback Linearization", IEEE TRANSACTIONS ON POWER ELECTRONICS, VOL. 27, NO. 5, MAY 2012 [35] Matlab, simulink,"wind generation" simscape,simpower system, distributed resources library. 